UNIVERSIDADE DE SÃO PAULO

ESCOLA DE ENFERMAGEM DE RIBEIRÃO PRETO

MARCIA PASCHOALINA VOLPATO

Ensino clínico sob o paradigma da prática embasada em evidências: integração da teoria e prática para a prevenção da úlcera por pressão

Ribeirão Preto 


\section{Ensino clínico sob o paradigma da prática embasada em evidências: integração da teoria e prática para a prevenção da úlcera por pressão}

Tese apresentada à Escola de Enfermagem de Ribeirão Preto da Universidade de São Paulo, para obtenção do título de Doutor em Ciências, Programa de Pós-Graduação Enfermagem Fundamental.

LINHA DE PESQUISA:

Fundamentação teórica metodológica e tecnológica do processo de cuidar em enfermagem

ORIENTADOR:

Prof ${ }^{-}$. Dr ${ }^{\mathrm{a}}$. Maria Helena Larcher Caliri

Ribeirão Preto 
Autorizo a reprodução e divulgação total ou parcial deste trabalho, por qualquer meio convencional ou eletrônico, para fins de estudo e pesquisa, desde que citada a fonte.

Volpato, Marcia Paschoalina

Ensino clínico sob o paradigma da prática embasada em evidências: integração da teoria e prática para a prevenção da úlcera por pressão. Ribeirão, 2014.

182 p. : il. ; $30 \mathrm{~cm}$

Tese de Doutorado, apresentada à Escola de Enfermagem de Ribeirão Preto/USP. Área de concentração: Enfermagem Fundamental.

Orientador: Maria Helena Larcher Caliri

1.Úlcera por Pressão. 2.Prática Baseada em Evidências. 3.Ensino. 4.Aprendizagem. 5. Pesquisa em Enfermagem. 
VOLPATO, Marcia Paschoalina

Ensino clínico sob o paradigma da prática embasada em evidências: integração da teoria e prática para a prevenção da úlcera por pressão

Tese apresentada à Escola de Enfermagem de Ribeirão Preto da Universidade de São Paulo, para obtenção do título de Doutor em Ciências, Programa de Pós-Graduação Enfermagem Fundamental.

Aprovado em:

COMISSÃo JULGADORA

Prof. Dr.

Instituição:

Assinatura

Prof. Dr.

Instituição:

Assinatura

Prof. Dr.

Instituição:

Assinatura

Prof. Dr.

Instituição:

Assinatura

Prof. Dr.

Instituição: Assinatura 



\section{Dedicatória}

As minhas filhas, Bruna e Beatriz, bens de minha vida, que me fazem acreditar no amor. 


\section{AGRADECIMENTOS ESDECIAIS}

A Deus, Pai, Filho e Espírito Santo,

Senhor e Salvador, sentido de todo o meu trabal ho e existência, pela condução da minha vida.

À Profa Dra. Maria Helena Larcher Caliri, Pessoa admirável.

Todos nós temos exemplos de pessoas que espelham nossas ações. Espero poder refletir, na minha trajetória pessoal e profissional, os exemplos de competência, de ensinamentos e orientação a que demonstrou durante esta trajetória. Obrigada pela sua sensibilidade que sempre demonstrou ao perceber-me como gente, ser humano nos momentos de dificuldades.

Aos meus pais, Sebastião e Páscoa, que me deram a vida e por ter conseguido chegar até aqui.

A minha irmã Tina,

pelo apoio e pela dedicação incansấvel às minhas filhas nas minhas ausências. Muito obrigada. 
Ao meu irmão Marcio,

que durante as minhas ausências, muitas vezes foi pai das minhas filhas.

Ao meu irmão Wilson, in memorian, pena que não está aqui para me dar um abraço e compartilhar todo o conhecimento adquirido.

A Profa Dra. Júlia Trevisan Martins, pelas contribuições valiosas, disponibilidade e colaboração, fundamentais para a concretização deste trabalho.

A Profa. Dra. Ana Elisa Bauer de Camargo Silva que por sua análise crítica, direcionou o desenvolvimento deste trabalho, meu sincero agradecimento. 


\title{
AGRADECIMENTOS
}

Aos estudantes da $2^{a}$ série do Curso de Enfermagem da VEL, que tornaram possível a realização desse trabalho.

\begin{abstract}
Às amigas Mitiko e Maria Clara, que prontamente me substituíram, na minha ausência, nos cuidados com o meu pai.

Eternas amigas.
\end{abstract}

Às minhas colegas da área Fundamentos de enfermagem, que souberam compreender a minha ausência, sempre me apoiando e incentivando para seguir em frente, com ânimo e alegria.

À amiga Flāvia Pieri, por toda amizade e experiências compartilhadas nas viagens para Ribeirão Preto.

À Profa Dra Miyeko Hayshida,

pela construção do banco de dados e na realização da estatística descritiva.

À Proa Dra Soraia Assad Nasbine Rabeh, pela contribuição no exame de qualificação. 
$\bar{A}$ todos os docentes do Doutorado pela qualidade de ensino oferecido.

À todos que contribuíram direta e indiretamente para o meu crescimento pessoal e profissional, cujos nomes não foram mencionados, minhas sinceras desculpas e meu eterno agradecimento. 
Não fiz o melhor, mas fiz tudo para que o melhor fosse feito. Não sou o que deveria ser, mas não sou o que era antes.

(Martin Luther King) 


\section{RESUMO}

VOLPATO, M.P. Ensino clínico sob o paradigma da prática embasada em evidências: integração da teoria e prática para a prevenção da úlcera por pressão. 2014, 182f. Tese (Doutorado). Escola de Enfermagem de Ribeirão Preto da Universidade de São Paulo, Ribeirão Preto, SP, 2014.

A úlcera por pressão, considerada um evento adverso, compromete a segurança do paciente sob os cuidados dos profissionais de saúde. Uma das formas de proporcionar segurança é por meio da prática baseada em evidência que pode ser implementada com estudantes pelo uso de metodologias ativas de ensinoaprendizagem. O objetivo geral do estudo foi propor uma metodologia de ensino para estudantes do curso de Enfermagem da Universidade Estadual de Londrina, pela avaliação do risco de desenvolvimento da úlcera por pressão em pacientes internados em uma unidade médico-cirúrgica e pela identificação das prescrições de enfermagem para a prevenção nos registros em prontuários. A pesquisa foi aprovada pelo Comitê de Ética e Pesquisa institucional e realizou-se utilizando métodos quantitativos e qualitativos, com delineamento descritivo, ocorrendo em três fases. A primeira foi um workshop sobre prática baseada em evidência. A segunda foi desenvolvida pelos estudantes e pesquisadora e a coleta de dados foi realizada com 21 pacientes hospitalizados em unidade médico-cirúrgica durante 15 dias sequenciais, em que avaliou-se o risco para úlcera por pressão por meio da Escala de Braden e os registros das prescrições de enfermagem relacionados ao uso das evidências para prevenção de úlcera por pressão. A terceira foi desenvolvida com os estudantes para investigar o significado da experiência com a metodologia de ensino. Os 21 pacientes avaliados tinham a média de idade de 44,76 anos e diagnósticos médicos mais frequentes de doenças do sistema osteomuscular e do tecido conjuntivo $(42,86 \%)$. No primeiro dia de avaliação, considerando a escore total da Escala de Braden, 17 pacientes $(80,95 \%)$ tinham risco entre moderado e muito alto. $\mathrm{Na}$ inspeção da pele foram identificadas 25 úlceras por pressão, sendo a localização mais frequente na região sacral (44\%) e as classificações predominantes foram no estágio I e II. $\mathrm{Na}$ análise dos prontuários, não foram identificadas anotações dos enfermeiros referentes à avaliação do risco e nem ao uso da Escala de Braden. As prescrições de enfermagem mais frequentes para a prevenção da úlcera foram mudança de decúbito, uso de coxins, proteção contra a umidade e uso de cremes hidratantes, e a menos frequente foi a manutenção da cabeceira até 30 graus. Não foi encontrada associação entre as medidas de prevenção prescritas e os subescores da escala de Braden. O significado das experiências de oito estudantes que participaram da pesquisa foi investigado pela análise de conteúdo das falas obtidas nas discussões em grupo e identificaram-se duas categorias: aprendendo sobre o tema úlcera por pressão e conhecendo a realidade da instituição e da enfermagem sobre a úlcera por pressão. Concluiu-se que os estudantes relacionaram a teoria à prática, identificaram as competências do enfermeiro na avaliação do paciente com risco para úlcera por pressão, aprimoraram o conhecimento nos estágios da úlcera por pressão e identificaram a Escala de Braden como suporte para avaliação de risco para a úlcera por pressão. Os estudantes, ainda, identificaram a falta de cuidados pela equipe de enfermagem e a importância da presença da família e perceberam a necessidade da prática segura em relação à úlcera por pressão. 
Palavras-chave: Úlcera por Pressão. Prática Baseada em Evidências. Ensino. Aprendizagem. Pesquisa em Enfermagem. 


\begin{abstract}
ABSTRAT
VOLPATO, M.P. Clinical teaching under the evidence-based practice paradigm: integration between theory and practice for pressure ulcer prevention. 2014, 182p. Doctoral Dissertation. University of São Paulo at Ribeirão Preto College of Nursing, Ribeirão Preto, SP, 2014.
\end{abstract}

Pressure ulcers, considered an adverse event, compromise the safety of patients under the care of health professionals. One way to provide safety is through evidence-based practice, which can be implemented with students through the use of active teaching-learning methods. The general study objective was to propose a teaching method for students from the Nursing program at the Universidade Estadual de Londrina, to assess the risk of pressure ulcer development in patients hospitalized at a medical-surgical unit and to identify the nursing prescriptions for this prevention in the records in patient files. Approval for the research was obtained from the institutional Research Ethics Committee and quantitative and qualitative methods were applied, with a descriptive design, involving three phases. The first was a workshop on evidence-based practice. The second was developed by the students and researcher and the data were collected with 21 patients, hospitalized at the medical-surgical unit for 15 continuous days, in which the risk of pressure ulcer was assessed through the Braden Scale and the records of the nursing prescriptions related to the use of evidences to prevent pressure ulcers. The third was developed with the students to investigate the meaning of the experience with the teaching method. The 21 patients assessed had a mean age of 44.76 years and the most frequent medical diagnoses were diseases of the musculoskeletal system and connective tissue (42.86\%). On the first assessment day, considering the total score on the Braden Scale, 17 patients $(80.95 \%)$ had a moderate to very high risk. In the skin inspection, 25 pressure ulcers were identified, with the sacral region as the most frequent location (44\%) and stages I and II as the predominant classifications. In the analysis of the files, no nursing notes were identified with regard to the risk assessment, nor related to the use of the Braden Scale. The most frequent nursing prescriptions to prevent ulcers were decubitus change, use of cushions, protection against humidity and use of hydrating creams, and the least frequent was the maintenance of the headrest at 30 degrees. No association was found between the prescribed prevention measures and the subscores of the Braden scale. The meaning of the experience of the eight students who participated in the research was investigated by means of the content analysis of the statements obtained in the group discussions and two categories were identified: learning about the theme pressure ulcer and getting to know the reality of the institution and nursing with regard to pressure ulcer. In conclusion, the students related the theory with the practice, identified the nurses' competences in the assessment of patients with risk of pressure ulcers, improved the knowledge on the pressure ulcer stages and identified the Braden Scale to support the risk assessment for pressure ulcer. The students also identified the lack of care by the nursing team and the importance of the family's presence and perceived the need for safe practice with regard to pressure ulcers.

Keywords: Pressure Ulcer. Evidence-Based Practice. Teaching. Learning. Nursing Research. 


\section{RESUMEN}

VOLPATO, M.P. Enseñanza clínica bajo el paradigma de la práctica basada en evidencias: integración de la teoría y práctica para la prevención de la úlcera por presión. 2014, 182h. Tesis (Doctorado). Escuela de Enfermería de Ribeirão Preto de la Universidad de São Paulo, Ribeirão Preto, SP, 2014.

La úlcera por presión, considerada un evento adverso, compromete la seguridad del paciente bajo los cuidados de los profesionales de salud. Una de las formas de proporcionar seguridad es mediante la práctica basada en evidencia que puede ser implementada con estudiantes a través del uso de metodologías activas de enseñanza-aprendizaje. El objetivo general del estudio fue proponer una metodología de enseñanza para estudiantes del curso de Enfermería de la Universidade Estadual de Londrina, mediante la evaluación del riesgo de desarrollo de la úlcera por presión en pacientes internados en una unidad médico-quirúrgica y mediante la identificación de las prescripciones de enfermería para la prevención en los registros en prontuarios. La investigación fue aprobada por el Comité de Ética e Investigación institucional y fue desarrollada con el uso de métodos cuantitativos y cualitativos, con diseño descriptivo, en tres fases. La primera fue un workshop sobre práctica basada en evidencia. La segunda fue desarrollada por los estudiantes e investigadora y los datos fueron recolectados con 21 pacientes hospitalizados en unidad médico-quirúrgica durante 15 días secuenciales, en que se evaluó el riesgo para úlcera por presión mediante la Escala de Braden y los registros de las prescripciones de enfermería relacionados al uso de las evidencias para prevención de úlcera por presión. La tercera fue desarrollada con los estudiantes para investigar el significado de la experiencia con la metodología de enseñanza. El edad medio de los 21 pacientes evaluados fue 44,76 anos y los diagnósticos médicos más frecuentes fueron enfermedades del sistema musculoesquelético y del tejido conjuntivo $(42,86 \%)$. En el primer día de evaluación, considerando el escore total de la Escala de Braden, 17 pacientes (80,95\%) tenían riesgo entre moderado y muy alto. En la inspección de la piel, fueron identificadas 25 úlceras por presión, siendo la localización más frecuente en la región sacra (44\%) y las clasificaciones predominantes fueron en el estadio I y II. En el análisis de los archivos, no fueron identificadas anotaciones de los enfermeros referentes a la evaluación de riesgo y ni al uso de la Escala de Braden. Las prescripciones de enfermería más frecuentes para la prevención de la úlcera fueron cambio de decúbito, uso de cojines, protección contra la humedad y uso de cremes hidratantes, y la menos frecuente fue la manutención de la cabecera hasta 30 grados. No fue encontrada asociación entre las medidas de prevención prescritas y los sub-scores de la escala de Braden. El significado de las experiencias de ocho estudiantes que participaron de la investigación fue investigado por el análisis de contenido de las hablas recolectadas en las discusiones en grupo y fueron identificadas dos categorías: aprendiendo sobre el tema úlcera por presión y conociendo la realidad de la institución y de la enfermería sobre la úlcera por presión. Se concluyó que los estudiantes relacionaron la teoría a la práctica, identificaron las competencias del enfermero en la evaluación del paciente con riesgo para úlcera por presión, perfeccionaron el conocimiento en los estadios de la úlcera por presión e identificaron la Escala de Braden como soporte para evaluación de riesgo para la úlcera por presión. Los estudiantes identificaron la falta de cuidados por el equipo de enfermería y la importancia de la 
presencia de la familia y percibieron la necesidad de la práctica segura con relación a la úlcera por presión.

Palabras clave: Úlcera por Presión. Práctica Basada en la Evidencia. Enseñanza. Aprendizaje. Investigación em Enfermería. 


\section{LISTA DE SIGLAS}

$\begin{array}{ll}\text { UP } & \text { ÚLCERA POR PRESSÃO } \\ \text { PBE } & \text { PRÁTICA BASEADA EM EVIDÊNCIA } \\ \text { UEL } & \text { UNIVERSIDADE ESTADUAL DE LONDRINA } \\ \text { UTI } & \text { UNIDADE DE TERAPIA INTENSIVA } \\ \mathbf{C I} & \text { CURRÍCULO INTEGRADO } \\ \text { HUL } & \text { HOSPITAL UNIVERSITÁRIO DE LONDRINA } \\ \text { NPUAP } & \text { NATIONAL PRESSURE ULCER ADVISORY PANEL } \\ \text { NPUAP/EPUAP } & \text { NATIONAL PRESSURE ULCER ADVISORY PANEL/ } \\ & \text { EUROPEAN PRESSURE ULCER ADVISORY PANEL } \\ \text { SAE } & \text { SISTEMATIZAÇÃO DA ASSISTÊNCIA DE ENFERMAGEM } \\ \text { PE } & \text { PROCESSO DE ENFERMAGEM }\end{array}$




\section{LISTA DE FIGURAS}

Figura 1 - Médias dos subescores da Escala de Braden em todas as avaliações.

Figura 2 - Prescrição de enfermagem referente ao uso da medida de prevenção mudança de decúbito.

Figura 3 - Prescrição de enfermagem referente ao uso de colchão especial.

Figura 4 - Prescrição de enfermagem referente ao uso de coxins

Figura 5 - Prescrição de enfermagem referente ao uso da medida de prevenção suplemento nutricional.

Figura 6 - Prescrição de enfermagem referente ao uso da medida de prevenção para proteção da pele em relação a umidade.

Figura 7 - Prescrição de enfermagem referente ao uso de hidratantes........

Figura 8 - Prescrição de enfermagem referente ao uso da medida de prevenção uso de curativo/cobertura

Figura 9 - Prescrição de enfermagem referente ao uso da medida de prevenção manutenção da cabeceira elevada até $30^{\circ}$ 


\section{LISTA DE QUADROS}

Quadro 1 Demonstrativo das categorias e subcategorias identificadas a partir das falas dos estudantes da $2^{\underline{a}}$ série do curso de enfermagem. Londrina, PR, 2012 ………………………....... 93 


\section{LISTA DE TABELAS}

Tabela 1 - Distribuição dos pacientes internados na Unidade Masculina, avaliados e em risco para desenvolver úlcera por pressão por dia. Londrina, PR, 2012

Tabela 2 - Distribuição dos pacientes considerando a faixa etária. Londrina, PR, 2012.

Tabela 3 - Distribuição da frequência e porcentagem da categoria do diagnóstico médico principal dos pacientes da Unidade Masculina, agrupados pelas categorias do CID-10. Londrina, PR, 2012

Tabela 4 - Distribuição dos pacientes quanto ao número de avaliações referente ao risco para UP. Londrina, PR, 2012.

Tabela 5 - Distribuição dos pacientes em relação ao escore total da Escala de Braden da primeira avaliação, segundo o nível de risco. Londrina, PR, 2012

Tabela 6 - Distribuição dos valores mínimo, máximo, médio, mediano e desvio-padrão dos subescores da Escala de Braden da primeira avaliação. Londrina, PR, 2012

Tabela 7 - Distribuição dos valores mínimo, máximo, médio, mediano e desvio-padrão dos subescores da escala de Braden de todas as avaliações. Londrina, PR, 2012

Tabela 8 - Distribuição dos pacientes nas 15 avaliações em relação às condições da pele. Londrina, PR, 2012.

Tabela 9 - Distribuição das 25 úlceras identificadas na primeira avaliação dos pacientes, segundo a localização e classificação. Londrina, PR, 2012...

Tabela 10 - Distribuição da média, mediana, desvio-padrão, mínimo e máximo do escore total da Escala de Braden na presença e ausência de UP. Londrina, PR, 2012. 
Tabela 11 - Associações e quantificação entre as variáveis: faixa etária, cor, tipo de saída, diagnóstico principal, nível de risco para UP, com a presença ou ausência de úlcera por pressão. Londrina, PR, 2012

Tabela 12 - Distribuição dos registros realizados por enfermeiros nos prontuários quanto à presença ou a ausência de UP. Londrina, PR, 2012.

Tabela 13 - Distribuição do uso das medidas de prevenção na prescrição de enfermagem, considerando categorias da UP Avançada ou Leve. Londrina, PR, 2012

Tabela 14 - Distribuição das medidas de prevenção prescritas e a limitação, ou não, da Percepção Sensorial. Londrina, PR, 2012

Tabela 15 - Distribuição das medidas de prevenção prescritas e a presença de Umidade da Pele. Londrina, PR, 2012.................

Tabela 16 - Distribuição das medidas de prevenção prescritas e a limitação na Atividade. Londrina, PR, 2012........................... 88

Tabela 17 - Distribuição das medidas de prevenção prescritas e a limitação na Mobilidade. Londrina, PR, 2012...........................

Tabela 18 - Distribuição das medidas de prevenção prescritas e adequação da Nutrição. Londrina, PR, 2012...........................

Tabela 19 - Distribuição das medidas de prevenção prescritas e problemas em relação à Fricção e Cisalhamento. Londrina, PR, 2012. 


\section{SUMÁRIO}

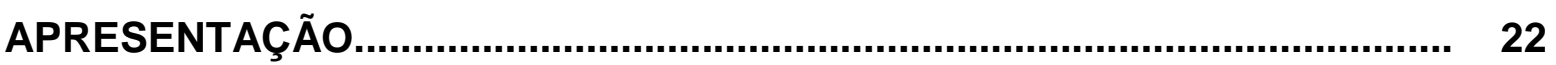

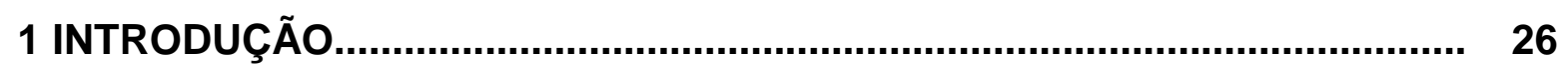

1.1 Referencial teórico .................................................................... 4

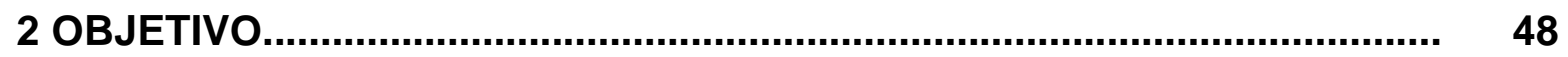

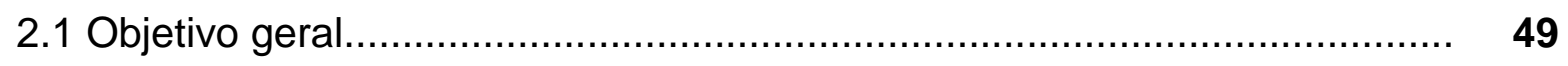

2.2 Objetivo específico........................................................................ 49

3 MATERIAL E MÉTODO............................................................... 50

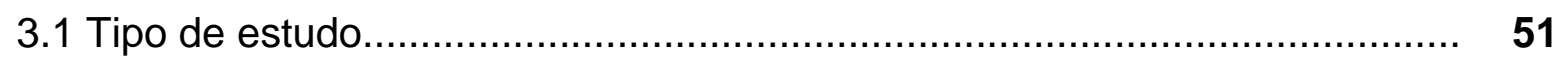

3.2 Procedimentos éticos..................................................................... 51

3.3 Caracterização do local do estudo................................................... 52

3.4 População/amostra........................................................................ 54

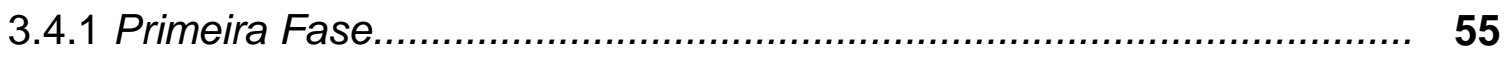

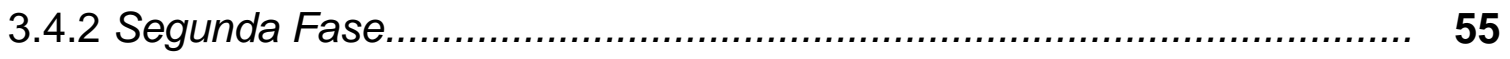

3.4.3 Terceira Fase ..................................................................... 55

3.5 Procedimentos da pesquisa......................................................... $\quad 55$

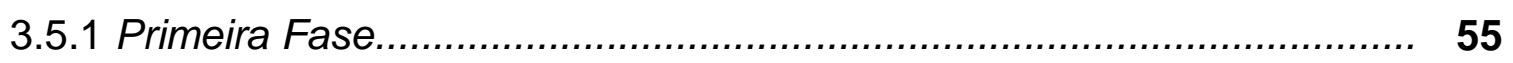

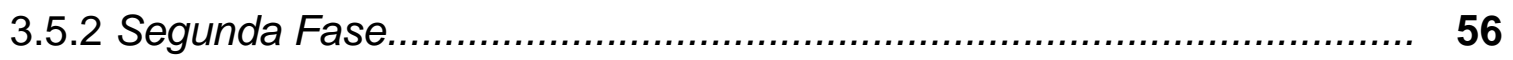

3.5.3 Procedimentos para análise dos dados........................................... 58

3.5.4 Terceira Fase ..................................................................... 59

4 RESULTADOS

4.1 Identificação do risco para úlcera por pressão e a ocorrência do

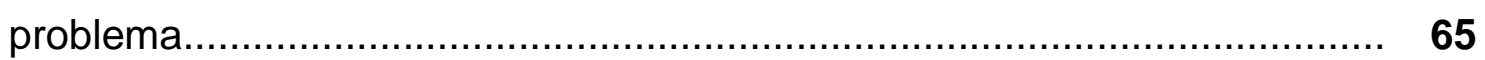

4.2. Identificação das ações para prevenção da úlcera por pressão prescritas ou não pelos enfermeiros....................................................................... $\quad 75$

4.3. Significado da experiência dos estudantes da $2^{2}$ série do curso de enfermagem da UEL referente à metodologia de ensino proposta ............. 92

4.3.1 Primeira categoria - Aprendendo sobre o tema úlcera por pressão....... 94

4.3.1.1 Correlacionando a teoria à prática.............................................. 94

4.3.1.2 O despertar para as competências da enfermagem na avaliação do paciente com risco para úlcera por pressão........................... 95 
4.3.1.3 Aprimorando o conhecimento dos estágios da úlcera por 96 pressão

4.3.1.4 Aprimorando o conhecimento sobre os fatores de risco da úlcera por pressão.

4.3.1.5 A Escala de Braden como suporte para avaliação de risco da úlcera por pressão.

4.3.2 Segunda categoria - Conhecendo a realidade da Instituição e da Enfermagem sobre a úlcera por pressão.

4.3.2.1 A falta de cuidado de prevenção da úlcera por pressão.

4.3.2.2 A importância da família nos cuidados de enfermagem na úlcera por pressão.

4.3.2.3 Identificando a realidade da prescrição e das anotações de enfermagem em relação à úlcera por pressão.

4.3.2.4 Percebendo a necessidade de transformar a prática da enfermagem em relação à úlcera por pressão

5 DISCUSSÃO

5.1 Identificação do risco para úlcera por pressão e a ocorrência do problema..

5.2 Exploração da relação entre a presença da úlcera e algumas variáveis demográficas e clínicas

5.3 Registro das evidências para a prevenção da úlcera por pressão pelos enfermeiros nas prescrições de enfermagem.

5.4 Significado da experiência dos estudantes da $2^{\mathrm{a}}$ série do curso de enfermagem da UEL referente à metodologia de ensino proposta.

6 CONSIDERAÇÕES FINAIS

7 CONCLUSÃO

REFERÊNCIAS

APÊNDICES.

APÊNCIDE A - TERMO DE CONSENTIMENTO LIVRE E ESCLARECIDOALUNO.

APÊNDICE B - TERMO DE CONSENTIMENTO LIVRE E ESCLARECIDOPACIENTE 
APÊNCIDE C - TERMO DE CONFIDENCIALIDADE E SIGILO DA

PESQUISADORA

APÊNCIDE C1- TERMO DE CONFIDENCIALIDADE E SIGILO DOS

ESTUDANTES

APÊNDICE D - INSTRUMENTO DE COLETA DE DADOS - AVALIAÇÃO DA

PELE

APÊNDICE E - PLANO DE ENSINO DO WORKSHOP DA PRÁTICA

BASEADA EM EVIDÊNCIA...

APÊNDICE F - INSTRUMENTO PARA IDENTIFICAR O CONHECIMENTO E EXPERIÊNCIAS SOBRE ÚLCERA POR PRESSÃO PELO ALUNO.

APÊNDICE G - COMPETÊNCIAS DO ENFERMEIRO NA PREVENÇÃO DE ÚLCERA POR PRESSÃO- objetivos, conteúdo, estratégias de ensino-aprendizagem.

ANEXOS.

ANEXO A - APROVAÇÃO DO COMITE DE ÉTICA EM PESQUISA. 177

ANEXO B - INSTRUMENTO PARA AVALIAÇÃO DO RISCO DA ÚLCERA POR PRESSÃO - ESCALA DE BRADEN.

ANEXO C - INSTRUMENTO PARA COLETA DE DADOS SOBRE O REGISTRO DA IDENTIFICAÇÃO DO RISCO PARA ÚLCERA POR PRESSÃO, DAS CARACTERISTICAS DA PELE, DA UP E DAS MEDIDAS DE PREVENÇÃO.

ANEXO D - ESCALA DE BRADEN. 
Apresentação 
Durante minha trajetória profissional, tive oportunidade de atuar em diferentes áreas da enfermagem. Logo após a conclusão do curso de graduação em enfermagem pela Universidade Estadual de Londrina (UEL), no ano 1986, iniciei minhas atividades como enfermeira assistencial em Unidade de Terapia Intensiva (UTI) e permaneci por seis anos.

Após, surgiu o desejo de exercer atividades de ensino na Enfermagem e, assim, ingressei na docência no curso de Auxiliar de Enfermagem do Hospital Irmandade Santa Casa de Londrina, onde fiquei até o ano 1997. Foram anos de desafios, conquistas e aprendizado na arte de ensinar, tempos de uma verdadeira e "valiosa" escola.

No ano 1997, fui aprovada em concurso público para a área de Enfermagem Fundamental do Curso de Graduação em Enfermagem da UEL. Até o ano 1999 desempenhei a função de docente, onde o ensino era realizado no modelo tradicional de ensinar, aprender e avaliar. Porém, com a reformulação curricular, ocorrida no ano 2000, passei a vivenciar um novo modelo de currículo, o tão desejado currículo integrado $(\mathrm{Cl})$ no qual a proposta metodológica de ensinar está pautada na problematização.

Assim, me deparei com novas metodologias de ensino-aprendizado, ou seja, metodologias ativas de ensinar e aprender. Foram momentos de muitos questionamentos, dúvidas e incertezas, inseguranças na nova maneira de ensinar, experimentando novas situações como: dificuldades de avaliar, de correlacionar a teoria com prática, de integração do ciclo básico com o profissionalizante, de interrelacionamento com professores e estudantes, enfim, como ensinar para uma aprendizagem significativa, considerando que o modelo que tive na minha formação e parte da docência foi pautado na metodologia tradicional. Entretanto, o sonho foi se concretizando aos poucos e até hoje ainda tenho buscado aprimoramento constante nessa nova maneira de ensino-aprendizado.

Durante o processo de reformulação do referido currículo, bem como depois de sua implementação, participei de diversas oficinas de trabalho, organizadas pelo Colegiado do Curso de Enfermagem, centradas na discussão de 
temas como: perfil profissional, competências do enfermeiro, integração entre o ciclo básico e clínico, integração teoria e prática, processo ensino-aprendizagem, processo de avaliação, metodologias ativas como, por exemplo: a problematização, dentre outros.

Ainda nessa trajetória tive a oportunidade de me aprofundar no conhecimento em cuidados de enfermagem em feridas, tanto para a graduação, no módulo Práticas do Cuidar I, como para a pós-graduação, por meio da participação, organização e implementação do Curso de Especialização intitulado "Assistência de Enfermagem ao paciente com feridas". Durante a realização do curso de especialização foram desenvolvidas atividades que proporcionassem a busca do conhecimento através de metodologias ativas. Foram cinco anos de muito aprendizado e, desde então, o tema feridas tem sido uma linha de pesquisa evidente na vida profissional.

Destaco, também, a minha atuação na assistência a pacientes com feridas crônicas, por meio de um projeto de extensão, na qual fui, em anos anteriores, e atualmente, coordenadora, e ainda sou Membro da Comissão de Lesões de Pele do Hospital Universitário de Londrina (HUL). Essa Comissão foi constituída em agosto de 2008, tendo como objetivo padronizar normas e rotinas referentes aos cuidados de feridas. Trata-se de uma comissão multidisciplinar, constituída por enfermeiros, farmacêuticos e médicos, que se reúnem quinzenalmente, com a finalidade de discutir rotinas, tratamentos e medicamentos adotados no cuidado de feridas, bem como avaliar e discutir casos clínicos. Essa comissão também tem por objetivo capacitar todos os membros da equipe no manejo dos pacientes portadores de feridas.

A minha atuação no tema feridas me proporcionou a inserção nessa linha de pesquisa com mais consistência, onde pude orientar várias pesquisas de Trabalho de Conclusão de Curso e iniciação científica extensionista. A pesquisa tem sido um elemento essencial para a minha formação e atuação como docente, possibilitando exercer trabalho com os estudantes, na formulação de novos conhecimentos ou no questionamento dos já existentes. 
Diante das considerações anteriores e pela observação empírica no decorrer desses anos, vê-se que a construção do conhecimento, por meio da metodologia da problematização, tem propiciado a formação de profissionais mais críticos e reflexivos, que há interação maior entre a teoria e a prática e nova forma de avaliar. Entretanto, ainda tenho observado, também de forma empírica, algumas limitações no processo de ensino-aprendizagem e lacunas que precisam ser mais bem trabalhadas como, por exemplo: o ensino do tema Úlcera por Pressão (UP), que é abordado na $2^{\underline{a}}$ série do curso de Enfermagem, no módulo Práticas do Cuidar, na qual sou uma das docentes responsável pelo mesmo da teoria até a prática hospitalar.

Com base nessas afirmações e por ocasião do meu ingresso no Programa de Doutorado em Enfermagem na Área Fundamental na Escola de Enfermagem de Ribeirão Preto, fui motivada a desenvolver esta pesquisa com a finalidade de propiciar aos estudantes da segunda série do Curso de Graduação em Enfermagem que estivessem no módulo Práticas do Cuidar, um novo modelo de ensino pautado na Prática Baseada em Evidência ( $\mathrm{PBE}$ ), no tema úlcera por pressão e identificar se a mesma colaborou significativamente para o aprendizado desse estudante.

Assim, pretendo com este estudo, contribuir para o ensinoaprendizagem em enfermagem por meio de uma metodologia que proporcione efetiva integração teoria e prática e, assim, oportunizar uma formação de profissionais com conhecimento para os cuidados na prevenção da UP. 


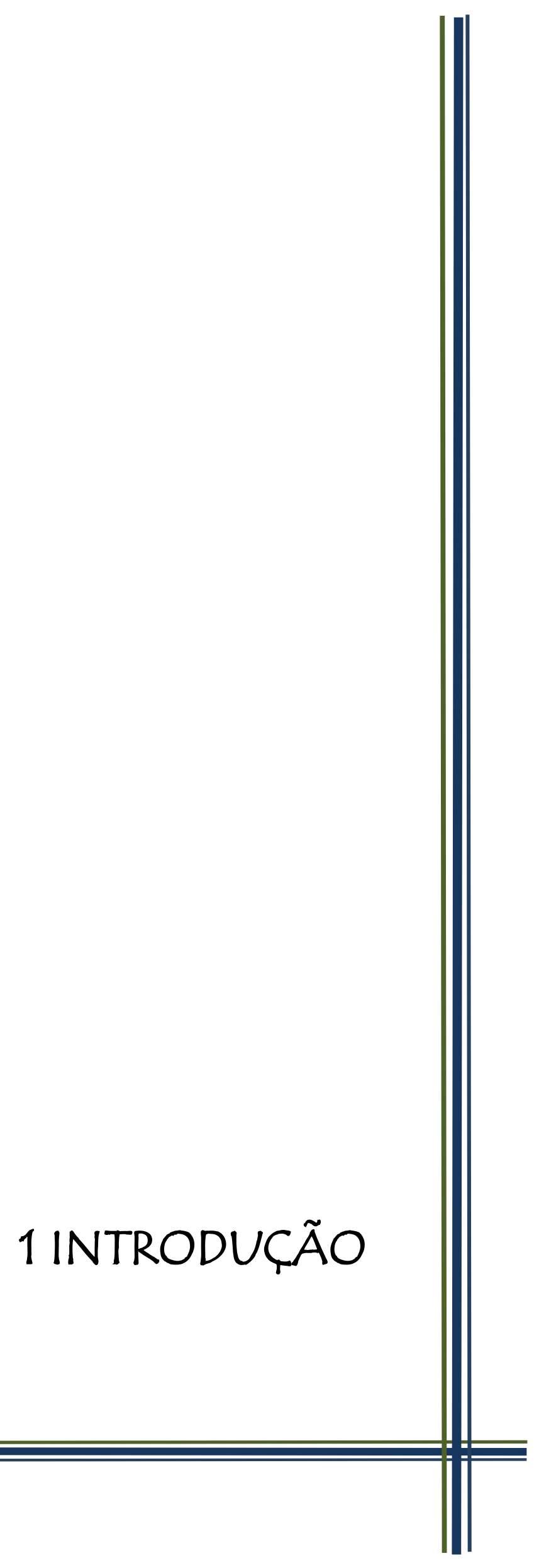


A formação do enfermeiro, enquanto profissional da equipe multidisciplinar de saúde, deve ser dinâmica e munida de reflexões constantemente, com a finalidade de formar pessoas com competência e perfil, para provocar as mudanças que são necessárias nas práticas de saúde (ALMEIDA, 2012).

As Diretrizes Curriculares Nacionais para os cursos da área de saúde preconizam que é fundamental promover adequações nos modelos de formação que vem, de certa maneira, se contradizendo com as necessidades do sistema de saúde e da sociedade para o qual está organizado. Assim têm-se que:

Os processos formativos devem considerar o acelerado ritmo de evolução do conhecimento, as mudanças do processo de trabalho em saúde (...) espera-se formar cidadãos-profissionais críticos e reflexivos, com conhecimentos, habilidades e atitudes que os tornem aptos a atuarem em um sistema de saúde qualificado e integrado (BRASIL, 2007, p.19).

Ao se analisar a Lei das Diretrizes Curriculares Nacionais dos Cursos de Enfermagem está implícita, dentro das competências gerais, a formação do enfermeiro na assistência ao paciente com UP, descritas no art. $4^{\circ}$ nos itens de atenção à saúde, tomada de decisão, comunicação e educação permanente (BRASIL, 2001).

As competências do enfermeiro na prevenção da UP aos pacientes de risco são apresentadas por Pieper (2013), baseadas na diretrizes da National Pressure Ulcer Advisory Panel - NPUAP (2009) como: compreender a incidência e prevalência da UP; identificar os fatores etiológicos que contribuem para a ocorrência da UP; realizar avaliação de risco estruturada na admissão, repeti-la com certa regularidade e frequência para os pacientes em cuidados críticos; certificar-se de que a realização da avaliação da pele faça parte da avaliação de risco nas instituições de saúde; desenvolver e implementar um programa individualizado de cuidados com a pele; demonstrar posicionamento e reposicionamento adequado na prevenção e tratamento da UP; escolher superfície de suporte apropriada para os pacientes, baseada na avaliação de risco realizada; implementar intervenções nutricionais adequadas na prevenção da UP; documentar com acurácia os 
resultados da avaliação de risco, avaliação da pele e as estratégias de prevenção; aplicar raciocínio clínico nas tomadas de decisões em relação ao impacto que poderá causar nas mudanças com o indivíduo com risco para UP e fazer encaminhamentos para outros profissionais de saúde baseados na avaliação de risco.

Dessa forma, os profissionais de saúde deverão ser formados para desenvolverem competências essenciais como: conhecimentos, habilidades e atitudes, possibilitando a sua participação e atuação multiprofissional, beneficiando tanto os indivíduos como a comunidade (ORGANIZACIÓN PANAMERICANA DE LA SALUD,1997). No que diz respeito à formação dos enfermeiros, sabe-se que é imprescindível que adquiram conhecimentos, habilidades e atitudes para a prática clínica. Assim, sua formação deve englobar o desenvolvimento de competências para o saber, como fazer, porquê e para quê fazer (ORGANIZACIÓN PANAMERICANA DE LA SALUD, 1997).

Ter competência para fazer ou realizar uma tarefa significa ter conhecimento, habilidade e atitudes compatíveis com o desempenho dela e ser capaz de colocar esse potencial em prática, sempre que for preciso. Entretanto, pode-se afirmar que o conhecimento é o que as pessoas sabem ou que buscam aprender, habilidades, o que elas fazem, e atitudes, o que elas são. Atitude representa a vontade de fazer as coisas. Habilidade representa o saber fazer, o como fazer. Conhecimento representa o saber (BALSANELLI et al., 2008).

As abordagens em relação ao processo de transmitir e receber os saberes são realizados por diferentes metodologias de ensino, desde aquelas que enfatizam o ensino centrado no professor-transmissor de conteúdo, até aquelas em que o estudante é participante ativo da sua aprendizagem.

Nesse contexto social em que se vive, atualmente, o ensino nos cursos da área da saúde devem se aproximar da realidade social na formação de um profissional ativo e apto a aprender a aprender: aprender a conhecer, aprender a fazer, aprender a conviver e aprender a ser, buscando atendimento à saúde integralizado de qualidade, eficiência e com resolutividade (MILTRE, 2008). 
As metodologias ativas utilizam a problematização como uma das estratégias de ensino-aprendizagem, com a finalidade de alcançar e motivar o estudante ao raciocínio e à reflexão. É um método que focaliza o estudante como sujeito que desenvolve o seu aprendizado de maneira crítica e reflexiva, comprometida com a melhoria da profissão. Para que isso se concretize é preciso ensinar o processo de investigação e não o resultado da ciência, é colocar o estudante em confronto com a realidade (TACLA, 2002).

Os pressupostos metodológicos da problematização é bem explicitado por Bordenave e Pereira (2002) que adaptaram o Método do Arco, elaborado por Charles Maguerez, em 1960.

Dessa, forma na problematização, o processo de ensino começa com a exposição dos estudantes a um problema. Essa primeira etapa chama-se observação da realidade. A segunda etapa consiste em identificar as variáveis do problema, aquelas que, se modificadas, poderiam resultar na solução do problema.

Ainda, segundo os mesmos autores, a problematização possui uma terceira etapa, caracterizada pelo momento em que se busca a explanação teórica do problema. Posteriormente segue a etapa em que os estudantes propõem hipóteses de solução.

Buscando a excelência no ensino e na aprendizagem, o curso de Graduação em Enfermagem da UEL, foi criado em 1972, em seu percurso de 40 anos passou por sete reformulações curriculares com a finalidade de propiciar a formação de enfermeiros comprometidos e engajados com as necessidades dos indivíduos e da sociedade, sendo que a última mudança, em 2000, culminou com a implementação do Currículo Integrado (CI) (KIKUCHI; GUARIENTE, 2012; DESSUNTI et al., 2005).

A opção metodológica do $\mathrm{Cl}$ da UEL é a Metodologia da Problematização que, no primeiro momento, realiza a observação da realidade, no decorrer da qual o tema será trabalhado, desenvolvendo reflexão na busca dos possíveis fatores que estão associados ao problema emergente da realidade sob foco. 
No segundo momento, são definidos os aspectos que precisam ser conhecidos e compreendidos com a finalidade de levantar as possíveis soluções para esse problema, assim os pontos-chave, que direcionarão os estudos e análises subsequentes, são determinados.

A seguir, dá-se início ao estudo aprofundado sobre aspectos teóricos relacionados aos pontos-chave estabelecidos. É, portanto, no transcorrer da teorização que os estudantes identificam os pressupostos e fundamentos que os conduzirão à resolução do problema.

O aprofundamento teórico, comparado com a realidade, propicia a análise e discussão dos dados levantados e a proposição de hipóteses para a solução dos problemas encontrados, com a finalidade de intervir no que foi encontrado na realidade.

Por último, são implementadas as hipóteses que melhor atendam os problemas levantados, é o momento de aplicar à realidade ações que foram concretamente teorizadas e fundamentadas. Esse método foi denominado Método do Arco de Maguerez e foi proposto objetivando oferecer respaldo ao "[...] educador preocupado com o desenvolvimento de seus alunos e a sua autonomia intelectual, visando o pensamento crítico e criativo [...]" (BERBEL, 1999).

Assim sendo, a Metodologia da Problematização favorece aqueles que dela participam chegarem a uma ação prática transformadora, proveniente de um aprofundamento teórico em confronto com a realidade, em decorrência da elaboração de hipóteses de solução. Nessa metodologia, ocorre interação dinâmica entre o sujeito que aprende e o objeto do conhecimento é desvelado por meio de sucessivas aproximações. Dessa forma, o estudante tem possibilidade de aprender a pensar criticamente, desenvolvendo a capacidade de reconhecer a realidade e seus problemas, preparando-se para uma ação transformadora nos contextos profissional e social. Portanto, a Metodologia da Problematização possibilita ao estudante desenvolver a capacidade de construir seus conhecimentos por meio de situações observadas no contexto real, desencadeando um processo de açãoreflexão-ação, contínuo e progressivo (GODOY; SOUZA, 2001). 
$\mathrm{O} \mathrm{Cl}$ está estruturado por módulos onde as atividades de ensino e aprendizagem são desenvolvidas por diferentes métodos, tais como: aula expositivodialogada, leitura e discussão de textos, mesa-redonda, dramatização, seminários, estudo de caso, palestras, pesquisa bibliográfica e discussão de situação-problema. O curso fundamenta-se nos seguintes pressupostos: concepção político-pedagógica crítica e reflexiva; concepção de homem como ser histórico-social, capaz de transformar a si e ao mundo; equilíbrio entre vocação técnico-científica e humanista; organização integrada de conteúdos; análise do fenômeno em sua totalidade; interdisciplinaridade; teoria e prática indissolúveis; integração ensino, serviço e comunidade e aprendizagem significativa.

Assim sendo, os princípios pedagógicos do $\mathrm{Cl}$ visam permitir aprendizagem significativa e crítico-reflexiva, propiciando ao estudante ser sujeito ativo, crítico e responsável pela construção de seu próprio conhecimento, desenvolvendo competências para resolver problemas em sua área de atuação, exercer sua cidadania e assumir seu papel social na construção de sua realidade. Ao docente cabe o planejamento das estratégias e dos recursos, a orientação e o acompanhamento das atividades para promover situações que possibilitem 0 alcance das competências (DELLAROZA; VANUCHI, 2005).

$\mathrm{O} \mathrm{Cl}$ acontece ao longo de 4 anos e está dividido em séries, com destaque ao desenvolvimento do internato na $4^{a}$ série. As séries são divididas em módulos, sendo que cada módulo tem a sua competência, desempenhos e habilidades a serem atingidos pelos estudantes.

$\mathrm{Na} 1^{\underline{a}}$ série do curso o estudante já tem uma aproximação com realidade, teorização e desenvolve atividades praticas em Unidades Básicas de Saúde (UBS). Na $2^{a}$ série, os estudantes iniciam o módulo Práticas do Cuidar, tendo como competência desenvolver ações de enfermagem individuais e coletivas relativas à hospitalização do adulto e do idoso, assistindo-os na perspectiva do cuidado integral (MARTINS; VOLPATO; KRELING, 2005). Esse módulo tem também como objetivo desenvolver nos estudantes as habilidades técnicas para a realização de procedimentos de enfermagem. Trata-se do primeiro contato do estudante com o paciente hospitalizado. Uma das unidades desse módulo focaliza o tema úlcera por pressão, um fenômeno que permeia a assistência de enfermagem em todos os 
contextos de atuação profissional e cujo ensino para a prática tem preocupado os membros da equipe de enfermagem, desde os primórdios da profissão (CALIRI, 2002).

Em estudo realizado por Nonino (2006), no HUL, campo de prática clínica para os estudantes, foi identificado que a equipe de enfermagem que assiste os pacientes em risco para a úlcera dá maior ênfase às medidas curativas em detrimento das preventivas. A autora afirma ainda que talvez isso ocorre devido ao modelo biomédico de atenção à saúde que ainda tem prevalecido como prática desenvolvida pelos profissionais da saúde e, em especial, pela equipe de enfermagem. Assim, pode-se inferir que o preparo na formação dos profissionais, na grande maioria, não rompeu o tradicionalismo, ou seja, ensina-se para atender o que já está doente e a prevenção continua relegada a um segundo plano.

Rocha e Almeida (2000) e Oliveira et al. (2012) afirmam que a assistência à saúde ainda reproduz o modelo fragmentado de cuidar e baseado na doença e não na prevenção. Assim, nos campos de prática, não há atenção integral à saúde e, predominantemente, cuida-se somente da concepção unicausal da doença. Isso dificulta que o estudante aplique na prática o que foi ensinado por meio de outra concepção. Assim, a utilização do modelo biologicista tem revertido em exemplos que são perpetuados pelos estudantes ainda em formação.

Com relação à UP, o que se observa na prática não é diferente, ou seja a prevenção ainda é colocada em um segundo plano e, assim, continua sendo um desafio para a assistência de enfermagem. A UP é uma lesão que apresenta desenvolvimento muito rápido, e, após sua instalação, o paciente pode apresentar um período de internação prolongado, afetando a sua condição clínica. É resultante de pressão isolada ou de pressão combinada com fricção e/ou cisalhamento, sendo localizada na pele e/ou no tecido ou estrutura subjacente, geralmente sobre uma proeminência óssea (SANTOS; CALIRI, 2007).

Enfatiza-se que a incidência de UP é considerada como indicador (negativo) do resultado da qualidade dos serviços de saúde e da assistência de enfermagem (SIMÃO, 2010). A UP também é classificada mundialmente como evento adverso, ou seja, uma ocorrência indesejável. Porém, na maioria das vezes, 
pode ser prevenida, o que reafirma que o modelo biomédico é predominante na assistência ao paciente, pois, nesse modelo, trata-se a doença como forma de curar e não de preveni-la. Sua natureza danosa ou prejudicial compromete a segurança do paciente que se encontra sob os cuidados dos profissionais de saúde (NASCIMENTO, 2008).

Denota-se que, na atualidade, a segurança do paciente se constitui como um dos problemas mais críticos para a saúde. Dessa forma, são imprescindíveis ações crescentes com o objetivo de diminuir complicações que podem ser evitadas, bem como prevenir possíveis erros por meio da utilização da Prática Baseada em Evidências (PBE). Para tanto, exige-se relação efetiva entre os profissionais da beira do leito e a gerência da instituição (BRADLEY; DIXON, 2009).

Assim sendo, os profissionais de saúde que assistem os pacientes, principalmente os enfermeiros, que são essenciais no processo para evitar erros, impedir tomadas de decisões inadequadas, gerenciando a assistência com o uso de estratégias que promovam a segurança e qualidade do cuidado (AGÊNCIA NACIONAL DE VIGILÂNCIA SANITÁRIA, 2013).

É necessário repensar a prática, tendo o entendimento que é possível diminuir as complicações para o paciente. Sabe-se que há um despertar das instituições de saúde e dos profissionais em busca de formas de tornar a assistência de saúde mais segura para os pacientes e, por consequência, mais segura para os profissionais que prestam assistência (AGÊNCIA NACIONAL DE VIGILÂNCIA SANITÁRIA, 2013).

É fato que a enfermagem tem ainda desenvolvido mais o cuidado de forma fragmentada e pautado no modelo biomédico do que em evidências, o que muitas vezes não atende as reais necessidades do paciente. Dessa forma, é necessário propiciar capacitação e apoio aos enfermeiros para identificar e utilizar práticas baseadas em evidências, relacionadas à segurança do paciente como, por exemplo, as diretrizes de prevenção de UP. Verifica-se, ainda, que o sistema de saúde tem incentivado o desenvolvimento de boas práticas, impondo condições não reembolsáveis de custos relacionados aos cuidados pós-queda, infecções urinárias, úlcera por pressão, dentre outras (AGÊNCIA NACIONAL DE VIGILÂNCIA 
SANITÁRIA, 2013).

Nesse cenário, observa-se uma nova cultura gerencial e assistencial desenvolvida pela enfermagem, na qual se buscam maneiras de prevenir complicações, bem como as instituições de saúde têm aplicado cada vez mais recursos financeiros para a identificação e implementação de estratégias que visem a segurança dos indivíduos (AGÊNCIA NACIONAL DE VIGILÂNCIA SANITÁRIA, 2013).

Dessa forma, é imprescindível que os profissionais de saúde, em sua formação, desenvolvam competências para realizar ações que evitem resultados indesejáveis e que possam colocar os indivíduos em situações de risco. Uma das formas de proporcionar segurança ao paciente é por meio do cuidado de saúde de alta qualidade que pode ser alcançado utilizando-se a PBE, através de uma equipe de enfermagem habilitada para tal (SAMMER et al., 2010).

De acordo com World Health Organization (2011), para enfrentar de forma eficaz as questões que envolvem a segurança dos pacientes, é necessário compreender a amplitude dos problemas que são enfrentados no cotidiano laboral pelos profissionais de saúde, ou seja, repensar a culpabilidade somente dos trabalhadores, pois é notória a precariedade das instituições de saúde no que tange aos materiais, equipamentos, recursos humanos insuficientes, tanto em quantidade como em qualidade, dentre outros, que colaboram para que ocorram os erros ou se coloquem os paciente em situações de risco, porém, isso não quer dizer que os indivíduos não devam ser responsabilizados pelos seus atos.

Enfatiza-se que o ensino tem colaborado para a situação supracitada, visto que, desde a graduação, tem repassado aos estudantes que não se pode errar, ou colocar o paciente em situação de risco, posto que é vergonhoso, esse entendimento tem sido uma realidade também nos serviços de saúde, onde o erro, ou situações na qual o paciente é colocado em risco, é visto de uma maneira individualizada e que também ocorre pelo descuido do trabalhador (AGÊNCIA NACIONAL DE VIGILÂNCIA SANITÁRIA, 2013). 
ao estudante que errar é humano e que os profissionais de saúde não têm a intenção deliberada em errar, apenas em uma minoria de situações cometem violações deliberadas. É preciso saber que quanto mais se compreende como e porquê essas coisas acontecem mais aumenta a probabilidade de diminuir a reincidência. Assim, o ensino deve proporcionar aprendizagem significativa, partindo do princípio que o erro do profissional, bem como as situações de risco em que os pacientes muitas vezes se encontram, também, é resultante do sistema (REASON, 2003).

Ainda é preciso que os gestores investiguem os fatores que colaboram para o erro ou quais as situações de risco a que estão expostos os pacientes para que possam ser buscadas estratégias para impedi-los e assim prevenir e evitar agravos à saúde dos mesmos (REASON, 2003).

Uma situação de risco comum em instituições hospitalares, vivenciada pelos pacientes, está relacionada com as UPs. Vários pesquisadores investigaram a incidência de UP em hospitais universitários e públicos no Brasil. Os resultados encontrados variaram de 39,8 a 62,5\% (COSTA, 2003; FERNANDES, CALIRI, 2008; FERNANDES; TORRES, 2008; PARANHOS, 1999; ROGENSKI; SANTOS, 2005;

No HUL, uma pesquisa desenvolvida por Pachemshy (2009) revelou que a incidência de UPP foi de 33,6\%. A investigação incluiu 232 pacientes com maior grau de dependência para o cuidado (III e IV), internados em unidades de pronto-socorro, unidades masculina e feminina e também na UTI adulto. Tal pesquisa foi realizada no período de novembro de 2006 a fevereiro de 2007, sendo utilizada a Escala de Braden para avaliação do risco de UP. Os resultados apresentados pela autora mostraram que, nos pacientes com grau de dependência III, a incidência foi de 19,4\% e, nos pacientes com grau de dependência IV, o índice foi de 51,6\%, com predomínio de UP na região sacral (74,4\%). A incidência foi maior nos pacientes clínicos $(41,3 \%)$ do que nos pacientes cirúrgicos. No estudo não foi apresentado o nível de risco obtido dos pacientes na avaliação, por meio da Escala de Braden e também não foi feita a relação dos dados observados com os critérios para que os pacientes fossem classificados e cuidados conforme o grau de dependência, ou para que medidas fossem utilizadas para a prevenção. 
Ainda foi ressaltado que, no momento do estudo, não havia na instituição um protocolo institucional de medidas preventivas. Concluiu-se, para o contexto estudado, que há a necessidade de protocolos de medidas preventivas e melhor atenção aos pacientes com maior risco para desenvolver UP, assim como a educação continuada dos profissionais (PACHEMSHY, 2009).

Outro estudo, também desenvolvido no HUL, identificou o desenvolvimento de UP em 148 pacientes cirúrgicos e encontrou a incidência de $25 \%$. Essa pesquisa avaliou o desenvolvimento de UP em pacientes cirúrgicos, identificando que as áreas corporais mais acometidas pelas lesões foram: a região sacro/glútea (68\%), calcâneos (18\%), região dorsal (9\%) e o pavilhão auricular (5\%). Ainda, revelou que a maioria das lesões diagnosticadas foi de grau II (57\%), seguida por lesões de grau I (41\%) e grau III (2\%), sendo que não foi detectado nenhuma lesão de grau IV (URSI, 2010).

Ressalta-se que, no estudo anteriormente descrito, as variáveis consideradas como estatisticamente significantes para o desenvolvimento de úlcera por pressão foram: idade, sexo, avaliação por meio da classificação ASA (classificação em níveis de gravidade), tempo de anestesia, porte cirúrgico e presença de hipertensão arterial. Como conclusão da pesquisa, a autora se propôs a organizar a avaliação do desenvolvimento de UP no paciente cirúrgico através da aplicação da Escala de Braden e sugeriu que a mesma seja aplicada pelo enfermeiro no perioperatório, por ser intervenção de fácil realização.

Ainda outra pesquisa desenvolvida no HUL, por Lemos (2011), também identificou a incidência de UP por pressão em pacientes com restrição de movimentos, no pós-operatório imediato e tardio. Os pacientes foram avaliados, utilizando-se a Escala de Braden e identificou-se quais apresentavam risco para o desenvolvimento de UP. A coleta de dados durou 3 meses e incluiu 15 pacientes. A incidência de UP foi de 40\%. A faixa etária de maior incidência foi de 18 a 28 anos $(26,6 \%)$, diretamente relacionada à clínica de maior incidência, a ortopédica, com $50 \%$ das úlceras.

Em estudo de Simão (2010), investigou-se a incidência e prevalência de UP em 346 pacientes internados em quatro unidades de terapia intensiva de um 
hospital público de ensino do Estado de São Paulo, no mês de outubro de 2009, e a conformidade das ações de enfermagem, considerando os registros de enfermagem dos prontuários. A prevalência nas UTIs variou entre 9,52 e 26,47\% (no total de 15,6\%) e a incidência, de 11,84 a 16\% (no total de 13,69\%). Dos 252 pacientes admitidos sem UP, somente 47 (19\%) não tinham risco e $39(15,47 \%)$ tinham risco alto e altíssimo. O estudo desvelou que ações de enfermagem não estavam em conformidade com as recomendações das diretrizes internacionais em relação ao uso da Escala de Braden, ao uso de medidas de prevenção, considerando o risco do paciente, e ao registro das características da pele e das úlceras.

Nesse mesmo estudo foram demonstrados ainda problemas relacionados à concordância entre os enfermeiros e a pesquisadora quanto à determinação de alguns subescores da Escala de Braden e a escala era realizada somente com a finalidade administrativa de fornecer informações institucionais (associadas aos índices de UP) para o programa Compromisso com a Qualidade Hospitalar (CQH), mantido pela Associação Paulista de Medicina (APM) e pelo Conselho Regional de Medicina do Estado de São Paulo (Cremesp), ao qual o hospital é afiliado (SIMÃO, 2010).

Em outra pesquisa, realizada com pacientes e profissionais de UTI do Hospital das Clínicas de Ribeirão Preto, evidenciou-se que as intervenções educativas não trouxeram impacto na redução dos índices de incidência e na prática clínica dos profissionais (FERNANDES; CALIRI; HAAS, 2008). No mesmo estudo foi identificado ainda que instrumentos para a avaliação das condições clínicas dos pacientes, como Escala de Braden e Escala de Glasgow, são eficazes para a detecção do risco e podem auxiliar o enfermeiro na identificação de pacientes em risco e para o planejamento da assistência (FERNANDES; CALIRI, 2008).

Em investigação desenvolvida no Hospital Universitário do Estado de São Paulo, com o objetivo de avaliar a implementação de um protocolo de prevenção de UP, por meio do estudo da prevalência e incidência, mostrou que, dentre os 87 pacientes avaliados, houve prevalência de 19,5\% e incidência de 18,4\% dos 190 pacientes de risco acompanhados. Em relação à implantação do protocolo, os resultados encontrados identificaram que as enfermeiras abordaram o protocolo como instrumento de trabalho adotado e avaliado segundo as experiências 
vividas durante 0 desempenho da assistência de enfermagem. Também, nesse mesmo estudo, foram apontadas dificuldades na adoção do protocolo por problemas relativos aos profissionais com restrição física, às vagas não repostas no quadro de pessoal e à necessidade de capacitação do pessoal (ROGENSKI, 2011).

Em pesquisa realizada em Hospital de Ensino da Universidade Federal do Paraná, onde 311 pacientes foram avaliados com o objetivo de verificar a prevalência e os fatores de risco para presença de UP, apresentou-se como resultado uma prevalência de $9,97 \%$. Os pacientes avaliados pertenciam às unidades de internação do referido hospital, com maior prevalência para o centro de terapia semi-intensivo, com $66,67 \%$, seguido da unidade de internação de infectologia adulta, com 42,86\% (RIBAS, 2011).

A literatura destaca que, para que seja prestada assistência de qualidade ao paciente em risco para UP, é fundamental que toda a equipe de saúde esteja envolvida, devido à multicausalidade do problema. Entretanto, a equipe de enfermagem é a que está mais próxima do paciente. Nesse aspecto, o enfermeiro possui papel ímpar, pois é o responsável pela prescrição de enfermagem, pela supervisão e gerência da equipe para que se tenha adesão às recomendações e às medidas preventivas (FERNANDES, 2006). Porém, estudos têm evidenciado que nem sempre os enfermeiros possuem o conhecimento necessário para que possam implementar o Processo de Enfermagem (PE), utilizando as evidências sobre o assunto (MIYAZAKI, 2009; POLETTI, 2005). Esses estudos mostram, ainda, que o problema pode estar associado à formação do enfermeiro.

Poletti (2005) investigou a questão do ensino de graduação em enfermagem referente ao tema UP e à falta do uso de estratégias embasadas em evidências, pelos professores, para que conduzam a aprendizagem significativa pelo estudante. A pesquisa descritiva do tipo inquérito foi realizada com 36 docentes dos cursos de graduação em enfermagem de 8 instituições públicas de ensino superior do Estado de São Paulo. Dentre os participantes, 28\% ministravam conteúdo teórico em sala de aula, 75,6\% em estágio curricular e 33,3\% teórico-prático em laboratório. O método mais utilizado em sala de aula era aula expositiva $(44,4 \%)$ e, em laboratório de ensino, a demonstração de procedimentos pelo professor $(58,3 \%)$. No ensino clínico, a estratégia utilizada com maior frequência era a aprendizagem por 
repetição, em que um estudante fazia o procedimento e os demais observavam $(83,3 \%)$. O ensino da prevenção era centralizado nos fatores de risco $(91,7 \%)$, e $41,7 \%$ dos docentes acreditavam que não estavam preparados para o ensino do tema e consideravam o assunto complexo. O estudo apontou, ainda, que diversas competências do estudante para a assistência de enfermagem ao paciente com UP - as quais poderiam ser desenvolvidas no campo clínico, não estavam sendo abordadas pelos docentes e poderiam ser enfocadas dentro do ensino das fases da Sistematização da Assistência de Enfermagem (SAE), um componente básico e obrigatório do ensino de graduação e da prática profissional.

Em estudos sobre o conhecimento dos estudantes de graduação em Enfermagem e dos profissionais (enfermeiros e membros da equipe de enfermagem) sobre a prevenção da UP, utilizando-se um instrumento construído a partir das recomendações para a PBE, identificaram-se que existem aspectos da prevenção nos quais ambos os grupos de participantes apresentaram déficits de conhecimento. Isso foi verificado independentemente da formação do profissional, do tempo de experiência na enfermagem e do ano da realização da pesquisa (CALIRI; MIYAZAKI; PIEPER, 2003; FERNANDES; CALIRI; HAAS, 2008; MIYAZAKI, 2009; RANGEL, 2004).

Miyazaki (2009), utilizando um teste com itens verdadeiros e falsos sobre a prevenção e avaliação da UP, identificou que o conhecimento dos enfermeiros foi insuficiente (média de 79,4\%) e que muitas medidas inadequadas, ou que poderiam causar danos, ou colocar os pacientes em risco, foram consideradas corretas. Ainda, de acordo com a mesma autora, outros estudos nacionais e internacionais obtiveram resultados semelhantes na porcentagem de acertos, mostrando que o déficit de conhecimento sobre a fundamentação teórica da assistência de enfermagem é um problema mundial.

Denota-se que esse mesmo panorama foi observado na pesquisa de Fernandes, Caliri e Haas (2008). Nela, mostrou-se a deficiência no conhecimento entre os enfermeiros, técnicos e auxiliares de enfermagem quando questionados sobre o estadiamento e as medidas de prevenção da UP.

Ainda, os estudos citados anteriormente de Fernandes, Caliri e Haas 
(2008) apontam que estudantes e profissionais expostos a métodos ativos de aprendizagem, durante a sua formação, prática profissional ou pós-graduação, tiveram melhores escores nos testes de conhecimento (com diferenças estatisticamente significantes), implicando que o conhecimento depende do processo ensino e aprendizagem que ocorre ao longo da formação e da prática profissional.

Considerando as estratégias para o ensino-aprendizagem das competências para prevenção e tratamento de UP, é possível afirmar que o pensamento crítico para a tomada de decisão baseada em evidências seja uma estratégia necessária (POLLETI, 2005).

Embora a SAE não seja uma estratégia de ensino-aprendizagem, o enfermeiro deve utilizá-la, por meio do julgamento clínico, como método para tomada de decisão ante o paciente com risco para desenvolvimento de UP. Esse instrumento metodológico é conhecido internacionalmente e no Brasil é reconhecido pelo Conselho de Enfermagem (CONSELHO FEDERAL DE ENFERMAGEM, 2009).

A SAE deve ser utilizada para organizar e planejar ações assistenciais, gerenciais, científicas ou em pesquisas. A sua aplicação traz muitos benefícios, como as observadas na redução da incidência e tempo das internações hospitalares e prevenção de erros, pois favorece boa comunicação entre a equipe de enfermagem e de saúde e, por consequência, na prevenção da UP (AMANTE; ROSSETO; SCHNEIDER, 2009; ALFARO-LEFEVRE, 2005).

Ressalta-se que a SAE orienta o enfermeiro para assistência eficiente, sistematizada, direcionada e de baixo custo. É uma forma de os enfermeiros avaliarem constantemente sua prática e refletir como poderiam desenvolvê-la com mais eficácia e segurança para o paciente e, consequentemente, para a equipe de enfermagem (AMANTE; ROSSETO; SCHNEIDER, 2009).

Reforça-se que prevenção da UP é significativa se a avaliação do risco do paciente para UP, as intervenções para a prevenção e a avaliação dos resultados da assistência forem atividades inter-relacionadas, e não trabalhadas isoladamente. As etapas do PE - avaliação, diagnóstico, planejamento, 
implementação e evolução — são tão relevantes no gerenciamento pelo enfermeiro da avaliação de risco para UP quanto no gerenciamento de qualquer outra condição clínica (MAGNAN; MAKLEBUST, 2009).

O processo de ensino e aprendizagem pode ser estimulado com o uso de diferentes métodos. O aprender pela busca e o uso das evidências são estratégias que permitem a articulação do conhecimento com as competências para a prática, ao incitar o estudante a adotar uma postura ativa (PERRENOUD, 1999). Para Schmidt e Brown (2007), a meta do ensino na graduação em enfermagem é desenvolver competências requeridas para a PBE.

Diante das considerações anteriores e pela observação empírica que a incidência e a prevalência de UP no HUL ainda constituem problema de enfermagem de difícil solução e que os alunos do Curso de Graduação de Enfermagem, que realizam suas práticas clínicas no referido hospital, embora estejam vivenciando um currículo integrado têm dificuldades de relacionar a teoria com a prática é que este estudo foi proposto. Acredita-se que a partir deste estudo, onde é utilizada uma metodologia de ensino para propiciar aos estudantes conhecerem as melhores evidências na prevenção da UP, advindas das diretrizes recomendadas na literatura científica pertinente e observarem a prática assistencial, as experiências de aprendizagem serão significativas.

\subsection{Referencial Teórico}

A prática baseada em evidências tem sido amplamente discutida na literatura em todo o mundo, e poderá trazer mudanças significativas da prática de enfermagem que ainda está alicerçada em tradição, rituais e tarefas propiciando mudanças para uma prática reflexiva pautada em conhecimento científico, favorecendo a melhoria da qualidade da assistência de enfermagem ao paciente (GALVÃO; SAWADA; MENDES, 2002).

A prática clínica baseada em evidências consiste em fazer escolhas, em relação ao melhor exame para diagnosticar uma doença e ao tratamento mais efetivo para o paciente. A tomada de decisão clínica para as melhores escolhas 
dependem do conhecimento da evidência pelo profissional, das suas habilidades e atitudes, dos recursos disponíveis e expectativas e preferência do paciente (GLASZIOU, 2010). O termo "baseado em evidências" apareceu pela primeira vez de forma documentada por Gordon Guyatt e ao Evidence Based Medicine Working Group, em 1992, onde descreveram que a medicina baseada em evidência deveria ser além da intuição, da experiência clínica não sistemática e da fisiopatologia (CULLUM et al., 2010).

A prática baseada em evidência na medicina consiste em um processo que segue as seguintes etapas: $1^{\circ}$ - levantamento dos problemas e formulação das questões; $2^{\circ}$ - pesquisa da literatura sobre o tema em questão; $3^{\circ}$ avaliação e interpretação dos estudos coletados mediante os critérios estabelecidos; 4ํ- utilização das evidências encontradas relacionadas com a assistência, ensino ou com a elaboração cientifica (DRUMMOND, 2002).

De acordo com Simon (1999), a prática baseada em evidências não se baseia na intuição, observações não sistematizadas ou princípios patológicos. Ela dá ênfase à utilização de pesquisas para conduzir a tomada de decisão clínica. Essa abordagem precisa do aprendizado de novas habilidades para serem utilizadas nos processos de tomada de decisão. Essas habilidades envolvem a utilização formal das regras da evidência ao avaliar a literatura. Dessa forma, a prática baseada em evidências envolve a pesquisa com a experiência clínica e as preferências do paciente para que seja tomada a decisão sobre um problema específico (SIMON, 1999).

A evidência é fundamental e se caracteriza como algo que dá provas para a tomada de decisão, envolve resultados de investigações científicas e consenso de especialistas de renome. Dentro de uma organização devem ser incluídos fatos ou dados provenientes do trabalho desenvolvido (STETLER et al.,1998).

A prática da enfermagem baseada em evidências surge no movimento da medicina baseada em evidências, que é conceituada como o consciencioso, explícito e criterioso uso da melhor evidência para tomar decisão sobre o cuidado individual a ser prestado ao paciente, é uma prática que envolve a 
integração da experiência clínica individual com a melhor evidência externa avaliada, proveniente de revisão sistemática de pesquisas (SACKETTI, 1996).

Assim como na medicina baseada em evidências, a aplicação da enfermagem baseada em evidências depende do discernimento e especialização do enfermeiro, da evidência de pesquisa válida e relevante, dos recursos disponíveis e das preferências e circunstâncias do paciente (CULLUM et al., 2010).

Com relação à enfermagem baseada em evidências, Ingersoll (2000) defini-a como o uso consciencioso, explícito e criterioso de informações provenientes de teorias, pesquisas para a tomada de decisão sobre o cuidado prestado ao paciente ou grupo de pacientes, levando em consideração as necessidades individuais e preferências dos mesmos (INGERSOLL, 2000).

Para que enfermagem baseada em evidências seja amplamente utilizada é imprescindível que o enfermeiro tenha conhecimento e competência para interpretar os resultados advindos de pesquisa, os quais auxiliarão na tomada de decisão relacionada com a assistência de enfermagem. É necessário, ainda, o desenvolvimento de uma cultura gerencial e organizacional que propicie e estimule a utilização de pesquisas (MCSHERRY; PROCTOR-CHILDS, 2001).

Corrobora a afirmação supracitada Simpson (1996), ao afirmar que, no Canadá, ações foram tomadas para que fosse desenvolvida a prática baseada em evidências; hospitais e instituições de saúde definiram a relação entre a pesquisa e a prática, e estratégias essências foram tomadas para sua implementação, tais como: a criação de comissões orientadas para a pesquisa na enfermagem, desenvolvimento de planos estratégicos, articulação de incentivos voltados para a pesquisa e o uso de modelos na prática profissional. Introduziram-se programas que revelam ideias oriundas da prática, promoção de diretrizes baseadas em pesquisa e estímulo para a tomada de decisões baseadas na prática em evidências pela equipe de enfermagem. Os hospitais incentivaram e apoiaram incondicionalmente medidas para promover o uso de pesquisa na prática como, por exemplo: programas educativos para a equipe de enfermagem, desenvolvimento de projetos de pesquisa nas unidades laborais, definição do papel de pesquisador para o avanço da prática de enfermagem, por meio da utilização de pesquisas, sendo 
que, em alguns serviços, o acesso à informação foi agilizado por meio do uso da informática.

Assim, para ser utilizada a prática baseada em evidências, o enfermeiro precisa de um ambiente de trabalho organizado que proporcione recursos, para conseguir as evidências disponíveis, e tempo para as discussões entre os profissionais envolvidos na assistência sobre a viabilidade das mudanças a serem executadas. A prática clínica atualizada, fundamentada nos resultados da investigação científica, proporciona ao enfermeiro segurança na tomada de decisões, à qualidade dos cuidados prestados e maior autonomia da enfermagem (CHICÓRIA, 2013).

Enfatiza-se que é fundamental que o enfermeiro seja competente tecnicamente, tenha capacidade de julgamentos independentes e tenha habilidade para a tomada de decisão. Assim sendo, deve ser capaz de analisar dados de pesquisa e utilizar os seus resultados na assistência de enfermagem ao paciente. Fica então desvelado que precisa de conhecimento científico para utilizar na prática profissional, isto é, precisa entender o processo de pesquisa e da investigação sistemática dos problemas oriundos da prática (CULLUM et al., 2010).

Galvão, Sawada e Rossi (2002) são enfáticos ao afirmarem que a implementação da prática baseada em evidências na enfermagem poderá contribuir para a melhoria da qualidade da assistência prestada ao paciente e à redução de custos. Para tanto, é preciso que o enfermeiro faça a formulação de questões, busque as evidências disponíveis por meio de pesquisas que possam responder às questões levantadas, após, deve realizar uma avaliação dos resultados provenientes dessas pesquisas sobre a viabilidade de aplicação na prática e implementar as mudanças baseadas nas informações coletadas.

Melnyk et al. (2008) colocam que, para acelerar a translação dos resultados de pesquisa para a prática clínica, duas principais atividades precisam ocorrer: 1) os enfermeiros que prestam assistência direta e os especialistas precisam adquirir habilidades e conhecimento suficientes, assim como desenvolver crenças sobre o valor da PBE; 2) os educadores precisam ensinar o processo da PBE para os estudantes, a fim de que o incorporem em suas competências para a 
prática profissional, visando o cuidado com a melhor qualidade possível.

Para Melnyk e Fineout-Overholt (2005), a PBE é um método inovador para a solução de problemas da prática e para aplicá-lo é preciso: 1) a busca sistemática, assim como a avaliação e síntese das melhores e mais relevantes pesquisas para responder uma questão clínica (evidências externas); 2) a própria experiência clínica do profissional, que inclui as evidências internas (de seu contexto de prática), geradas por meio do projeto de melhoria de qualidade ou gerenciamento de resultados, pela avaliação completa do paciente e da disponibilidade e pelo uso de recursos necessários, para a obtenção dos resultados esperados para o paciente e 3) as preferências e os valores dos pacientes.

Pelo exposto, pode-se afirmar que a PBE é um dos recursos que deve ser utilizado na saúde para cuidar dos pacientes, visto que é uma forma de prestar assistência com qualidade e voltada para as necessidades individuais de cada pessoa. Porém, para que isso se formalize, é necessário a utilização de protocolos para dar suporte à prática diária aos cuidados ao paciente. Os protocolos são fundamentais porque descrevem como se deve fazer a prática baseada na evidência.

As instituições de saúde internacionais e nacionais utilizam diretrizes clínicas para subsidiarem a construção de protocolos para a assistência de pacientes, considerando os problemas de maior prevalência, os quais geram maior custo ou causem maior impacto na qualidade dos serviços (MIYAZAKI, 2009). As diretrizes mais atuais em relação ao tema prevenção e tratamento de UP são da Associação Norte-Americana de enfermeiros especialistas em feridas, estomas e incontinências Wound Ostomy and Continence Nurses Society (2010) e as do National Pressure Ulcer Advisory Panel/European Pressure Ulcer Advisory Panel (NPUAP/EPUAP) (2009). Em ambas as versões, a maioria das intervenções recomendadas é decorrente da opinião de especialistas, demonstrando a necessidade de mais pesquisas sobre 0 assunto. Verifica-se que essas recomendações formam um corpo de conhecimento que deve ser incorporado no ensino da assistência ao paciente, fundamentadas na avaliação do risco do paciente, na inspeção das condições de integridade tecidual e no estabelecimento das medidas de prevenção, considerando os fatores de risco presentes. 
Assim sendo, é necessário que as práticas sejam seguras no cuidado dos pacientes. A segurança do paciente tem ganhado relevância de especialidade, chamando para a necessidade da enfermagem de se capacitar cientificamente e se comprometer eticamente com ações sistêmicas de avaliação e prevenção, tentando viabilizar a redução de desfechos indesejados, bem como a de analisar o impacto sobre a qualidade do cuidado, a eles oferecido (VARGAS; LUZ, 2010).

Os autores anteriormente citados afirmam que, para se ter práticas seguras e que atendam as transformações tecnológicas, sociais e econômicas, é preciso traduzi-las para indicadores de qualidade, qualidade do cuidado, protocolos assistenciais e/ou do cuidado, gestão de risco, enfermagem baseada em evidências, eventos adversos, segurança do paciente, acreditação hospitalar, comissão de ética e estratégias preventivas.

A qualidade em saúde é definida como qualidade com o grau de atendimento a padrões estabelecidos, diante de normas e protocolos que organizam as ações e práticas, assim como aos atuais conhecimentos técnico-científicos (VITURI; MATSUDA, 2009).

Para Jung (2005), os protocolos de cuidados, com base no princípio da prática baseada em evidência, constituem-se em mais uma ferramenta que pode ser utilizada com qualidade para complementar a prescrição de enfermagem e orientar a construção de sistemas de avaliação de eficiência e eficácia. Outras motivações para a utilização de protocolos clínicos incluem a proteção contra o risco de acusações relacionadas à prática profissional e à redução de custos (JUNG, 2005).

$\mathrm{Na}$ atualidade, estima-se que $50 \%$ das ações propostas para a efetivação de práticas seguras estão diretamente relacionadas ao cuidar do paciente pela enfermagem, sendo que a elaboração e a aplicação de protocolos são essenciais, visto que impactam sobre a segurança e a qualidade do cuidado e, por consequência, propiciam a aceleração da recuperação, a redução de uma ou mais complicações, as falhas e eventos adversos, a redução do tempo de internação e do custo hospitalar, a organização da equipe de trabalho e a satisfação dos pacientes e 
familiares (VARGAS; LUZ, 2010).

É fato que os protocolos são importantes, mas apresentam limites, e embora estejam alicerçados em referências científicas e tecnológicas, não devem ser utilizados para além de sua necessidade, pois sua utilização sem avaliação constante de acompanhamento gerencial sistemático e revisões científicas regulares pode constituir-se em ferramenta com possibilidades de cristalizar ações de planejamento, de inovações, ou seja, os gestores podem ficar desestimulados e não buscar mais as renovações e inovações. Assim sendo, o protocolo gera a necessidade de os gestores estarem atentos e avaliarem a sua eficácia constantemente (SCHEIND et al., 2003).

Diante das considerações anteriores, pode-se afirmar que a PBE tem se configurado em um paradigma de grande relevância para a enfermagem no cuidar dos pacientes. Assim, por acreditar que esse modelo propicia a melhoria na qualidade da assistência de enfermagem, diminui os riscos para o paciente e equipe de saúde, dentre outros fatores, é o que selecionamos como referência para embasar teoricamente a presente investigação. 


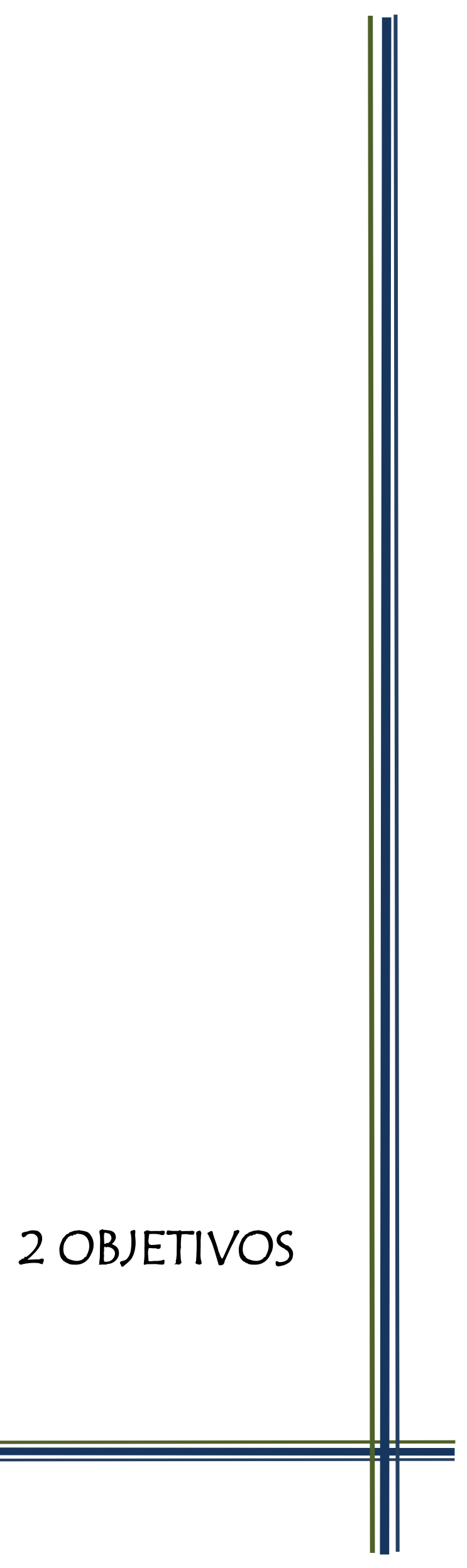




\subsection{Objetivo geral}

Propor uma metodologia de ensino para estudantes da $2^{\underline{a}}$ série do curso de Enfermagem da UEL, para a avaliação do risco de desenvolvimento da úlcera por pressão, em pacientes internados em unidade médico-cirúrgica, e observação do uso de ações de prevenção pelos profissionais, de acordo com o referencial da prática baseada em evidência.

\subsection{Objetivos específicos}

2.2.1 Identificar se, após um workshop sobre a prática baseada em evidência e apresentação das evidências para prevenção da UP, os estudantes foram capazes de reconhecer o risco para úlcera por pressão e a ocorrência do problema em pacientes da Unidade Masculina do HUL.

2.2.2 Investigar se, após um workshop sobre a prática baseada em evidência e apresentação das evidências para a prevenção da UP, os estudantes foram capazes de identificar as ações para a prevenção de UP, utilizadas ou não pelos enfermeiros do HUL, por meio da análise dos registros das prescrições de enfermagem em prontuários.

2.2.3 Revelar o significado da experiência dos estudantes da $2^{\text {a }}$ série do curso de enfermagem da UEL, referente a metodologia proposta. 
3 MATERIAL E MÉTODO 


\subsection{Tipo de estudo}

A pesquisa foi desenvolvida a partir da utilização de métodos quantitativos e qualitativos, com delineamento descritivo. A coleta de dados foi realizada em 3 fases. A primeira constou de um workshop com estudantes de graduação e ocorreu no mês de outubro de 2012. A segunda foi desenvolvida pela docente/pesquisadora tendo os estudantes como auxiliares de pesquisa e foi realizada com pacientes que estavam internados durante 15 dias sequenciais, nos meses de novembro e dezembro de 2012. A terceira fase foi realizada com os estudantes no mês de dezembro de 2012.

\subsection{Procedimentos éticos}

Para o desenvolvimento deste projeto de pesquisa foi atendido o que consta na Resolução 196/96, do Conselho Nacional de Saúde, quanto à pesquisa envolvendo seres humanos (BRASIL, 1998).

O projeto foi aprovado pelo Comitê de Ética e Pesquisa da UEL (ANEXO A), juntamente com os Termos de Consentimento Livre e Esclarecido e Termo de Confidencialidade e Sigilo (APÊNDICES A, B e C).

Os Termos de Consentimento foram obtidos dos estudantes participantes na primeira e terceira fase da pesquisa (APÊNDICE A) e dos pacientes ou familiares dos pacientes que não apresentavam condições físicas ou psicológicas de fazê-lo, na segunda fase (APÊNDICE B).

O Termo de Confidencialidade e Sigilo foi obtido da pesquisadora e dos estudantes que se comprometeram a manter sigilo sobre todas as informações obtidas do prontuário do paciente na coleta de dados correspondente à segunda fase da pesquisa (APÊNDICE C e C1). 


\subsection{Caracterização do local do estudo}

A primeira fase da pesquisa foi realizada por meio de workshop em sala de aula e laboratório, nas dependências do Centro de Ciências da Saúde, do HUL, da UEL. A sala com capacidade para 30 estudantes, possuía infraestrutura adequada para o desenvolvimento da atividade, era silenciosa e dispunha de equipamentos de multimídia, cadeiras confortáveis, configurando-se como ambiente propício para o workshop. O laboratório estava equipado com materiais e equipamentos para treinamento dos procedimentos e técnicas fundamentais para a enfermagem.

Para a segunda fase, a pesquisa foi desenvolvida na Unidade Médico-Cirúrgica Masculina do HUL, um órgão suplementar da UEL, e o único hospital público de grande porte localizado no norte do Estado do Paraná. A instituição atende a população de Londrina, da região norte do Paraná, bem como a de algumas cidades dos Estados de São Paulo e Mato Grosso do Sul. Possui capacidade para 333 leitos, distribuídos em 6 unidades de internação (médicocirúrgica masculina, médico-cirúrgica feminina, pediatria, maternidade, moléstias transmissíveis e tisiologia). Todos os leitos estão disponíveis ao Sistema Único de Saúde (SUS): 289 no próprio HUL e 44 conveniados com a Maternidade Municipal de Londrina. Possui ainda 120 salas de consultas no Ambulatório Hospital das Clínicas e 7 salas cirúrgicas.

A Unidade Masculina do HUL é uma unidade de internação, com capacidade para 67 leitos. Atende pacientes adultos e idosos em quase todas as especialidades médico-cirúrgicas: bucomaxifacial, cardiologia, endocrinologia, gastroenterologia, hematologia, nefrologia, neurologia, oftalmologia, oncologia, otorrinolaringologia, plástica, pneumologia, psiquiatria, reumatologia, urologia e vascular.

A equipe de trabalho dessa unidade é composta por 11 enfermeiros, 31 técnicos de enfermagem, 24 auxiliares de enfermagem, 4 técnicos administrativos, 2 atendentes de enfermagem e 7 auxiliares operacionais. $O$ método 
de trabalho é o cuidado integral, em que um auxiliar ou técnico de enfermagem é responsável por duas enfermarias, com 6 leitos cada uma, em turnos de 6 horas durante o dia e 12 horas à noite. Em cada turno de trabalho são escalados 2 enfermeiros para a supervisão da assistência de enfermagem e um enfermeiro para as atividades gerenciais (chefe de setor) com carga horária de oito horas diárias.

A SAE no referido hospital está implantada em todas as unidades de internação, porém, não em todas as fases conforme preconizado: Histórico de Enfermagem, Exame Físico, Diagnóstico de Enfermagem, Prescrição da Assistência de Enfermagem, Evolução da Assistência de Enfermagem, Relatório de Enfermagem (CONSELHO FEDERAL DE ENFERMAGEM, 2009). Nas Unidades Pronto-Socorro Masculina e Feminina e na Unidade Tisiologia, a SAE é realizada e registrada pelos enfermeiros somente na fase de prescrição de enfermagem. A evolução é feita apenas para pacientes graves e registrada no espaço do prontuário designado para anotação de enfermagem pela equipe. Nas unidades críticas, como UTI Neonatal, Pediátrica e Adulto, além da prescrição de enfermagem, é realizada a evolução de enfermagem para todos os pacientes. A prescrição de enfermagem é informatizada em todas as unidades e foi elaborada propondo intervenções de acordo com as necessidades humanas básicas. A informatização foi desenvolvida pela equipe técnica de informática do HUL, juntamente com a Comissão da SAE. Essa comissão é constituída pela Diretoria de Enfermagem, cuja composição é de enfermeiros da Diretoria de Enfermagem e docentes do Departamento de Enfermagem. Tem por finalidade revisar, avaliar e inovar a SAE já implantada na instituição.

Atualmente, na Unidade Masculina, os enfermeiros realizam a SAE, coletando dados na internação e registrando-os no campo das anotações da prescrição de enfermagem. A prescrição de enfermagem é realizada diariamente para todos os pacientes, enquanto o registro da evolução da assistência de enfermagem é feito para os pacientes graves.

Embora a SAE não seja implementada em todas as fases, destacase que é de fundamental importância que as fases sejam realizadas, visto que, na prática, elas não se separam, mas se sobrepõem e ajudam o enfermeiro a abordar, 
de forma lógica, as situações que podem causar problemas e, por consequência, na solução de problemas. Acrescenta-se que através da SAE exige-se do enfermeiro pensamento crítico/raciocínio clínico e não apenas executante de tarefas. Dessa forma, pode-se atingir metas de enfermagem como as que se referem a evitar a doença e promover, manter e recuperar a saúde, promover, o máximo possível, a sensação de bem-estar; proporcionar cuidados eficientes e de baixo custo, atendendo as necessidades individuais e estar sempre procurando maneiras de melhorar a satisfação do seu cliente em relação aos cuidados prestados (ALFAROLEFREVE, 2005; CARPENITO-MOYET, 2007).

A Unidade Masculina é uma das unidades que compõe o campo de estágio dos estudantes do curso de graduação de Enfermagem da UEL, no módulo Práticas do Cuidar.

Os estágios acontecem 3 vezes por semana, no período da tarde, e uma vez por semana, no período matutino. São desenvolvidas, com os estudantes, atividades relacionadas à assistência de enfermagem, que visam alcançar as seguintes competências: identificação do conceito e da importância do cuidado na enfermagem, conhecimento do complexo hospitalar, relacionando-o ao atendimento das necessidades humanas básicas do paciente hospitalizado, conhecimento e aplicação dos princípios de biossegurança; desenvolvimento de ações de enfermagem, atendendo a necessidade de higiene, conforto e segurança e integridade da pele, manutenção dos sinais vitais, nutrição, eliminação, terapêutica e desenvolvimento de ações de enfermagem através da aplicação da SAE.

Os docentes do módulo supervisionam diretamente um grupo de 7 a 8 estudantes, dividindo as atividades com os mesmos entre cuidados e medicação.

\subsection{População/amostra}

A amostra foi constituída de acordo com as fases da pesquisa. 


\subsubsection{Primeira Fase}

Estudantes da $2^{\text {a }}$ série do curso de enfermagem que concordaram em participar da pesquisa, tinham terminado o módulo Práticas do Cuidar e participaram do treinamento da PBE, de acordo com as diretrizes estabelecidas pela NPUAP/EPUAP (2009). Participaram 8 estudantes, 7 do sexo feminino e um masculino, idade entre 19 e 31 anos.

A inclusão dos 8 estudantes nesta fase refere-se ao mesmo grupo que desenvolveu atividades práticas/estágio, na Unidade Masculina do HUL, por período de 20 dias, totalizando 120 horas, com a pesquisadora no módulo Práticas do Cuidar.

\subsubsection{Segunda Fase}

Para atender os objetivos 2.2.1 e 2.2.2 os estudantes convidaram todos os pacientes admitidos na Unidade Masculina durante 15 dias sequenciais, nos meses de novembro e dezembro de 2012, acamados ou restritos à cadeira e que aceitaram participar da pesquisa, totalizando 21 pacientes. Os dados foram coletados dos pacientes que apresentaram risco para o desenvolvimento da UP e de seus prontuários. Também foram incluídos todos os pacientes com UP independente do nível de risco.

\subsubsection{Terceira Fase}

Foram incluídos todos os estudantes que participaram da primeira e segunda fase da pesquisa.

\subsection{Procedimento da Pesquisa}

\subsubsection{Primeira Fase}

A primeira fase, como descrita anteriormente, foi realizada com os estudantes da $2^{\text {a }}$ série que tinham concluído o módulo Práticas do Cuidar no 
primeiro semestre de 2012 e que também participaram do workshop sobre UP. O workshop teve duração de 60 horas com atividades teóricas e práticas e constou de temas pertinentes ao tema UP (APÊNDICE E). O workshop foi oferecido como atividade de extensão e ao final da atividade, os estudantes receberam certificado de participação.

Conforme descrito anteriormente, o workshop foi realizado em sala de aula, nas dependências do Centro de Ciências da Saúde da UEL, prédio anexo ao HUL. Foram utilizadas estratégias didáticas pautadas em metodologias ativas de ensino-aprendizado e conteúdos provenientes das diretrizes para prevenção da UP, considerando o referencial da PBE (NATIONAL PRESSURE ULCER ADVISORY PANEL AND EUROPEAN PRESSURE ULCER ADVISORY PANEL, 2009).

Após os três dias de atividades teóricas, foram desenvolvidas atividades teórico-práticas no laboratório de enfermagem com a finalidade de desenvolver a habilidade de avaliação do risco para UP. Essa avaliação foi realizada por meio de simulação em contexto de indivíduo que apresentava risco para UP e utilizou-se um manequim.

Após essa atividade foi iniciada a segunda fase da pesquisa.

\subsubsection{Segunda Fase}

Para alcançar os objetivos 2.2.1 e 2.2.2, realizou-se um estudo prospectivo, com o acompanhamento de pacientes hospitalizados na Unidade Masculina, para identificação do risco e a ocorrência de UP e análise dos registros referentes às prescrições de enfermagem. A coleta de dados foi realizada pelos estudantes (que se dividiram em duplas) com acompanhamento da pesquisadora/docente, utilizando instrumentos de coleta de dados para avaliação do risco para UP pela Escala de Braden, avaliação da pele e identificação dos registros em prontuário (APÊNDICE D, ANEXO B e C).

A Escala de Braden utilizada na avaliação de risco para UP é um instrumento validado e adaptado para a língua portuguesa por Paranhos (1999), 
com o objetivo de identificar os pacientes que possuem risco para 0 desenvolvimento da UP. De acordo com ela, são avaliados seis fatores de risco (subescalas) no cliente: 1) percepção sensorial, referente à capacidade do cliente de reagir significativamente ao desconforto relacionado à pressão; 2) umidade, que se refere ao nível em que a pele é exposta à umidade; 3) atividade, que avalia o grau de atividade física; 4) mobilidade, referente à capacidade do cliente em mudar e controlar a posição de seu corpo; 5) nutrição, a qual retrata o padrão usual de consumo alimentar do cliente; 6) fricção e cisalhamento, referentes à dependência do cliente para a mobilização e o posicionamento no leito (ANEXO D).

Cada subescala possui uma pontuação e, ao final da avaliação do paciente, chega-se à pontuação total, identificando o risco que o paciente possui para o desenvolvimento de úlcera por pressão. Escore menor ou igual a 9 significa risco muito alto; de 10 a 12 significa risco alto; de 13 e 14, apresenta risco moderado; de 15 a 18 apresenta baixo risco; enquanto escores maior ou igual a 19 significa sem risco para o desenvolvimento de úlcera por pressão (WOUND OSTOMY AND CONTINENCE NURSES SOCIETY, 2010).

No primeiro dia do período estabelecido para a coleta de dados (22 de novembro de 2012), todos os pacientes que estavam internados na Unidade e constavam do censo e que estavam restritos ao leito ou à cadeira ou que tinham UP foram convidados a participar do estudo e a assinar o Termo de Consentimento. Para os que não tinham condições de fornecer consentimento, a autorização para participar foi solicitada aos familiares que estavam no hospital como acompanhantes. A solicitação para a participação foi feita individualmente, informando o paciente ou o familiar sobre os objetivos e procedimentos da pesquisa (APÊNDICE B).

A coleta de dados foi iniciada por meio da avaliação do risco para UP com a aplicação da Escala de Braden (ANEXO B) para identificação dos subescores e do escore total que foram registrados no instrumento. Em seguida, procedeu-se a inspeção da pele e registro no instrumento (APÊNDICE D). Para os pacientes que apresentavam UP a localização e classificação foram registradas no instrumento e foi solicitada a autorização para registro fotográfico da lesão. As 
imagens das UPs foram utilizadas posteriormente como material de apoio para as discussões dos casos com os estudantes.

As avaliações subsequentes desses pacientes e dos que internaram posteriormente foram feitos diariamente pelos estudantes e pesquisador/docente até a alta, transferência, óbito ou o término do período estabelecido para a coleta de dados.

Para a coleta de dados, referentes ao objetivo 2.2.2, a revisão do prontuário de cada paciente, considerando as prescrições e as anotações de enfermagem, também foi feita pelos estudantes em duplas com acompanhamento da pesquisadora/docente. Os dados foram registrados em instrumento adaptado a partir do estudo de Simão (2010) com itens referentes à identificação no prontuário do Escore total da Escala de Braden, a classificação como paciente em risco para UP, condições da pele e as ações prescritas pelo enfermeiro referentes ao risco ou ao cuidado com a UP (ANEXO C).

Diariamente, após o término da coleta de dados, o grupo de estudantes e a pesquisadora se reuniram em sala para a discussão do que havia sido realizado: apresentação das avaliações com o paciente, intervenções prescritas para os pacientes com risco e com UP, além de outros problemas encontrados.

\subsubsection{Procedimentos para análise dos dados}

Os dados coletados foram transcritos pela pesquisadora para uma planilha do aplicativo Microsoft Excel e foi feita a validação por meio de dupla digitação. Posteriormente foram exportados e analisados por meio de estatística descritiva.

Para verificar a associação entre as variáveis, os dados foram submetidos ao teste exato de Fisher (FISHER, 1935). Além disso, a quantificação dessa associação foi mensurada por meio de modelos de regressão logística (HOSMER; LEMESHOW, 1989) onde se calculou o Odds Ratio bruto (OR) com seus respectivos intervalos de confiança de 95\%. Essas análises estatísticas foram realizadas com a utilização do software estatístico $S A S \circledR 9.0$. Valores de p menores 
que 0,05 foram considerados significativos.

Foi utilizado também o teste $\mathrm{t}$ de Student, o qual consiste em comparar duas médias provenientes de amostras não pareadas. Para a realização desse procedimento foi utilizado o procedimento PROC TTEST do software SAS ${ }^{\circledR}$ 9.0. Valores de $p$ menores que 0,05 foram considerados significativos.

Utilizou-se também a análise de variância (ANOVA) (MONTGOMERY, 2000). Esse procedimento foi realizado através do software SASß 9.0, utilizando a PROC GLM. Valores de $\mathrm{p}$ menores que 0,05 foram considerados significativos.

\subsubsection{Terceira Fase}

A terceira fase atendeu o objetivo 2.2.3 que buscou revelar o significado da experiência dos estudantes, referente à avaliação do risco de pacientes para desenvolvimento da UP e às ações de prevenção utilizadas pelos profissionais.

Os dados foram coletados a partir das discussões em grupo realizadas com os estudantes participantes das atividades da pesquisa que teve como moderadora a própria pesquisadora e que foram gravadas. Segundo Flick (2009), a discussão em grupo é utilizada quando se tem um pequeno número de pessoas reunidas discutindo coletivamente sobre um tema, problema, alternativas para os problemas, dentre outros. Por meio das discussões pode-se estabelecer a análise das opiniões individuais e chegar-se a uma opinião compartilhada, comum a todos os participantes.

O autor supracitado coloca ainda que uma das formas de grupo, ou seja, de formação de grupo com fins metodológicos são os grupos chamados reais ou naturais, isto é, aqueles que são reunidos para fins de pesquisa, de acordo com critérios determinados, na qual todos os membros partem de uma história de interação compartilhada em relação ao assunto em discussão, já tendo então desenvolvido formas de atividades e padrões subjacentes de significados. 
Destaca-se que, em grupos homogêneos, os membros são passíveis de comparação nas dimensões fundamentais relativas à questão de pesquisa e possuem formação homogênea (FLICK, 2009).

Denota-se que as discussões em grupo são mais do que entrevistas de questões norteadoras, pois há interação entre os participantes, o que permite que os mesmos desenvolvam novas ideias a partir das falas dos demais membros do grupo.

Antes de iniciar a reunião em grupo foi solicitada a permissão dos estudantes para a gravação das entrevistas e a assinatura do Termo de Consentimento Livre e Esclarecido (APÊNDICE A). Para preservar o anonimato, as falas provenientes das discussões foram identificadas com códigos previamente determinados pela pesquisadora, isto é, cada estudante foi identificado com as letras A1, A2, A3, A4, A5, A6, A7 e A8.

Para a discussão no grupo foi utilizada a seguinte questão norteadora: - Fale-me o que significou para você a experiência de ter participado das etapas anteriores da pesquisa sobre a prevenção da úlcera por pressão.

Ressalta-se que, da questão norteadora, o pesquisador/moderador elaborou um roteiro de perguntas, somente para seu controle, que permitisse o direcionamento da discussão sobre o tema UP no que se refere a: estágios da úlcera por pressão, fatores de risco, medidas preventivas, avaliação do paciente, uso da Escala de Braden (APÊNDICE F). As discussões continuaram até o momento em que o pesquisador/moderador identificou que a discussão de um tópico havia sido saturada/esgotada, ou seja, coube à mesma tomar a decisão de encerrar a discussão quando percebeu que todos os temas propostos no roteiro haviam sido contemplados e para isso adotou como critério a convergência nas falas dos estudantes (FLICK, 2009; BARDIN, 2010).

Assim, em data agendada, logo após o término da segunda fase do estudo, a pesquisadora reuniu-se com o grupo de 8 estudantes em uma sala nas dependências do Centro de Ciências da Saúde, selecionada por ser confortável, com boa ventilação e iluminação e que permitia a privacidade das atividades. A 
reunião teve duração de, aproximadamente, duas horas, e para cada estudante foi entregue, de forma impressa, a pergunta norteadora, com média de 5 minutos para reflexão. Após esse tempo foi aberta à palavra para quem quisesse iniciar as discussões, sendo orientada a importância de que todos expusessem suas ideias e opiniões. Assim, aleatoriamente, os estudantes foram verbalizando as suas experiências e, no momento em que começou a ocorrer a convergência das falas em relação ao fenômeno estudado sobre a UP, a pesquisadora/moderadora encerrou as discussões (BARDIN, 2010).

As discussões gravadas foram posteriormente transcritas na íntegra para análise com identificação e categorização dos temas mais comuns. A técnica utilizada para a análise dos dados foi Análise de Conteúdo, definida como

\footnotetext{
um conjunto de técnicas de análise das comunicações, com a finalidade de obter, por meio de procedimentos sistemáticos e objetivos de descrição do conteúdo das mensagens, os indicadores que permitem deduzir conhecimentos relativos às condições de produção e recepção destas mensagens (BARDIN, 2010, p. 42).
}

$\mathrm{Na}$ análise de conteúdo, denomina-se unidade de contexto a resposta obtida em relação ao tema, representando a parte mais ampla do conteúdo a ser analisado; as unidades de registro ou unidades de significação são as frases ou palavras significativas em relação ao tema estudado, enquanto os significados representam o material principal da análise.

Conforme Bardin (2010), a análise de conteúdo ocorre por meio de três etapas: pré-análise, exploração dos materiais e tratamento dos resultados.

\section{Pré-análise}

É o momento em que se dá a escolha do material a ser analisado mediante uma organização que se processa em algumas fases, a seguir.

a) LeituRA FLUTUANTE: é o momento em que o pesquisador tem o primeiro contato com o material a ser analisado, deixando-se sensibilizar pelas impressões e 
orientações do conteúdo. Nesta etapa, podem ser formulados os objetivos e as hipóteses, definindo-se o corpo do trabalho (BARDIN, 2010). Neste estudo, os objetivos foram previamente formulados, consistindo apenas em uma fase de leitura das unidades de contexto.

b) Escolha dos documentos: através dos princípios da exaustividade, representatividade, homogeneidade e adequação, o pesquisador, nessa fase, escolhe as unidades de contexto que poderão fornecer dados sobre o problema em estudo. A exaustividade nada mais é do que garantir que todos os documentos sejam analisados; a representatividade é a seleção dos documentos que realmente refletem o problema do estudo; a homogeneidade refere-se a utilizar a mesma técnica para a escolha dos documentos e ter as mesmas características, e a adequação proporciona materiais que mostram informações adequadas aos objetivos da pesquisa (BARDIN, 2010). Neste estudo, a transcrição das falas no grupo de discussão foi considerada como documento de análise.

C) FoRmulaçÃo de hipóteses e obJetivos: é uma etapa que pode ou não estar presente, partindo-se de ideias pré-concebidas. Neste trabalho, optou-se por ideias pré-concebidas, determinadas pelos objetivos traçados, isto é, previamente determinadas, acreditando que, com a implantação de uma nova metodologia de ensino, através da PBE, o aprendizado tenha resultados mais significativos.

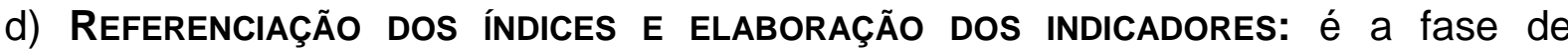
indicação dos núcleos de significados, que se dá por meio do recorte dos discursos, ou seja, é o momento de identificar as frequências de certas palavras, expressões e até temas. Assim sendo, identificam-se as possíveis categorias e subcategorias advindas dos discursos.

e) Preparação do material: através da transcrição fiel das falas das discussões realizadas, o material foi codificado, e os dados brutos foram transformados e agregados em núcleos, descrevendo as características do conteúdo.

\section{Exploração dos materiais}

Esta fase nada mais é do que administrar sistematicamente as decisões tomadas anteriormente. Nela, é realizada a exploração profunda dos materiais explorados e que serão submetidos à análise dos princípios, pressupostos 
e referencias teóricos adotados nas investigações (BARDIN, 2010).

Assim, nessa fase, os dados brutos do material foram codificados, com a finalidade de construir as categorias ou o núcleo de compreensão do texto e subcategorias, a partir das unidades de registro ou unidade de significação.

Categoria é o termo utilizado para expressar elementos ou aspectos que possuem as mesmas características, os quais são ordenados de acordo com as semelhanças; é o registro do que cada unidade tem em comum com as outras. As categorias são obtidas por meio da convergência das subcategorias (MARTINS, 2008).

3 Tratamento dos resultados

Consiste na última fase da análise de conteúdo. As categorias são interpretadas e fundamentadas de acordo com a literatura pertinente, subsidiando o processo reflexivo. 
4 RESULTADOS 
Os resultados da pesquisa são apresentados segundo seus objetivos específicos.

\subsection{Identificação do risco para úlcera por pressão e a ocorrência do problema}

As Tabelas de número 1 a 11 apresentam os resultados que foram alcançados pelos estudantes e a pesquisadora em relação ao problema em pacientes da Unidade Masculina do HUL.

No período estabelecido para a coleta de dados, 21 pacientes da Unidade Masculina do HUL atenderam os critérios para inclusão no estudo.

A Tabela 1, abaixo, apresenta o número de pacientes internados na unidade em cada um dos 15 dias do estudo, o número de pacientes novos avaliados diariamente e o número de pacientes em risco que foram incluídos no estudo.

Tabela 1 - Distribuição dos pacientes internados na Unidade Masculina, avaliados e em risco para desenvolver úlcera por pressão por dia. Londrina, PR, 2012

\begin{tabular}{|c|c|c|c|}
\hline $\begin{array}{l}\text { Período do } \\
\text { estudo }\end{array}$ & $\begin{array}{c}\text { № de pacientes } \\
\text { internados }\end{array}$ & $\begin{array}{l}\text { № de pacientes } \\
\text { novos avaliados } \\
\text { diariamente }\end{array}$ & $\begin{array}{c}\text { № de pacientes } \\
\text { em risco, incluídos } \\
\text { no estudo } \\
\text { diariamente }\end{array}$ \\
\hline $1^{\circ} \mathrm{dia}$ & 47 & 47 & 10 \\
\hline $2^{\circ}$ dia & 50 & 7 & 3 \\
\hline 3ํ dia & 45 & 2 & 1 \\
\hline $4^{\circ} \mathrm{dia}$ & 47 & 8 & - \\
\hline 5 dia & 49 & 12 & 3 \\
\hline 60 dia & 43 & 2 & 1 \\
\hline $7^{\circ} \mathrm{dia}$ & 47 & 6 & 1 \\
\hline 8o dia & 47 & 5 & - \\
\hline 9 dia & 45 & 3 & - \\
\hline $10^{\circ}$ dia & 46 & 4 & - \\
\hline $11^{\circ} \mathrm{dia}$ & 43 & 4 & - \\
\hline $12^{\circ}$ dia & 46 & 3 & 1 \\
\hline $13^{\circ}$ dia & 50 & 10 & 1 \\
\hline $14^{\circ} \mathrm{dia}$ & 47 & 6 & - \\
\hline $15^{\circ}$ dia & 52 & 5 & - \\
\hline Total & 704 & 124 & 21 \\
\hline
\end{tabular}


No primeiro dia de avaliação, verificou-se que, dos 47 pacientes que se encontravam internados na Unidade Masculina do HUL, 10 pacientes apresentavam risco para o desenvolvimento da UP. Posteriormente, novos pacientes com risco para desenvolvimento de UP foram incluídos e foram avaliados para seguimento pelos estudantes e pesquisadora/docente. Ao final do período da coleta de dados, 21 pacientes foram avaliados.

$\mathrm{Na}$ sequência, apresenta-se a Tabela 2 com a faixa etária dos pacientes participantes do estudo.

Tabela 2 - Distribuição dos pacientes considerando a faixa etária. Londrina, PR, 2012

\begin{tabular}{l|c|c}
\hline \hline Faixa etária & Frequência & Porcentagem \\
\hline \hline $19-39$ anos & 8 & 38,10 \\
$40-59$ anos & 9 & 42,86 \\
$\geq 60$ anos & 4 & 19,05 \\
\hline \hline Total & $\mathbf{2 1}$ & $\mathbf{1 0 0}$ \\
\hline \hline
\end{tabular}

A idade mínima dos pacientes foi 19 anos e a máxima 86. A idade média foi 44,76 (DP=19,79) e mediana 47.

Quanto à cor da pele $14(66,67 \%)$ tinham pele branca, $4(19,05 \%)$ negra, 2 (9,52\%) amarela e 1 (4,76\%) parda.

Os diagnósticos médicos dos pacientes estão apresentados na Tabela 3, considerando-se as categorias do Código Internacional das Doenças (CID10). 
Tabela 3 - Distribuição da frequência e porcentagem da categoria do diagnóstico médico principal dos pacientes da Unidade Masculina, agrupados pelas categorias do CID-10. Londrina, PR, 2012

\begin{tabular}{lcc}
\hline Categoria do diagnóstico médico principal & Frequência & Porcentagem \\
\hline $\begin{array}{l}\text { Doenças do sistema osteomuscular e do tecido } \\
\text { conjuntivo }\end{array}$ & 9 & 42,86 \\
Doenças do sistema nervoso & 6 & 28,57 \\
Doenças do aparelho digestivo & 3 & 14,29 \\
Doenças do aparelho genitourinário & 1 & 4,76 \\
Doenças da pele e do tecido subcutâneo & 1 & 4,76 \\
Doenças do aparelho circulatório & 1 & 4,76 \\
\hline Total & 21 & 100 \\
\hline \hline
\end{tabular}

Os diagnósticos mais comuns foram as doenças referentes ao sistema osteomuscular e do tecido conjuntivo (42,86\%), seguidas das doenças do sistema nervoso (28,57\%). As doenças do sistema osteomuscular mais frequentes foram as fraturas de membros inferiores e superiores, restringindo os pacientes ao leito.

Dos 21 pacientes avaliados, ao término do período de coleta de dados, 7 (33,33\%) tiveram alta hospitalar, 13 (61,91\%) permaneceram internados e $1(4,76 \%)$ foi a óbito.

Em relação ao tempo de internação dos pacientes na unidade antes do início da coleta de dados, a média foi 3,33 dias ( $D P=5,05)$, mediana 1 , mínimo 0 e máximo de 17 dias. Quanto ao tempo de internação hospitalar antes do início da coleta de dados, obteve-se a média de 14,10 dias $(\mathrm{DP}=16,78)$, mediana 7 , mínimo 0 e máximo de 60 dias.

Os 21 pacientes que participaram do estudo tiveram entre 2 e 15 avaliações quanto ao risco para UP, com média de 8,67 avaliações (DP=4,66). Nas Tabelas 4 a 7 e Figura 1 são apresentados os resultados das avaliações considerando o escore total e subescores da Escala de Braden. 
Tabela 4 - Distribuição dos pacientes quanto ao número de avaliações referente ao risco para UP. Londrina, PR, 2012

\begin{tabular}{lcc}
\hline \multicolumn{1}{c}{ № de avaliações } & Frequência & $\%$ \\
\hline $\mathbf{2 - 4}$ & 5 & 23,8 \\
$\mathbf{5 - 7}$ & 5 & 23,9 \\
$\mathbf{8 - 1 0}$ & 3 & 14,3 \\
$\mathbf{1 1 - 1 3}$ & 2 & 9,5 \\
$\mathbf{1 4 - 1 5}$ & 6 & 28,5 \\
\hline \hline Total & $\mathbf{2 1}$ & $\mathbf{1 0 0}$ \\
\hline \hline
\end{tabular}

No primeiro dia de avaliação dos pacientes, considerando o escore total da Escala de Braden, o escore mínimo foi 6, o máximo 19, média 11,9 $(\mathrm{DP}=3,81)$ e mediana 13 . Identificou-se que somente um paciente não tinha risco para UP na primeira avaliação (Tabela 5).

Tabela 5 - Distribuição dos pacientes em relação ao escore total da Escala de Braden da primeira avaliação, segundo o nível de risco. Londrina, PR, 2012

\begin{tabular}{|c|c|c|}
\hline Nível de risco & Frequência & $\%$ \\
\hline Risco muito alto $(\leq 9)$ & 7 & 33,33 \\
\hline Risco alto (10-12) & 3 & 14,29 \\
\hline Risco moderado (13-14) & 7 & 33,33 \\
\hline Baixo risco (15-18) & 3 & 14,29 \\
\hline Sem risco $(\geq 19)$ & 1 & 4,76 \\
\hline Total & 21 & 100 \\
\hline
\end{tabular}


Considerando as subescalas, observou-se que na primeira avaliação as menores médias foram obtidas nos domínios Atividade e Fricção (Tabela 6)

Tabela 6 - Distribuição dos valores mínimo, máximo, médio, mediano e desviopadrão dos subescores da Escala de Braden da primeira avaliação. Londrina, PR, 2012

\begin{tabular}{lccccccc}
\hline \hline & $\begin{array}{c}\text { Percepção } \\
\text { sensorial }\end{array}$ & Umidade & Atividade & Mobilidade & Nutrição & Fricção \\
\hline Média & 3,10 & 2,67 & 1,19 & 1,57 & 2,19 & 1,19 \\
Desvio- & 1,22 & 1,15 & 0,68 & 0,68 & 1,17 & 0,40 \\
padrão & & & & & & \\
Mediana & 4 & 3 & 1 & 1 & 2 & 1 \\
Mínimo & 1 & 1 & 1 & 1 & 1 & 1 \\
Máximo & 4 & 4 & 4 & 3 & 4 & 2 \\
\hline \hline
\end{tabular}

Tabela 7 - Distribuição dos valores mínimo, máximo, médio, mediano e desviopadrão dos subescores da Escala de Braden de todas as avaliações. Londrina, PR, 2012

\begin{tabular}{lccccc}
\hline Variáveis & Média & $\begin{array}{c}\text { Desvio- } \\
\text { padrão }\end{array}$ & Mediana & Mínimo & Máximo \\
& \multicolumn{5}{c}{} \\
\hline Percepção sensorial & 3,15 & 1,17 & 4,00 & 1,00 & 4,00 \\
Umidade & 2,56 & 1,12 & 3,00 & 1,00 & 4,00 \\
Atividade & 1,15 & 0,63 & 1,00 & 1,00 & 4,00 \\
Mobilidade & 1,68 & 0,67 & 2,00 & 1,00 & 3,00 \\
Nutrição & 2,10 & 0,93 & 2,00 & 1,00 & 4,00 \\
Fricção e cisalhamento & 1,12 & 0,32 & 1,00 & 1,00 & 2,00 \\
\hline \hline
\end{tabular}

A Figura 1 representa a distribuição das média dos subescores da Escala de Braden em todas as avaliações realizadas. 


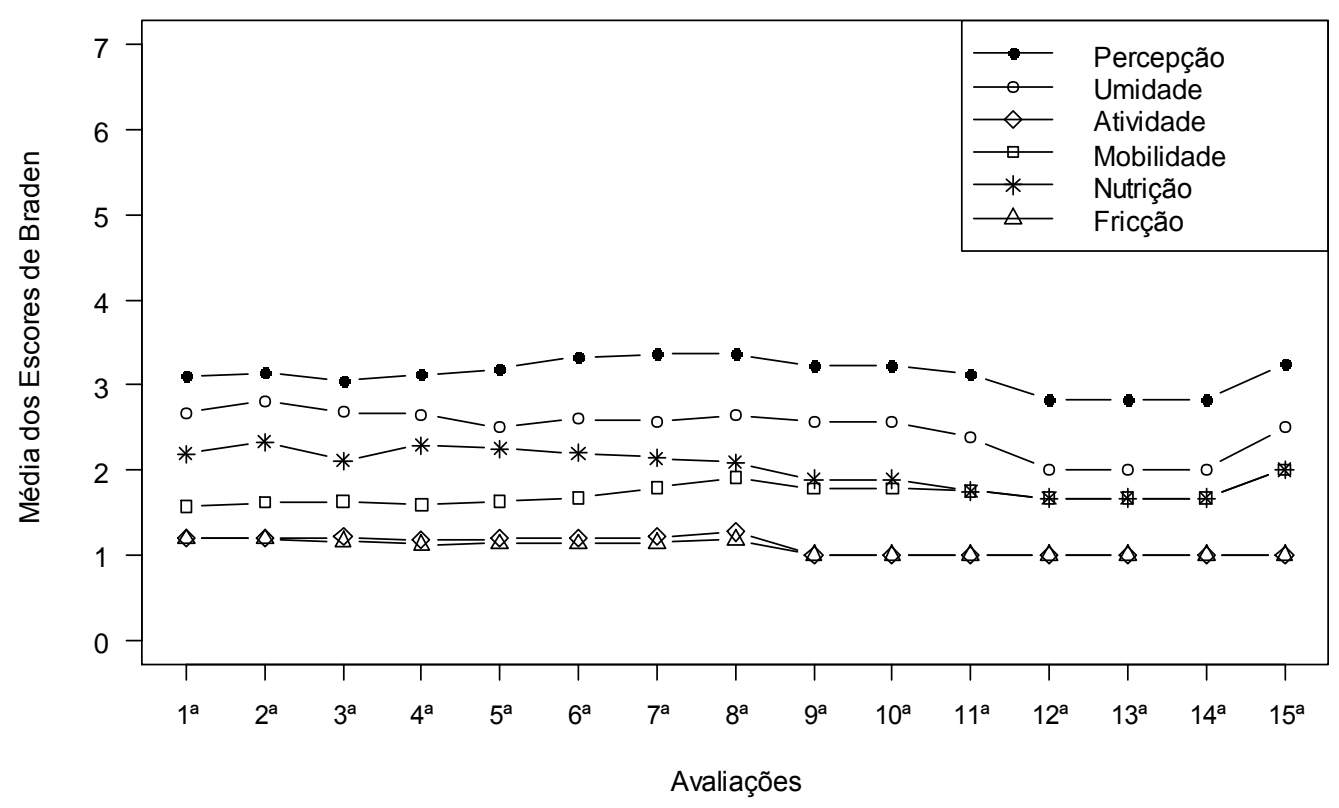

Figura 1 - Médias dos subescores da Escala de Braden em todas as avaliações

Analisando os dados da Tabela 7 e Figura 1 observa-se que a maior média durante todo o período de observação foi na subescala Percepção Sensorial, indicando que os pacientes avaliados apresentavam pouca limitação na capacidade de reagir à pressão relacionada com o desconforto. As menores médias foram na subescala Atividade e na subescala Fricção e Cisalhamento, evidenciando o baixo grau de atividade física dos pacientes que estavam confinados ao leito ou à cadeira e que requeriam assistência de moderada a máxima para se moverem.

Quanto à avaliação das condições da pele dos pacientes, no primeiro dia de coleta de dados da pesquisa, identificou-se que $13(61,90 \%)$ apresentavam úlcera por pressão e $8(38,10 \%)$ apresentavam pele íntegra. A Tabela a seguir apresenta a distribuição dos pacientes em relação às condições da pele nas 15 avaliações. 
Tabela 8 - Distribuição dos pacientes nas 15 avaliações em relação às condições da pele. Londrina, PR, 2012

\begin{tabular}{cccc}
\hline \hline & Pele íntegra & \multicolumn{2}{c}{ Presença de UP } \\
\hline Avaliações & $\mathbf{n}(\%)$ & $\mathbf{n}(\%)$ & Total \\
\hline $\mathbf{1}$ & $\mathbf{8}(38,10)$ & $13(61,90)$ & $21(100,0)$ \\
$\mathbf{2}$ & $7(33,33)$ & $14(66,67)$ & $21(100,0)$ \\
$\mathbf{3}$ & $6(31,58)$ & $13(68,42)$ & $19(100,0)$ \\
$\mathbf{4}$ & $3(17,65)$ & $14(82,35)$ & $17(100,0)$ \\
$\mathbf{5}$ & $2(12,50)$ & $14(82,35)$ & $16(100,0)$ \\
$\mathbf{6}$ & $2(13,33)$ & $13(86,67)$ & $15(100,0)$ \\
$\mathbf{7}$ & $2(14,29)$ & $12(85,71)$ & $14(100,0)$ \\
$\mathbf{8}$ & $2(18,18)$ & $9(81,82)$ & $11(100,0)$ \\
$\mathbf{9}$ & $2(22,22)$ & $7(77,78)$ & $9(100,0)$ \\
$\mathbf{1 0}$ & $2(22,22)$ & $7(77,78)$ & $9(100,0)$ \\
$\mathbf{1 1}$ & $2(25,00)$ & $6(75,00)$ & $6(100,0)$ \\
$\mathbf{1 2}$ & $1(16,67)$ & $5(83,33)$ & $6(100,0)$ \\
$\mathbf{1 3}$ & $1(16,67)$ & $5(83,33)$ & $6(100,0)$ \\
$\mathbf{1 4}$ & $1(16,67)$ & $5(83,33)$ & $4(100,0)$ \\
$\mathbf{1 5}$ & $1(25,00)$ & $3(75,00)$ & \\
\hline \hline
\end{tabular}

Identifica-se pela tabela acima a grande frequência de UP nos pacientes avaliados.

$\mathrm{Na}$ primeira avaliação, os 13 que tinham UP apresentavam 25 lesões, com média de 1,92 úlcera/paciente.

A distribuição das 25 úlceras, segundo a localização e a classificação, está apresentada na Tabela 9. 
Tabela 9 - Distribuição das 25 úlceras identificadas na $1^{\text {a }}$ avaliação dos pacientes, segundo a localização e classificação. Londrina, PR, 2012

\begin{tabular}{lcccccc}
\hline \multirow{2}{*}{ Localização } & \multicolumn{5}{c}{ Estágio da UPP } \\
\cline { 2 - 7 } & I & II & III & IV & Não classificável & Total \\
\hline \hline Sacral & $3(12,0 \%)$ & $2(8,0 \%)$ & $3(12,0 \%)$ & $2(8,0 \%)$ & $1(4,0 \%)$ & $11(44,0 \%)$ \\
Trocantérica & $1(4,0 \%)$ & $0(0,0 \%)$ & $1(4,0 \%)$ & $0(0,0 \%)$ & $0(0,0 \%)$ & $2(8,0 \%)$ \\
Calcâneo & $2(8,0 \%)$ & $2(8,0 \%)$ & $0(0,0 \%)$ & $0(0,0 \%)$ & $2(8,0 \%)$ & $6(24,0 \%)$ \\
Maléolo & $0(0,0 \%)$ & $4(16,0 \%)$ & $0(0,0 \%)$ & $0(0,0 \%)$ & $0(0,0 \%)$ & $4(16,0 \%)$ \\
Cotovelo & $2(8,0 \%)$ & $0(0,0 \%)$ & $0(0,0 \%)$ & $0(0,0 \%)$ & $0(0,0 \%)$ & $2(8,0 \%)$ \\
\hline \hline Total & $\mathbf{8 ( 3 2 , 0 \% )}$ & $\mathbf{8 ( 3 2 , 0 \% )}$ & $\mathbf{4 ( 1 6 , 0 \% )}$ & $\mathbf{2 ( 8 , 0 \% )}$ & $\mathbf{3 ( 1 2 , 0 \% )}$ & $\mathbf{2 5 ( 1 0 0 , 0 \% )}$ \\
\hline \hline
\end{tabular}

Observa-se que 16 (64\%) UPs eram de estágio/grau I ou II. Na segunda avaliação, mais um paciente que tinha pele íntegra desenvolveu UP na região do calcâneo em estágio I, totalizando 26 UPs em 14 pacientes, com média de 1,85 úlcera/paciente. Ao final do acompanhamento, 5 pacientes mantiveram a pele íntegra e 16 apresentavam UP, totalizando 29 lesões.

Para explorar a possível associação entre o escore da Escala de Braden dos pacientes e a presença de UP, na Tabela 10 é apresentada a distribuição da média (DP), mediana, valores mínimo e máximo do escore total da Escala de Braden da primeira avaliação, considerando os pacientes com e sem UP durante o período do estudo.

Tabela 10 - Distribuição da média, mediana, desvio-padrão, mínimo e máximo do escore total da Escala de Braden na presença e ausência de UP. Londrina, PR, 2012

\begin{tabular}{lcccccc}
\hline \hline & \multicolumn{5}{c}{ Escore total } \\
$\begin{array}{l}\text { Úlcera por } \\
\text { pressão }\end{array}$ & $\mathbf{N}$ & Média & Desvio-padrão & Mínimo & Mediana & Máximo \\
\hline \hline Ausência & 5 & 11,00 & 3,87 & 6,00 & 12,00 & 15,00 \\
Presença & 16 & 12,19 & 3,87 & 6,00 & 13,00 & 19,00 \\
\hline \hline p-valor referente ao test t de Student=0,5562 & $\operatorname{IC}(95 \%)=-5,33$ & 2,96 & &
\end{tabular}


Observa-se que os pacientes que apresentaram UP tiveram escore médio maior do que os que não apresentavam UP, porém, a diferença não teve significância estatística.

$\mathrm{Na}$ Tabela 11 são apresentados os testes de associação e sua quantificação (Odds Ratio bruto) entre as variáveis faixa etária, cor, tipo de saída, diagnóstico médico principal, nível de risco para UP, com a presença e ausência de úlcera por pressão. 
Tabela 11 - Associações e quantificação entre as variáveis: faixa etária, cor, tipo de saída, diagnóstico principal, nível de risco para UP, com a presença ou ausência de úlcera por pressão. Londrina, PR, 2012

\begin{tabular}{|c|c|c|c|c|c|c|}
\hline & \multicolumn{2}{|c|}{$\begin{array}{l}\text { Úlcera por } \\
\text { pressão }\end{array}$} & \multirow[t]{2}{*}{ Total } & \multirow[t]{2}{*}{ p-valor } & \multirow[t]{2}{*}{$\begin{array}{l}\text { Odds Ratio } \\
\text { bruto }\end{array}$} & \multirow[t]{2}{*}{ IC (95\%) } \\
\hline & $\begin{array}{c}\text { Ausência } \\
\text { n (\%) }\end{array}$ & $\begin{array}{c}\text { Presença } \\
\text { n (\%) }\end{array}$ & & & & \\
\hline \multicolumn{7}{|l|}{ Faixa Etária } \\
\hline 19-39 anos & $3(14,29)$ & $5(23,81)$ & $8(38,10)$ & 0,5542 & 1,000 & Referência \\
\hline 40-59 anos & $1(4,76)$ & $8(38,10)$ & $9(42,86)$ & & 4,799 & $(0,385 ; 59,884)$ \\
\hline$\geq 60$ anos & $1(4,76)$ & $3(14,29)$ & $4(19,05)$ & & 1,800 & $(0,124 ; 26,196)$ \\
\hline \multicolumn{7}{|l|}{ Cor } \\
\hline Branco+amarelo & $2(9,52)$ & $14(66,67)$ & $16(76,17)$ & 0,0630 & 10,499 & $\begin{array}{c}(1,029 \\
107,150)\end{array}$ \\
\hline Negra+parda & $3(14,29)$ & $2(9,52)$ & $5(23,81)$ & & 1,000 & Referência \\
\hline \multicolumn{7}{|l|}{ Tipo de saída } \\
\hline Alta & $1(4,76)$ & $6(28,57)$ & $7(33,33)$ & 0,7049 & -- & -- \\
\hline Transferência + hospitalizado & $4(19,05)$ & $9(42,86)$ & $13(61,90)$ & & -- & -- \\
\hline Óbito & $0(0,00)$ & $1(4,76)$ & $1(4,76)$ & & -- & -- \\
\hline \multicolumn{7}{|l|}{ Diagnóstico principal } \\
\hline Doenças do aparelho genitourinário & $0(0,00)$ & $1(4,76)$ & $1(4,76)$ & 0,8461 & -- & -- \\
\hline Doenças do sistema nervoso & $2(9,52)$ & $4(19,05)$ & $6(28,57)$ & & -- & -- \\
\hline Doenças do aparelho circulatório & $0(0,00)$ & $1(4,76)$ & $1(4,76)$ & & -- & -- \\
\hline Doenças do aparelho digestivo & $0(0,00)$ & $3(14,29)$ & $3(14,29)$ & & -- & -- \\
\hline $\begin{array}{l}\text { Doenças da pele e do tec. } \\
\text { Subcutâneo }\end{array}$ & $0(0,00)$ & $1(4,76)$ & $1(4,76)$ & & -- & -- \\
\hline $\begin{array}{l}\text { Doenças do sistema osteomuscular e } \\
\text { do tec. conjuntivo }\end{array}$ & $3(14,29)$ & $6(28,57)$ & $9(42,86)$ & & -- & -- \\
\hline \multicolumn{7}{|l|}{ Nível de risco } \\
\hline Muito alto & $2(9,52)$ & $5(23,81)$ & $7(33,33)$ & 1,000 & -- & -- \\
\hline Alto & $1(4,76)$ & $2(9,52)$ & $3(14,29)$ & & -- & -- \\
\hline Moderado & $1(4,76)$ & $6(28,57)$ & $7(33,33)$ & & -- & -- \\
\hline Baixo & $1(4,76)$ & $2(9,52)$ & $3(14,29)$ & & -- & -- \\
\hline Sem risco & $0(0,00)$ & $1(4,76)$ & $1(4,76)$ & & -- & -- \\
\hline
\end{tabular}

$\mathrm{p}$-valor referente ao teste exato de Fisher

Os resultados do teste apontam que não houve associação entre a presença de UP e qualquer das variáveis investigadas. Entretanto, pode-se observar que, em relação à cor da pele, o valor obtido $(p=0,0630)$ estava próximo do nível de significância, indicando que indivíduos de cor branca e amarela teriam maior chance de ter UP. 
A participação dos estudantes na coleta de dados da pesquisa permitiu identificar o risco dos pacientes para UP, os fatores de risco e as condições de integridade da pele, assim como a presença e a evolução das UPs.

\subsection{Identificação das ações para prevenção da úlcera por pressão prescritas ou não pelos enfermeiros}

As Tabelas de número 12 a 19 e Figuras de número 2 a 9 apresentam os resultados que atendem ao segundo objetivo específico da presente pesquisa que se constituiu em investigar se, após o treinamento da PBE, os estudantes foram capazes de apontar o uso das evidências para a prevenção de UP utilizadas pelos enfermeiros do HUL, por meio da análise dos registros das prescrições de enfermagem em prontuários.

$\mathrm{Na}$ análise dos prontuários não foi encontrado, em nenhum dos dias das avaliações, anotações realizadas pelos enfermeiros referentes ao uso da Escala de Braden e os escores de risco para desenvolvimento de UP.

Quanto ao registro sobre as condições da pele dos pacientes, durante todos os dias das avaliações, para os pacientes que tinham pele íntegra, foram encontrados somente 2 registros. Considerando os pacientes que tinham UP e os dias de avaliação (apresentados anteriormente na Tabela 8), em 30 (21,4\%) prontuários foram encontrados registros sobre a presença da UP. A Tabela 12 apresenta os resultados dos registros pelos enfermeiros nos prontuários sobre a presença ou ausência de UP. 
Tabela 12 - Distribuição dos registros realizados por enfermeiros nos prontuários quanto à presença ou à ausência de UP. Londrina, PR, 2012

\begin{tabular}{lccc}
\hline \multicolumn{4}{c}{ Registro UP } \\
\hline Avaliações & $\mathbf{n ~ ( \% )}$ & $\mathbf{N a ̃ o}$ \\
$\mathbf{1}$ & $2(9,52)$ & $\mathbf{n}(\%)$ & Total \\
$\mathbf{2}$ & $2(9,52)$ & $19(90,48)$ & $21(100,0)$ \\
$\mathbf{3}$ & $2(10,53)$ & $17(89,47)$ & $21(100,0)$ \\
$\mathbf{4}$ & $2(11,76)$ & $15(88,24)$ & $17(100,0)$ \\
$\mathbf{5}$ & $3(18,75)$ & $13(81,25)$ & $16(100,0)$ \\
$\mathbf{6}$ & $2(13,33)$ & $13(86,67)$ & $15(100,0)$ \\
$\mathbf{7}$ & $2(14,29)$ & $12(85,71)$ & $14(100,0)$ \\
$\mathbf{8}$ & $3(27,27)$ & $8(72,73)$ & $11(100,0)$ \\
$\mathbf{9}$ & $2(22,22)$ & $7(77,78)$ & $9(100,0)$ \\
$\mathbf{1 0}$ & $2(22,22)$ & $7(77,78)$ & $9(100,0)$ \\
$\mathbf{1 1}$ & $2(25,00)$ & $6(75,00)$ & $8(100,0)$ \\
$\mathbf{1 2}$ & $2(33,33)$ & $4(66,67)$ & $6(100,0)$ \\
$\mathbf{1 3}$ & $2(33,33)$ & $4(66,67)$ & $6(100,0)$ \\
$\mathbf{1 4}$ & $2(33,33)$ & $4(66,67)$ & $6(100,0)$ \\
$\mathbf{1 5}$ & $0(0,00)$ & $4(100,0)$ & $4(100,0)$ \\
\hline \hline
\end{tabular}

Observa-se pequena frequência de registros de enfermagem considerando o número de pacientes que apresentava UP, identificados pelos estudantes e pela pesquisadora (Tabela 8).

Em relação à classificação (estágio/grau) da UP, em nenhum prontuário foi encontrado registro de informações. Quanto à anotação em prontuário referente à região corporal de localização das úlceras por pressão, ocorreu de forma mais frequente na $1^{\text {a }}$ e $2^{\text {a }}$ avaliação em 2 (15,38\%) prontuários dos 13 pacientes com o problema. Nas outras avaliações, somente para um paciente houve o registro em prontuário.

Os registros em prontuário sobre a prescrição de enfermagem das medidas de prevenção realizados pelos enfermeiros são apresentados nas figuras a seguir. 


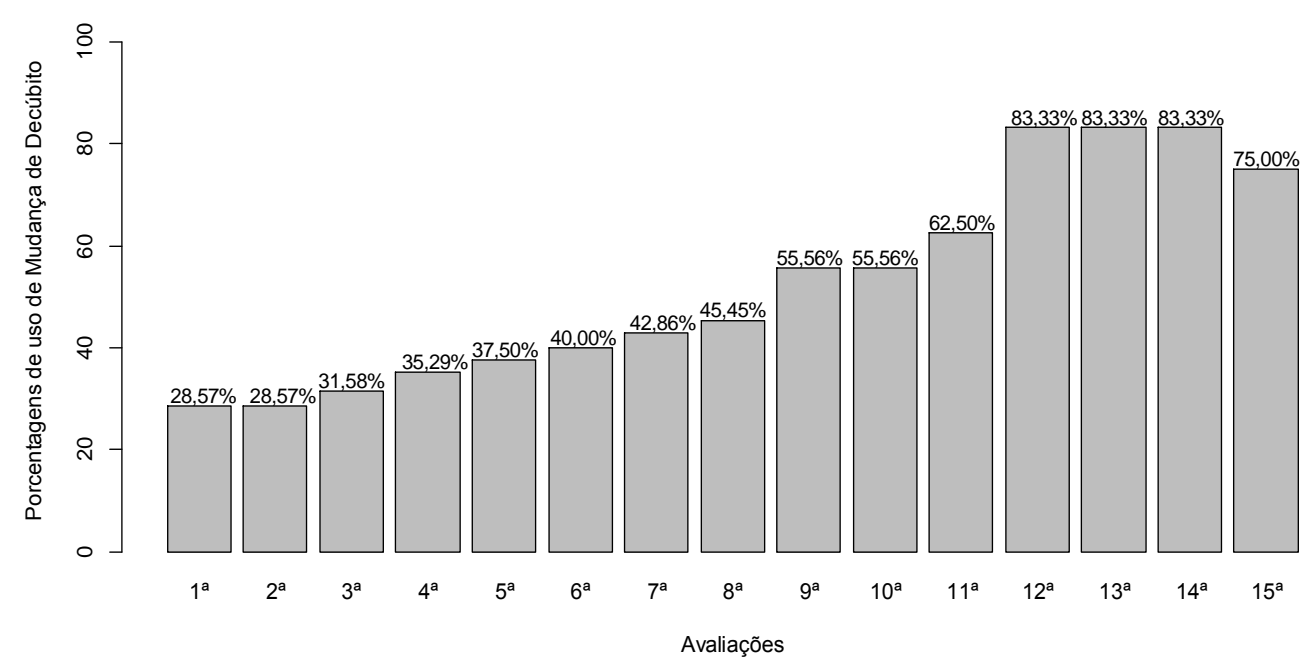

Figura 2 - Prescrição de enfermagem referente ao uso da medida de prevenção mudança de decúbito

A Figura 2 mostra que, até a $8^{\text {a }}$ avaliação, menos de $50 \%$ dos pacientes tiveram prescrição dessa intervenção e que houve aumento dos registros da $12^{\mathrm{a}}$ à $14^{\mathrm{a}}$ avaliação (83,33\%).

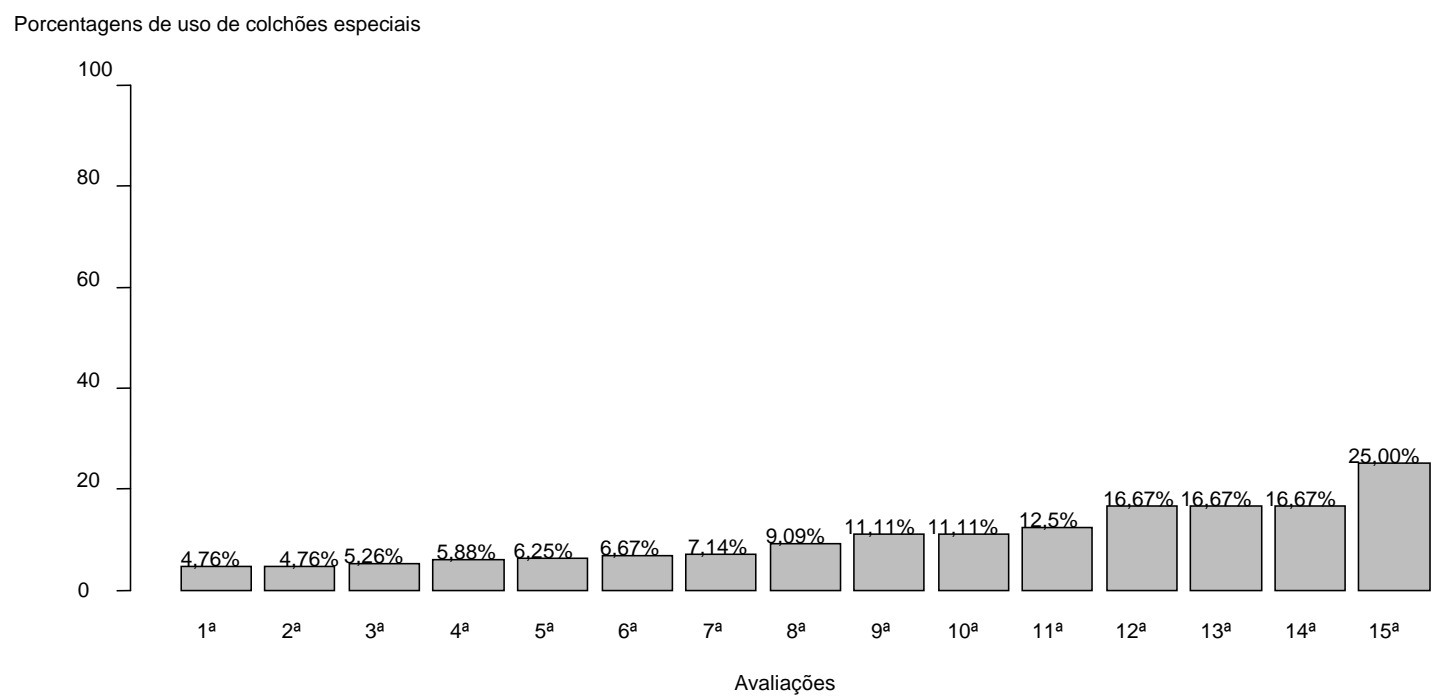

Figura 3 - Prescrição de enfermagem referente ao uso de colchão especial 
Identificou-se que, durante as 15 avaliações, somente para um paciente foi prescrito pelos enfermeiros o uso de colchão especial. Entretanto, essa medida de prevenção está na relação da prescrição de enfermagem informatizada do HUL como "manter em colchão de viscoelástico, instalar colchão de viscoelástico e colocar/manter colchão caixa de ovo. O uso do colchão viscoelástico ainda não foi adquirido pela instituição, estando em processo de licitação para que os mesmos sejam utilizados no cuidado aos pacientes.

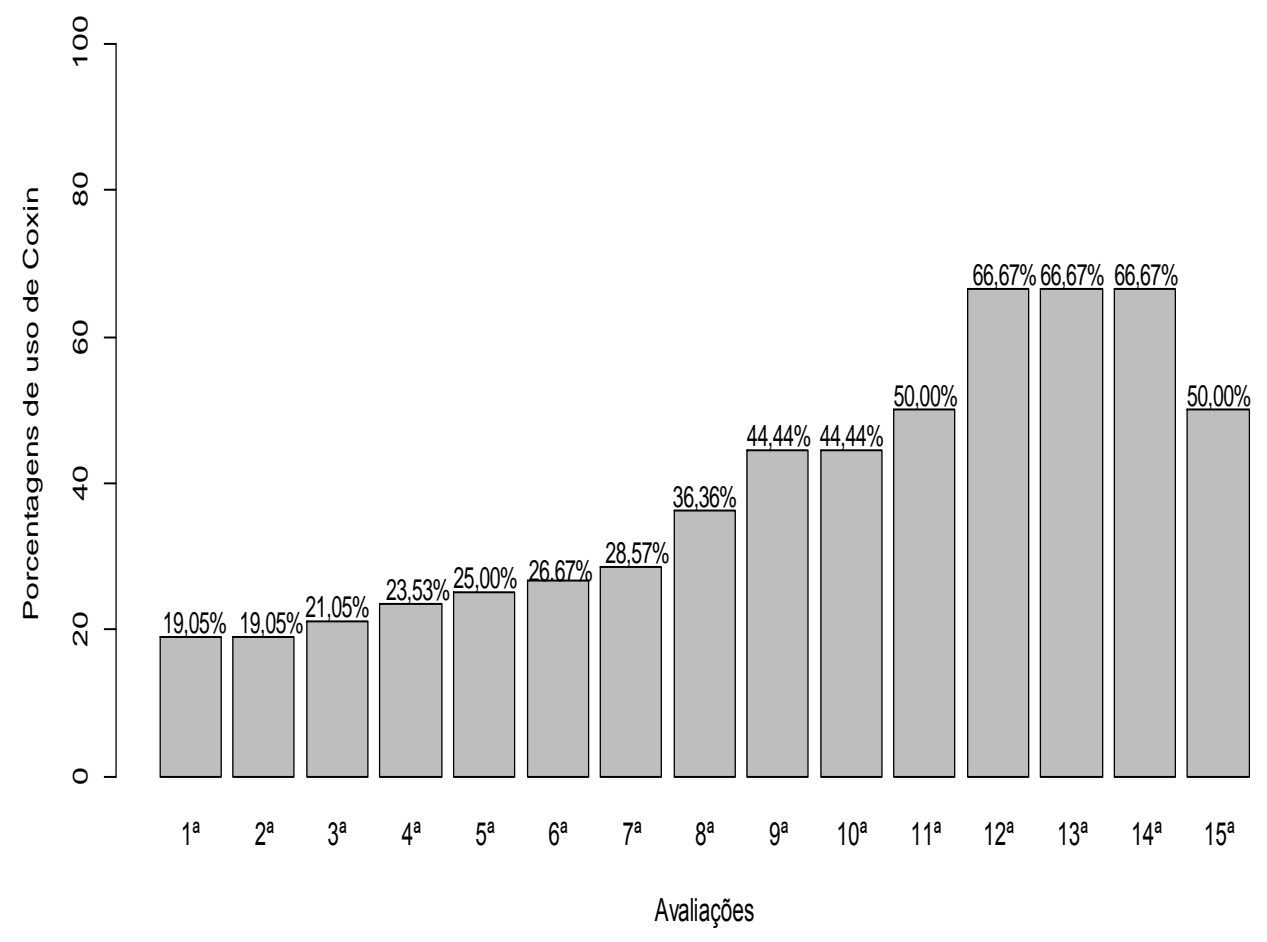

Figura 4 - Prescrição de enfermagem referente ao uso de coxins

Da $1^{\text {a }}$ à $11^{\text {a }}$ avaliação entre 19,5 e $50 \%$ dos pacientes tiveram prescrição para o uso de coxim, e com aumento da frequência de prescrição da $12^{\underline{a}}$ à $14^{a}$ avaliação $(66,67 \%)$. 


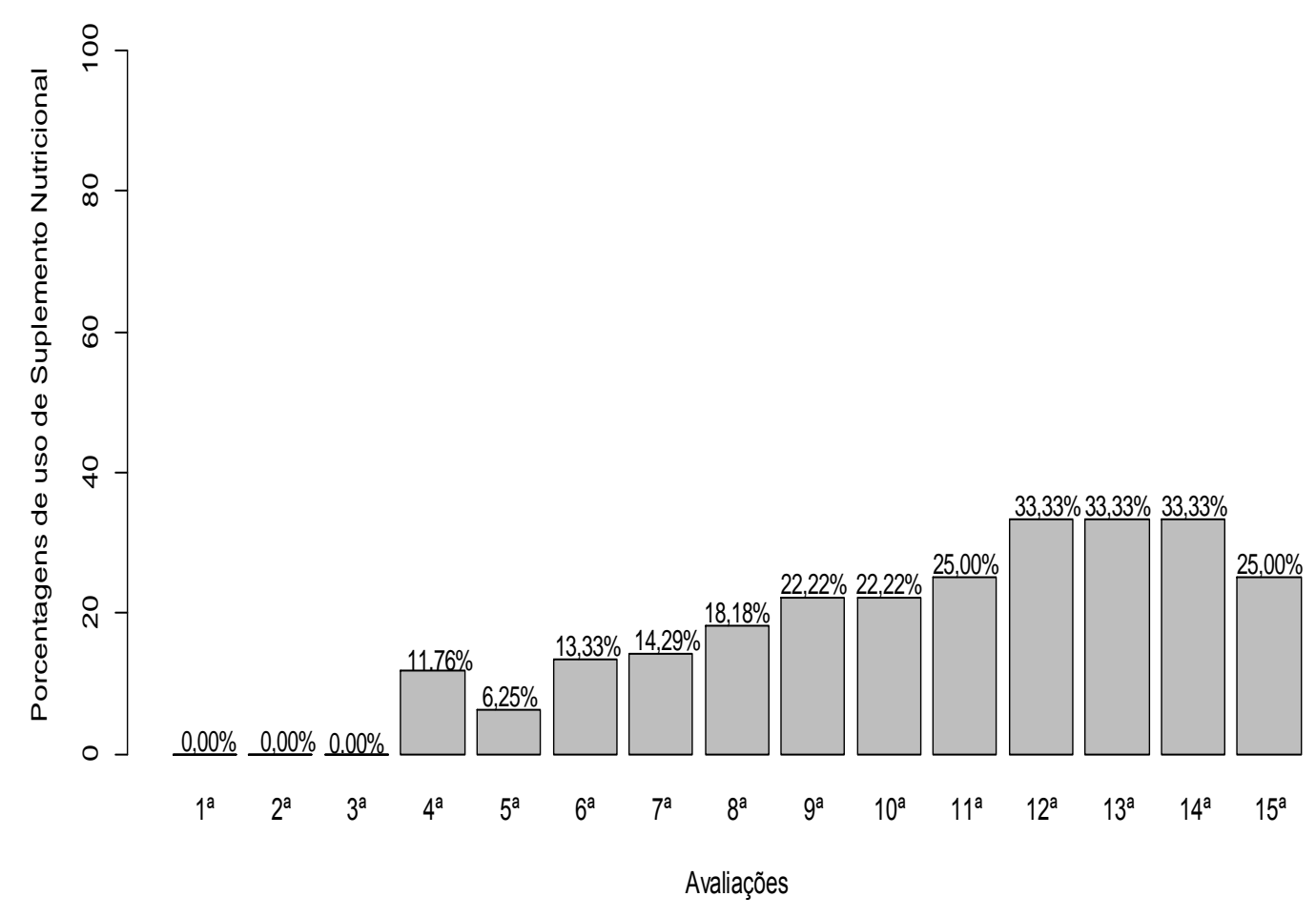

Figura 5 - Prescrição de enfermagem referente ao uso do suplemento nutricional

No HUL, a prescrição do suplemento nutricional é realizada pelo médico seguindo orientação da nutricionista do hospital. O enfermeiro, juntamente com esses profissionais, também colabora, identificando a necessidade de prescrever o uso de suplemento nutricional para os pacientes em risco para desenvolver UP e com UP. Dessa forma, o que está registrado na prescrição de enfermagem é a transcrição da prescrição médica em relação ao uso do suplemento nutricional. No entanto, observa-se na Figura 5 que nos três primeiros dias de avaliação nenhum paciente teve prescrito o suplemento nutricional. Verificou-se que, da $12^{\underline{a}}$ à $14^{\text {a }}$ avaliação, foi prescrito o uso do suplemento nutricional para $33,33 \%$ dos pacientes. 


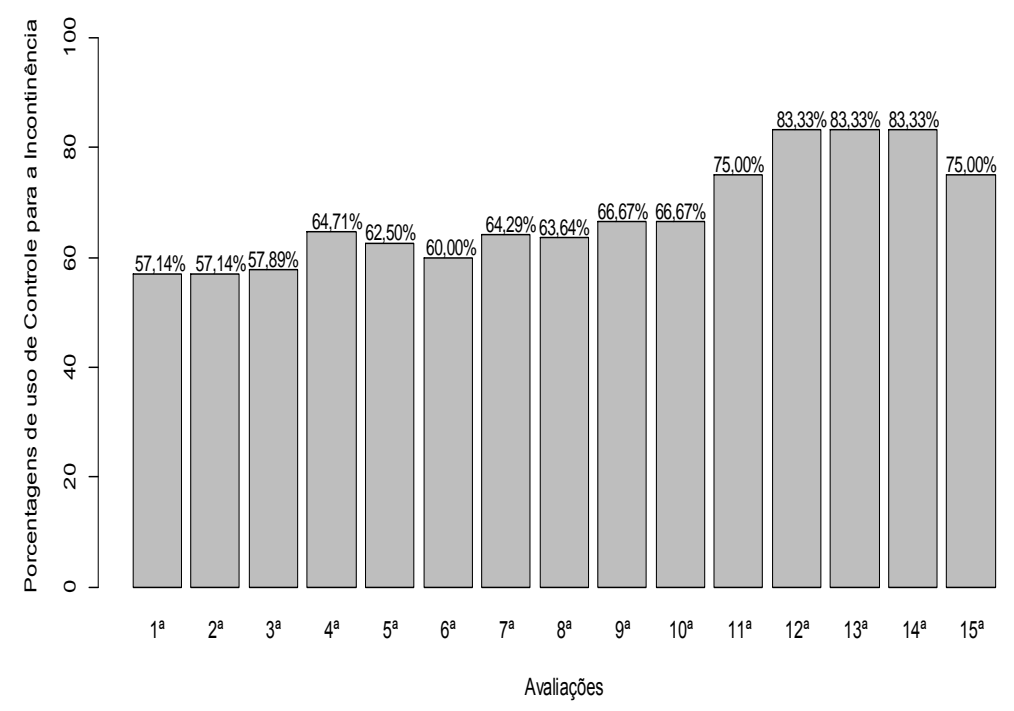

Figura 6 - Prescrição de enfermagem referente ao uso de medidas de prevenção para proteção da pele em relação a umidade

A medida de prevenção para "controle da incontinência", no HUL, refere-se à prescrição de enfermagem da intervenção: aplicar AGE e creme protetor para a pele em região perineal a cada troca de fraldas. Essa intervenção aplica-se à prevenção de UP e dermatite associada à incontinência.

Para mais da metade dos pacientes foi encontrada essa prescrição de enfermagem para controle dos efeitos da incontinência. Na primeira avaliação, $57,14 \%$ dos pacientes teve essa prescrição nos prontuários e houve acréscimo da $12^{a}$ à $14^{a}$ avaliação (83,33\%). 


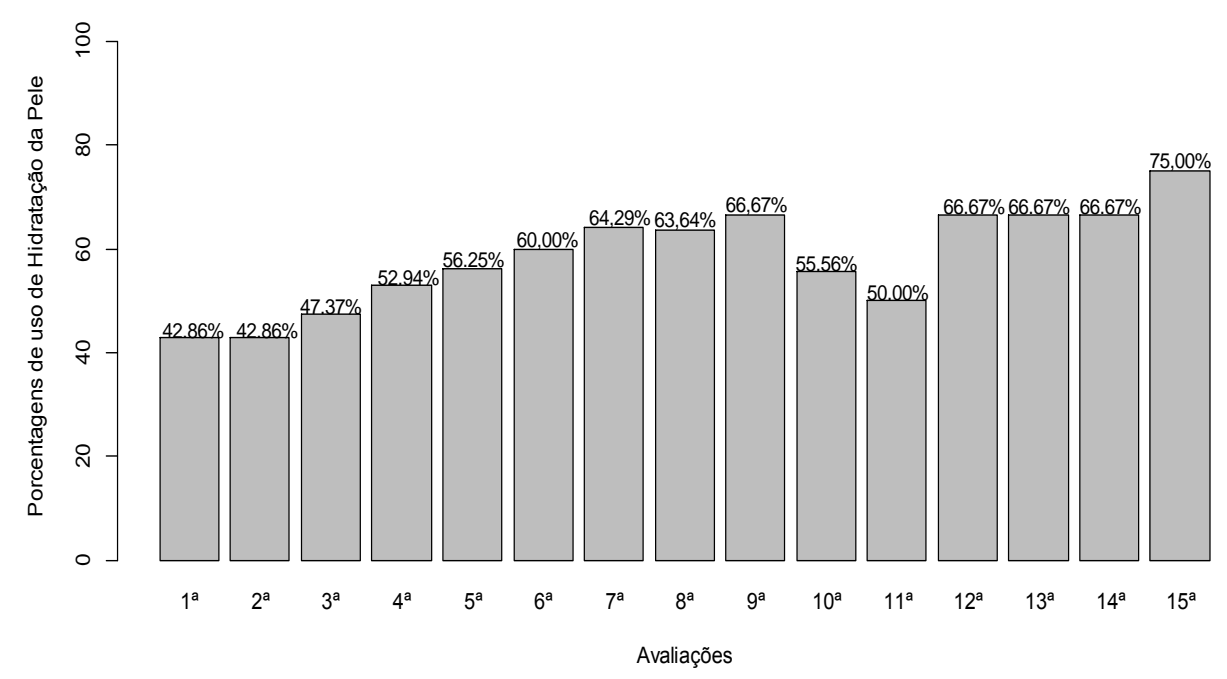

Figura 7 - Prescrição de enfermagem referente ao uso de hidratantes

A medida de prevenção hidratação da pele, no HUL, refere-se à prescrição de enfermagem das intervenções aplicar óleo vegetal em superfície corpórea, aplicar AGE e massagear toda a superfície corpórea.

Observa-se, na Figura 7, que, na primeira avaliação, 42,86\% apresentou na prescrição a hidratação da pele e paulatinamente a frequência foi aumentando, culminando com $75 \%$ na $15^{\text {a }}$ avaliação.

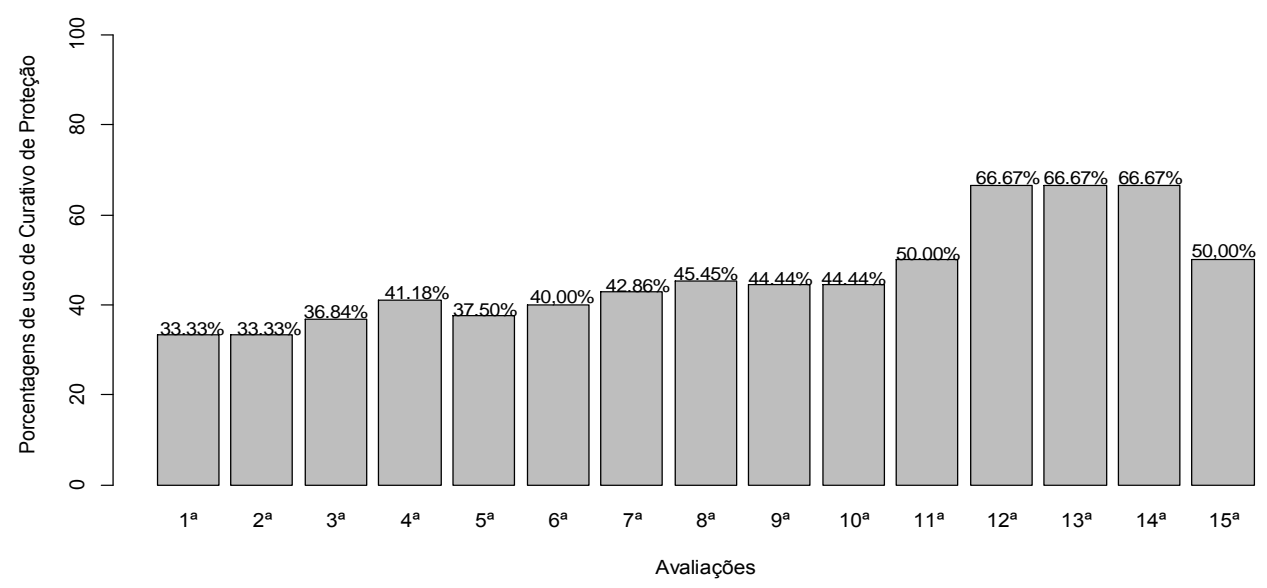

Figura 8 - Prescrição de enfermagem referente ao uso da medida de prevenção uso de curativo/cobertura 
No HUL, como medida de prevenção, é preconizado o uso de curativo de proteção/cobertura sobre a pele, porém, o que foi observado é que as coberturas eram utilizadas em pacientes com UP com o objetivo de tratamento. Não foi encontrada prescrição de enfermagem para prevenção.

Portanto, a Figura 8 mostra que foi prescrito pelo enfermeiro o uso do curativo como forma de tratamento em maior frequência $(66,67 \%)$, da $12^{\underline{a}}$ à $14^{\text {a }}$ avaliação.

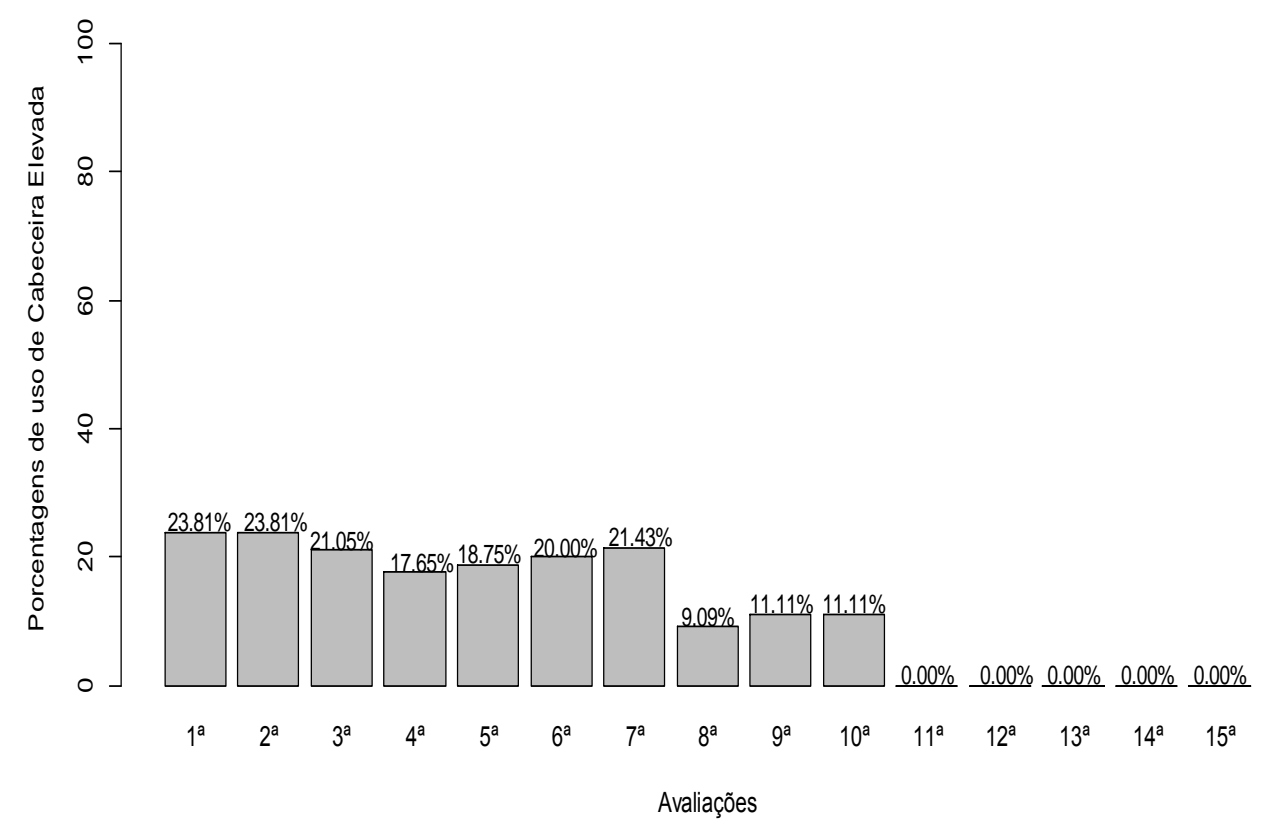

Figura 9 - Prescrição de enfermagem referente ao uso da manutenção da cabeceira elevada até $30^{\circ}$

No HUL, na prescrição de enfermagem eletrônica, não consta como medida de prevenção de UP manter a cabeceira elevada em $30^{\circ}$, entretanto, 0 enfermeiro pode elaborar essa intervenção e registrar na prescrição de enfermagem.

A Figura 9 mostra que essa medida foi pouco prescrita pelos enfermeiros. $\mathrm{Na} 1^{\underline{a}}$ e $2^{\underline{a}}$ avaliação foi prescrito, em $23,81 \%$, no prontuário dos pacientes, e nenhum registro foi observado da $11^{\text {a }}$ à $15^{\underline{a}}$ avaliação . 
Com base nos resultados apresentados, em relação à prescrição de enfermagem das medidas de prevenção, decidiu-se pela investigação da possível associação entre a prescrição da medida de prevenção pelos enfermeiros e a condição da pele ou a aparência da UP dos pacientes, considerando a classificação em estágios/graus. Para isso, consideraram-se duas categorias de pacientes: a categoria UP Avançada para aqueles com UP em estágio III e IV e não classificável e UP Leve para aqueles com UP em estágio I e II ou com pele íntegra, mas em risco.

A Tabela 13 mostra os resultados dos testes referentes à exploração da associação entre o uso das medidas de prevenção com as categorias da UP Avançada ou Leve. 
Tabela 13 - Distribuição do uso das medidas de prevenção na prescrição de enfermagem, considerando categorias da UP Avançada ou Leve. Londrina, PR, 2012

\begin{tabular}{|c|c|c|c|c|}
\hline \multicolumn{5}{|c|}{ Úlcera por pressão } \\
\hline & Avançada & Leve & & \multirow[b]{2}{*}{ p-valor } \\
\hline Mudança de decúbito & n (\%) & n (\%) & Total & \\
\hline Sim & $3(14,29)$ & $3(14,29)$ & $6(28,57)$ & 0,3544 \\
\hline Não & $4(19,05)$ & $11(52,38)$ & $15(71,53)$ & \\
\hline \multicolumn{5}{|l|}{ Colchão } \\
\hline Sim & $0(0,00)$ & $1(4,76)$ & $1(4,76)$ & 1,0000 \\
\hline Não & $7(3,33)$ & $13(61,90)$ & $20(95,24)$ & \\
\hline \multicolumn{5}{|l|}{ Coxim } \\
\hline Sim & $2(9,52)$ & $2(9,52)$ & $4(19,05)$ & 0,5743 \\
\hline Não & $5(23,81)$ & $12(57,14)$ & $17(80,95)$ & \\
\hline \multicolumn{5}{|l|}{ Suplemento nutricional } \\
\hline Sim & $0(0,00)$ & $0(0,00)$ & $0(0,00)$ & --- \\
\hline Não & $7(33,33)$ & $14(66,67)$ & $21(100,00)$ & \\
\hline \multicolumn{5}{|c|}{ Controle da incontinência } \\
\hline Sim & $4(19,05)$ & $8(38,10)$ & $12(38,10)$ & 1,0000 \\
\hline Não & $3(14,29)$ & $6(28,57)$ & $9(42,86)$ & \\
\hline \multicolumn{5}{|l|}{ Hidratação da pele } \\
\hline Sim & $3(14,29)$ & $6(28,57)$ & $9(42,86)$ & 1,0000 \\
\hline Não & $4(19,05)$ & $8(38,10)$ & $12(57,14)$ & \\
\hline \multicolumn{5}{|l|}{ Uso de curativo } \\
\hline Sim & $5(23,81)$ & $2(9,52)$ & $7(33,33)$ & 0,0173 \\
\hline Não & $2(9,52)$ & $12(57,14)$ & $14(66,67)$ & \\
\hline \multicolumn{5}{|c|}{ Cabeceira elevada até $30^{\circ}$} \\
\hline Sim & $0(0,00)$ & $5(23,81)$ & $5(23,81)$ & 0,1235 \\
\hline Não & $7(33,33)$ & $9(42,86)$ & $16(76,19)$ & \\
\hline
\end{tabular}

p-valor referente ao teste exato de Fisher

Utilizou-se o teste exato de Fisher para verificar se existia associação entre as prescrições com as categorias da UP (Avançada ou Leve). O teste apresentou significância estatística $(p$-valor $<0,05)$ somente para a prescrição do uso de curativo/cobertura, confirmando que a prescrição era feita para pacientes com UP de maior profundidade e não para úlceras em estágio I ou II ou para proteção da pele íntegra, em pacientes em risco. Não foram encontradas associações entre as prescrições de outras medidas e as categorias da UP. 
Também foram investigadas possíveis associações entre a prescrição das medidas de prevenção e os fatores de risco avaliados pela Escala de Braden. Para isso, os subescores de cada domínio da Escala foram dicotomizados considerando duas categorias.

Para a Percepção Sensorial, a categoria SIM incluiu o subescore referente à condição Completamente Limitada e Muito Limitada e a NÃO para a condição Levemente Limitada e Ausência de Deficiência Sensorial.

Para a Umidade, a categoria SIM incluiu o subescore referente à condição Constantemente Molhada e Frequentemente Molhada e a categoria NÃO para a condição Ocasionalmente Molhada e Raramente Molhada.

Para a Atividade, a categoria SIM incluiu o escore referente à condição Completamente Imóvel e Muito Limitada e a categoria NÃO para a condição Levemente Limitada e Nenhuma Limitação.

Para a Mobilidade, a categoria SIM incluiu o escore referente à condição Completamente Imóvel e Muito Limitada e a categoria NÃO para a condição Levemente Limitada e Nenhuma Limitação.

Para a Nutrição, a categoria SIM incluiu o escore referente à condição Muito Pobre e Provavelmente Inadequada e a categoria NÃO para a condição Adequada e Excelente.

Para a Fricção e Cisalhamento, a categoria SIM incluiu o escore referente à situação Problema e Problema Potencial e a categoria NÃO para a situação Nenhum Problema Aparente. 
Tabela 14 - Distribuição das medidas de prevenção prescritas e a limitação ou não, da Percepção Sensorial. Londrina, PR, 2012

\begin{tabular}{|c|c|c|c|c|}
\hline & \multicolumn{2}{|c|}{ Limitação da Percepção Sensorial } & \multirow[t]{2}{*}{$*$} & \multirow[b]{3}{*}{ p-valor } \\
\hline & SIM & NÃO & & \\
\hline Mudança de decúbito & n (\%) & n (\%) & Total & \\
\hline Sim & $2(9,52)$ & $4(19,05)$ & $6(28,27)$ & 1,0000 \\
\hline Não & $4(19,05)$ & $11(52,38)$ & $15(71,43)$ & \\
\hline \multicolumn{5}{|l|}{ Colchão } \\
\hline Sim & $0(0,00)$ & $1(4,76)$ & $1(4,76)$ & 1,0000 \\
\hline Não & $6(28,57)$ & $14(66,67)$ & $20(95,24)$ & \\
\hline \multicolumn{5}{|l|}{ Coxim } \\
\hline Sim & $2(9,52)$ & $2(9,52)$ & $4(19,05)$ & 0,5439 \\
\hline Não & $4(19,05)$ & $13(61,90)$ & $17(80,95)$ & \\
\hline \multicolumn{5}{|l|}{ Suplemento nutricional } \\
\hline Sim & $0(0,00)$ & $0(0,00)$ & $0(0,00)$ & -- \\
\hline Não & $6(28,57)$ & $15(71,43)$ & $21(100,00)$ & \\
\hline \multicolumn{5}{|c|}{ Controle da incontinência } \\
\hline Sim & $5(23,81)$ & $7(33,33)$ & $12(57,14)$ & 0,1778 \\
\hline Não & $1(4,76)$ & $8(38,10)$ & $9(42,86)$ & \\
\hline \multicolumn{5}{|l|}{ Hidratação da pele } \\
\hline Sim & $1(4,76)$ & $8(38,10)$ & $9(42,86)$ & 0,1778 \\
\hline Não & $5(23,81)$ & $7(33,33)$ & $12(57,14)$ & \\
\hline \multicolumn{5}{|l|}{ Curativo } \\
\hline Sim & $2(9,52)$ & $5(23,81)$ & $7(33,33)$ & 1,0000 \\
\hline Não & $4(19,05)$ & $10(47,62)$ & $14(66,67)$ & \\
\hline \multicolumn{5}{|c|}{ Cabeceira elevada até $30^{\circ}$} \\
\hline Sim & $2(9,52)$ & $3(14,29)$ & $5(23,81)$ & 0,5975 \\
\hline Não & $4(19,05)$ & $12(57,14)$ & $16(76,19)$ & \\
\hline
\end{tabular}

p-valor referente ao teste exato de Fisher

*SIM = Completamente Limitada e Muito Limitada; NÃO = Levemente Limitada e Ausência de Deficiência Sensorial

$\mathrm{Na}$ associação dos subescores referentes a percepção sensorial, a Tabela 14 mostra que não houve associação em nenhuma das medidas de prevenção. 
Tabela 15 - Distribuição das medidas de prevenção prescritas e a presença de umidade da pele. Londrina, PR, 2012

\begin{tabular}{|c|c|c|c|c|}
\hline \multicolumn{5}{|c|}{ Umidade da Pele* } \\
\hline & SIM & NÃO & & \\
\hline Mudança de decúbito & n (\%) & n (\%) & Total & p-valor \\
\hline Sim & $3(14,29)$ & $3(14,29)$ & $6(28,57)$ & 0,6311 \\
\hline Não & $5(23,81)$ & $10(47,62)$ & $15(71,43)$ & \\
\hline \multicolumn{5}{|l|}{ Colchão } \\
\hline Sim & $0(0,00)$ & $1(4,76)$ & $1(4,76)$ & 1,0000 \\
\hline Não & $8(38,10)$ & $12(57,14)$ & $20(95,24)$ & \\
\hline \multicolumn{5}{|l|}{ Coxim } \\
\hline Sim & $2(9,52)$ & $2(9,52)$ & $4(19,05)$ & 0,6177 \\
\hline Não & $6(28,57)$ & $11(52,38)$ & $17(80,95)$ & \\
\hline \multicolumn{5}{|l|}{ Suplemento nutricional } \\
\hline Sim & $0(0,00)$ & $0(0,00)$ & $0(0,00)$ & -- \\
\hline Não & $8(38,10)$ & $13(61,90)$ & $21(100,00)$ & \\
\hline \multicolumn{5}{|c|}{ Controle da incontinência } \\
\hline Sim & $6(28,57)$ & $6(28,57)$ & $12(57,14)$ & 0,3666 \\
\hline Não & $2(9,52)$ & $7(33,33)$ & $9(42,86)$ & \\
\hline \multicolumn{5}{|l|}{ Hidratação da pele } \\
\hline Sim & $3(14,29)$ & $6(28,57)$ & $9(42,86)$ & 1,0000 \\
\hline Não & $5(23,81)$ & $7(33,33)$ & $12(57,14)$ & \\
\hline \multicolumn{5}{|l|}{ Curativo } \\
\hline Sim & $3(14,29)$ & $4(19,05)$ & $7(33,33)$ & 1,0000 \\
\hline Não & $5(23,81)$ & $9(42,86)$ & $14(66,67)$ & \\
\hline \multicolumn{5}{|c|}{ Cabeceira elevada até $30^{\circ}$} \\
\hline Sim & $1(4,76)$ & $4(19,05)$ & $5(23,81)$ & 0,6065 \\
\hline Não & $7(33,33)$ & $9(42,86)$ & $16(76,19)$ & \\
\hline
\end{tabular}

$\mathrm{p}$-valor referente ao teste exato de Fisher

${ }^{*} \mathrm{SIM}=$ Constantemente Molhada e Frequentemente Molhada

NÃO = Ocasionalmente Molhada e Raramente Molhada

O subescore da subescala umidade da pele não apresentou associação com nenhuma das medidas de prevenção. 
Tabela 16 - Distribuição das medidas de prevenção prescritas e a limitação na Atividade. Londrina, PR, 2012

\begin{tabular}{|c|c|c|c|c|}
\hline \multicolumn{5}{|c|}{ Limitação da Atividade* } \\
\hline & SIM & NÃO & & \multirow[b]{2}{*}{ p-valor } \\
\hline Mudança de decúbito & n (\%) & n (\%) & Total & \\
\hline Sim & $6(28,57)$ & $0(0,00)$ & $6(28,57)$ & 1,0000 \\
\hline Não & $14(66,67)$ & $1(4,76)$ & $15(71,43)$ & \\
\hline \multicolumn{5}{|l|}{ Colchão } \\
\hline Sim & $1(4,76)$ & $0(0,00)$ & $1(4,76)$ & \multirow[t]{2}{*}{1,0000} \\
\hline Não & $19(90,48)$ & $1(4,76)$ & $20(95,24)$ & \\
\hline \multicolumn{5}{|l|}{ Coxim } \\
\hline Sim & $4(19,05)$ & $0(0,00)$ & $4(19,05)$ & \multirow[t]{2}{*}{1,0000} \\
\hline Não & $16(76,19)$ & $1(4,76)$ & $17(80,95)$ & \\
\hline \multicolumn{5}{|l|}{ Suplemento nutricional } \\
\hline Sim & $0(0,00)$ & $0(0,00)$ & $0(0,00)$ & \multirow[t]{2}{*}{--} \\
\hline Não & $20(95,24)$ & $1(4,76)$ & $21(100,00)$ & \\
\hline \multicolumn{5}{|c|}{ Controle da incontinência } \\
\hline Sim & $12(57,14)$ & $0(0,00)$ & $12(57,14)$ & \multirow[t]{2}{*}{0,4286} \\
\hline Não & $8(38,10)$ & $1(4,76)$ & $9(42,86)$ & \\
\hline \multicolumn{5}{|l|}{ Hidratação da pele } \\
\hline Sim & $9(42,86)$ & $0(0,00)$ & $9(42,86)$ & \multirow[t]{2}{*}{1,0000} \\
\hline Não & $11(52,38)$ & $1(4,76)$ & $12(57,14)$ & \\
\hline \multicolumn{5}{|l|}{ Curativo } \\
\hline Sim & $7(33,33)$ & $0(0,00)$ & $7(33,33)$ & \multirow[t]{2}{*}{1,0000} \\
\hline Não & $13(61,90)$ & $1(4,76)$ & $14(66,67)$ & \\
\hline \multicolumn{5}{|c|}{ Cabeceira elevada até $30^{\circ}$} \\
\hline Sim & $5(23,81)$ & $0(0,00)$ & $5(23,81)$ & \multirow[t]{2}{*}{1,0000} \\
\hline Não & $15(71,43)$ & $1(4,76)$ & $16(76,19)$ & \\
\hline
\end{tabular}

$\mathrm{p}$-valor referente ao teste exato de Fisher

*SIM = Confinado ao Leito e Confinado à Cadeira

NÃO = Anda Ocasionalmente e Anda Frequentemente

O subescore referente a atividade não apresentou associação com nenhuma medida de prevenção. A Tabela 17 mostra que 14 pacientes $(66,67 \%)$ que estavam Confinado ao Leito e Confinado à Cadeira não receberam a medida mudança de decúbito para reposicionamento do corpo. 
Tabela 17 - Distribuição das medidas de prevenção prescritas e a limitação na Mobilidade. Londrina, PR, 2012

\begin{tabular}{|c|c|c|c|c|}
\hline \multicolumn{5}{|c|}{ Limitação na Mobilidade* } \\
\hline & SIM & NÃO & & \multirow[b]{2}{*}{ p-valor } \\
\hline Mudança de decúbito & n (\%) & n (\%) & Total & \\
\hline Sim & $6(28,57)$ & $0(0,00)$ & $6(28,57)$ & 1,0000 \\
\hline Não & $13(61,90)$ & $2(9,52)$ & $15(71,43)$ & \\
\hline \multicolumn{5}{|l|}{ Colchão } \\
\hline Sim & $1(4,76)$ & $0(0,00)$ & $1(4,76)$ & \multirow[t]{2}{*}{1,0000} \\
\hline Não & $18(85,71)$ & $2(9,52)$ & $20(95,24)$ & \\
\hline \multicolumn{5}{|l|}{ Coxim } \\
\hline Sim & $4(19,05)$ & $0(0,00)$ & $4(19,05)$ & \multirow[t]{2}{*}{1,0000} \\
\hline Não & $15(71,43)$ & $2(9,52)$ & $17(80,95)$ & \\
\hline \multicolumn{5}{|l|}{ Suplemento nutricional } \\
\hline Sim & $0(0,00)$ & $0(0,00)$ & $0(0,00)$ & \multirow[t]{2}{*}{--} \\
\hline Não & $19(90,48)$ & $2(9,52)$ & $21(100,00)$ & \\
\hline \multicolumn{5}{|c|}{ Controle da incontinência } \\
\hline Sim & $12(57,14)$ & $0(0,00)$ & $12(57,14)$ & \multirow[t]{2}{*}{0,1714} \\
\hline Não & $7(33,33)$ & $2(9,52)$ & $9(42,86)$ & \\
\hline \multicolumn{5}{|l|}{ Hidratação da pele } \\
\hline Sim & $9(42,86)$ & $0(0,00)$ & $9(42,86)$ & \multirow[t]{2}{*}{0,4857} \\
\hline Não & $10(47,62)$ & $2(9,52)$ & $12(57,14$ & \\
\hline \multicolumn{5}{|l|}{ Curativo } \\
\hline Sim & $6(28,57)$ & $1(4,76))$ & $7(33,33)$ & \multirow[t]{2}{*}{1,0000} \\
\hline Não & $13(61,90)$ & $1(4,76)$ & $14(66,67)$ & \\
\hline \multicolumn{5}{|c|}{ Cabeceira elevada até $30^{\circ}$} \\
\hline Sim & $5(23,81)$ & $0(0,00)$ & $5(23,81)$ & \multirow[t]{2}{*}{1,0000} \\
\hline Não & $14(66,67)$ & $2(9,52)$ & $16(76,19)$ & \\
\hline
\end{tabular}

$\mathrm{p}$-valor referente ao teste exato de Fisher

* SIM = Completamente Imóvel e Muito Limitada

NÃO = Levemente Limitada e Nenhuma Limitação

O subescore da subescala mobilidade não apresentou associação com nenhuma das medidas de prevenção. Quinze pacientes $(71,43 \%)$ que apresentavam-se Completamente Imóvel e Muito Limitada, para eles não tiveram prescrito o uso do coxim. Em relação à mudança de decúbito 13 pacientes $(61,90 \%)$ completamente imóveis não receberam essa intervenção. 
Tabela 18 - Distribuição das medidas de prevenção prescritas e adequação da Nutrição. Londrina, PR, 2012

\begin{tabular}{|c|c|c|c|c|}
\hline \multicolumn{5}{|c|}{ Adequação da Nutrição* } \\
\hline & SIM & NÃO & & \multirow[b]{2}{*}{ p-valor } \\
\hline Mudança de decúbito & n (\%) & n (\%) & Total & \\
\hline Sim & $6(28,57)$ & $0(0,00)$ & $6(28,57)$ & 0,0456 \\
\hline Não & $7(33,33)$ & $8(38,10)$ & $15(71,43)$ & \\
\hline \multicolumn{5}{|l|}{ Colchão } \\
\hline Sim & $1(4,76)$ & $0(0,00)$ & $1(4,76)$ & \multirow[t]{2}{*}{1,0000} \\
\hline Não & $12(57,14)$ & $8(38,10)$ & $20(95,14)$ & \\
\hline \multicolumn{5}{|l|}{ Coxim } \\
\hline Sim & $4(19,05)$ & $0(0,00)$ & $4(19,05)$ & \multirow[t]{2}{*}{0,1312} \\
\hline Não & $9(42,86)$ & $8(38,10)$ & $17(80,95)$ & \\
\hline \multicolumn{5}{|l|}{ Suplemento nutricional } \\
\hline Sim & $0(0,00)$ & $0(0,00)$ & $0(0,00)$ & \multirow[t]{2}{*}{--} \\
\hline Não & $13(61,90)$ & $8(38,10)$ & $21(100,00)$ & \\
\hline \multicolumn{5}{|c|}{ Controle da incontinência } \\
\hline Sim & $8(38,10)$ & $4(19,05)$ & $12(57,14)$ & \multirow[t]{2}{*}{0,6731} \\
\hline Não & $5(23,81)$ & $4(19,05)$ & $9(42,86)$ & \\
\hline \multicolumn{5}{|l|}{ Hidratação da pele } \\
\hline Sim & $6(28,57)$ & $3(14,29)$ & $9(42,86)$ & \multirow[t]{2}{*}{1,0000} \\
\hline Não & $7(33,33)$ & $5(23,81)$ & $12(57,14)$ & \\
\hline \multicolumn{5}{|l|}{ Curativo } \\
\hline Sim & $6(28,57)$ & $1(4,76)$ & $7(33,33)$ & \multirow[t]{2}{*}{0,1736} \\
\hline Não & $7(33,33)$ & $7(33,33)$ & $14(66,67)$ & \\
\hline \multicolumn{5}{|c|}{ Cabeceira elevada até $30^{\circ}$} \\
\hline Sim & $2(9,52)$ & $3(14,29)$ & $5(23,81)$ & \multirow[t]{2}{*}{0,3254} \\
\hline Não & $11(52,38)$ & $5(23,81)$ & $16(76,19)$ & \\
\hline
\end{tabular}

$\mathrm{p}$-valor referente ao teste exato de Fisher

*SIM = Muito Pobre e Provavelmente Inadequada

NÃO = Adequada e Excelente

$\mathrm{Na}$ Tabela 18 observa-se que nenhum paciente com ingestão Muito Pobre ou Provavelmente Inadequada teve prescrição de suplemento nutricional. Foi encontrada uma associação significativa ( $p$-valor $=0,0456$ ) entre os subescores Muito Pobre e Provavelmente Inadequada com a prescrição mudança de decúbito. No entanto, do ponto de vista clínico, esse achado não é relevante. 
Tabela 19 - Distribuição das medidas de prevenção prescritas e problemas em relação a Fricção e Cisalhamento. Londrina, PR, 2012

\begin{tabular}{|c|c|c|c|}
\hline \multicolumn{4}{|c|}{ Fricção e cisalhamento* } \\
\hline & SIM & NÃO & \\
\hline Mudança de decúbito & n (\%) & $n(\%)$ & Total \\
\hline Sim & $6(28,57)$ & $0(0,00)$ & $6(28,57)$ \\
\hline Não & $15(71,43)$ & $0(0,00)$ & $15(71,43)$ \\
\hline \multicolumn{4}{|l|}{ Colchão } \\
\hline Sim & $1(4,76)$ & $0(0,00)$ & $1(4,76)$ \\
\hline Não & $20(95,24)$ & $0(0,00)$ & $20(95,24)$ \\
\hline \multicolumn{4}{|l|}{ Coxim } \\
\hline Sim & $4(19,05)$ & $0(0,00)$ & $4(19,05)$ \\
\hline Não & $17(80,95)$ & $0(0,00)$ & $17(80,95)$ \\
\hline \multicolumn{4}{|l|}{ Suplemento nutricional } \\
\hline Sim & $0(0,00)$ & $0(0,00)$ & $0(0,00)$ \\
\hline Não & $21(100,00)$ & $0(0,00)$ & $21(100,00)$ \\
\hline \multicolumn{4}{|c|}{ Controle da incontinência } \\
\hline Sim & $12(57,14)$ & $0(0,00)$ & $12(57,14)$ \\
\hline Não & $9(42,86)$ & $0(0,00)$ & $9(42,86)$ \\
\hline \multicolumn{4}{|l|}{ Hidratação da pele } \\
\hline Sim & $9(42,86)$ & $0(0,00)$ & $9(42,86)$ \\
\hline Não & $12(57,14)$ & $0(0,00)$ & $12(57,14)$ \\
\hline \multicolumn{4}{|l|}{ Curativo } \\
\hline Sim & $7(33,33)$ & $0(0,00)$ & $7(33,33)$ \\
\hline Não & $14(66,67)$ & $0(0,00)$ & $14(66,67)$ \\
\hline \multicolumn{4}{|c|}{ Cabeceira elevada até $30^{\circ}$} \\
\hline Sim & $5(23,81)$ & $0(0,00)$ & $5(23,81)$ \\
\hline Não & $16(76,19)$ & $0(0,00)$ & $16(76,19)$ \\
\hline
\end{tabular}

* $\mathrm{SIM}=$ Problema e Problema Potencial

NÃO = Nenhum Problema Aparente

A Tabela 19 mostra que todos pacientes tinham problema ou potencial para problema em relação a friç̧ão e cisalhamento. Entretanto, a medida de prevenção referente à cabeceira elevada até $30^{\circ}$ não foi prescrita para 16 pacientes $(76,19 \%)$ e o uso de curativo/cobertura não foi prescrito para 14 pacientes $(66,67 \%)$. 
4.3 Significado da experiência dos estudantes da $2^{a}$ série do curso de enfermagem da UEL referente a metodologia de ensino proposta

A seguir, passa-se a apresentar os resultados qualitativos da pesquisa atendendo o objetivo específico de revelar o significado da experiência dos estudantes da $2^{a}$ série do curso de enfermagem da UEL, referente a metodologia de ensino proposta.

A partir da análise de conteúdo da transcrição das falas das discussões em grupo realizadas com os estudantes, foram identificadas as unidades de contexto e as unidades de registro que compuseram as categorias: aprendendo sobre o tema úlcera por pressão e conhecendo a realidade da instituição e da enfermagem com as suas subcategorias (Quadro 1). 


\begin{tabular}{|c|c|}
\hline CATEGORIAS & SUBCATEGORIAS \\
\hline $\begin{array}{l}\text { 1. Aprendendo sobre o tema } \\
\text { úlcera por pressão }\end{array}$ & $\begin{array}{l}\text { 1.a Correlacionando a teoria com a } \\
\text { prática } \\
\text { 1.b O despertar para as competências } \\
\text { da enfermagem na avaliação do } \\
\text { paciente com risco para UP } \\
\text { 1.c Aprimorando o conhecimento dos } \\
\text { estágios da UP } \\
\text { 1.d Aprimorando o conhecimento } \\
\text { sobre os fatores de risco da UP } \\
\text { 1.e A Escala de Braden como suporte } \\
\text { para avaliação de risco da UP }\end{array}$ \\
\hline $\begin{array}{l}\text { 2. Conhecendo a realidade da } \\
\text { instituição e da enfermagem } \\
\text { sobre a UP }\end{array}$ & $\begin{array}{l}\text { 2.a A falta de cuidado de prevenção } \\
\text { na UP } \\
\text { 2.b A importância da família nos } \\
\text { cuidados de enfermagem na UP } \\
\text { 2.c Identificando a realidade da } \\
\text { prescrição e das anotações de } \\
\text { enfermagem em relação à UP } \\
\text { 2.c Percebendo a necessidade de } \\
\text { transformar a prática da enfermagem } \\
\text { em relação à UP }\end{array}$ \\
\hline
\end{tabular}

Quadro 1 - Demonstrativo das categorias e subcategorias identificadas a partir das falas dos estudantes da $2^{\mathrm{a}}$ série do curso de enfermagem. Londrina, PR, 2012 
4.3.1. Primeira categoria - Aprendendo sobre o tema úlcera por pressão

A categoria aprendendo sobre o tema UP é composta das falas dos estudantes, após a participação da primeira e segunda fase desta pesquisa.

Essa categoria está composta por cinco subcategorias, descritas a seguir.

\subsubsection{Correlacionando a teoria à prática}

Esta subcategoria mostra a visão dos estudantes sobre as formas de ensino-aprendizagem que foram utilizadas nas aulas sobre a temática em diferentes momentos de sua formação. Também expressa a satisfação que os estudantes apresentaram quando conseguiram fazer a correlação da teorização sobre a prevenção da UP com a prática assistencial vivenciada nos 15 dias que participaram da avaliação dos pacientes na Unidade Masculina do HUL, afirmando que a metodologia aplicada contribuiu para um aprendizado significativo. Mostra, ainda, a reflexão que fazem sobre o ensino de outros conteúdos ou temas cuja aprendizagem poderia ser facilitada pelo uso da mesma estratégia.

...ver ao vivo é bem diferente do que só a teoria (A1).

É igual a sonda vesical de demora, quando que fiz aqui (no laboratório) foi maravilhoso, fiz rapidinho. Quando chegou lá em cima (hospital), nossa!! Foi outra coisa. Lá você sabe que é de verdade... você não pode contaminar de jeito nenhum, é diferente...... Às vezes a gente tem que fazer isso, pra aprender (A1).

...o curso teórico sobre a úlcera por pressão foi importante na prática" A prática fixa o teórico" "Tivemos a teoria, que foi boa, depois a gente fixou na prática, que foram bastantes dias, isso ajudou muito (A2).

É muito bom (A3).

...é muito interessante a metodologia da teoria aplicada na prática, a gente consegue aprender mais (A4). A teoria é muito vaga (A4). A gente não aprendia nas aulas,....., e agora a gente pode ver a importância, porque paciente acamado se não cuidar vai desenvolver (A4).

.... gente consegue aprender muito (A5). Aprende muito (A5). 
Que nem no estágio (classificação da UP), antes de a gente ter essa teoria, a gente ficava perdido, eu não sabia se era uma úlcera, se não era, confundia grau 2 e 3 (A6).

...a gente conseguindo ver elas (as úlceras) pessoalmente e conseguir aplicar a teoria com a prática ficou mais interessante,...ficar só vendo as imagens ou então só a explicação teórica não dá mesmo para gente compreender (A7).

...com essa metodologia o nosso preparo foi diferente dos outros estudantes que não tiveram esse contato, eles não têm a mínima noção do que fazer (A7). Se a gente tivesse feito isso no exame físico, visto na prática, avaliando, teria ficado muito mais do que só a parte teórica (A7).

\subsubsection{O despertar para as competências da enfermagem na avaliação do paciente com risco para úlcera por pressão}

Os estudantes identificaram nesta subcategoria que realizar a avaliação dos pacientes, quanto ao risco para UP, é uma competência do enfermeiro e destacaram, também, a importância de saber realizar a prescrição de enfermagem com as intervenções apropriadas para a prevenção de UP, conforme demonstram as falas a seguir.

...bem legal conhecer quais as competências da enfermagem no contexto da úlcera.... ] é muito importante saber as nossas competências e exercer elas, senão a gente vai perder espaço (A1).

A prescrição de enfermagem é uma coisa que a gente não está sabendo preparar direito para UP (A1). Quando a gente estudou e descobriu que era em horas, nossa o que é isso (a partir dos 15 dias) 3, 4 horas já começa com hiperemia, nossa gente!! (A1).

...é importante avaliar a questão nutricional o que gosta de comer e a aceitação (A2).

...uma vez a gente avaliou um e não tinha e no outro dia ela já estava com grau I (A3).

...agora a gente pode ver a importância de avaliar o paciente acamado, pois se não cuidar ele vai desenvolver a úlcera (A4). 
O enfermeiro tem que avaliar se ele está com risco ou não. $O$ enfermeiro não faz uma avaliação quando admite o paciente no setor? Tem que fazer né. Precisa tomar banho pra se avaliar? Não pode fazer isso antes? (A8).

\subsubsection{Aprimorando o conhecimento dos estágios da úlcera por pressão}

As falas denotam, que os estudantes, durante a experiência, adquiriram o conhecimento e a habilidade para identificar os graus/estágios da úlcera por pressão, conforme se verifica a seguir.

... no grau I tem a hiperemia (Todos).

Não tem mais a pele, não tá mais íntegra (Referente ao estágio III). Vai ter a pele em cima (referente ao estágio não classificável). Três e quatro dá pra confundir. Lesão tissular é aquela que a gente confundia com o primeiro estágio? Ficava vermelho...É alguma coisa diferente da hiperemia...(A1).

...o estágio três atinge o músculo. ...no estágio quatro tem necrose e muitas vezes pode chegar perto do osso e dos nervos. ...tem um estágio chamado de não classificado [ ]. Tem aquele estágio que eu não lembro o nome, mas fica vermelho, diferente da hiperemia, a pele está íntegra, é o iceberg. Lesão tissular é o iceberg (A2).

...no grau Il a pele não está mais íntegra, atinge a epiderme, derme e tem bolhas. Não dá pra ver (referente ao estágio não classificável). As vezes eu confundo um pouco (A3).

...no estágio III você não vê o tecido ósseo. ...os dois são bem feios (referente ao estágio III e IV) (A4).

...a gente sabe que no grau l é bem mais característico a hiperemia.[ ] no grau não classificável precisa retirar a necrose para saber o grau (A6).

Ontem ainda deu um pouquinho de dúvida (A8). 


\subsubsection{Aprimorando o conhecimento sobre os fatores de risco da úlcera por pressão}

As falas mostram que os estudantes conseguiram, por meio da experiência de coletar os dados da pesquisa, identificar os principais fatores de risco para o desenvolvimento da UP, como identificado a seguir.

\footnotetext{
Ela (UP) escolhe quem está deitado ou sentado. O cisalhamento, ..., terminam de dar o banho e (os pacientes) já estão lá embaixo de novo... O lençol todo amassado. Aí você vai virar ele pra ver, tá as marquinhas do lençol, todo amassadinho. Já está com hiperemia, no mínimo. Neurologia é a clínica que mais pacientes apresentaram UP, talvez (A1).

...cisalhamento constante... Chegou do centro cirúrgico e tem $90 \%$ de chance de ter úlcera. Não faz a movimentação de 2/2 horas, porque o paciente tá cheio de aparelho, tá entubado e é mais difícil de mudar o decúbito (A2).

...pessoa acamada (A3).

Acho que está mais relacionado com a imobilidade mesmo. ...nutrição. Acho que foi a ortopedia (A6).

...umidade (A7).

...falta de mudança de decúbito (A8).
}

\subsubsection{A Escala de Braden como suporte para avaliação de risco da úlcera por pressão}

A importância de aplicar a Escala de Braden na avaliação de risco para UP e o significado dessa ferramenta na prática está expressa nas falas abaixo.

Ela é a base para a gente saber em que a gente vai se atentar (A1).

Avalia umidade (A1).

...eu acho que a escala descreve um padrão... para os enfermeiros, ela é tão fácil de usar [ ], você consegue fazer a avaliação, não perde tempo, e vai recuperar o paciente mais rapidamente (A2). 
... a escala explica bem na classificação (do risco), dá pra ver o grau (de risco) em que o paciente se encontrava (A3).

Avalia mobilidade (A7).

Avalia atividade, percepção sensorial (A8).

Avalia nutrição, friç̧ão e cisalhamento (A1, A5 e A2).

\subsubsection{Segunda categoria - CONHECENDO A REALIDADE DA INSTITUIÇÃO E DA ENFERMAGEM SOBRE A ÚLCERA POR PRESSÃO}

Esta categoria mostra a visão que os estudantes tiveram sobre a assistência de enfermagem na Unidade Masculina do HUL, em relação à prevenção da úlcera por pressão e as suas contribuições para transformar a prática da enfermagem. Dessa forma emergiram, quatro subcategorias que são apresentadas a seguir.

\subsubsection{A falta de cuidado de prevenção da úlcera por pressão}

Nas falas, ficou evidenciado que os estudantes perceberam que a equipe de enfermagem, nas suas atividades diárias, não realizava as medidas de prevenção para o desenvolvimento de UP e que existiam problemas institucionais que dificultavam que esse cuidado fosse realizado. Também verbalizaram que, muitas vezes, a assistência era focalizada no diagnóstico médico e não havia uma visão do cuidado integral ao paciente e apresentam sentimentos negativos em relação a isso.

...o lençol está sempre amarrotado [ ] É muito melhor você prevenir do que remediar, dá mais trabalho correr atrás do prejuízo depois. [ ],... aqueles coxins, travesseiros não eram bem usados. Por isso que eu falo: às vezes era mal usado né (uso do coxim). Quando tinha (assistência), a que mais tinha, na minha opinião era a mudança de decúbito. Tinha só aqueles coxins, travesseiros... A gente (enfermeiro) não quer assumir o nosso trabalho. Isso me deixa muito descontente. ...o paciente tava até sentado na poltrona, o colchão estava tão velho, tão velho, aí eu falei: que beleza, mais um pouco e 
ele deita no chão. Uma coisa que me deixa muito nervosa é gritar na unidade. Tem mais jeito de conversar. Às vezes o pessoal é muito bruto. Acho que eles se sentem ameaçados. Se ele tá fazendo mal e vem você e faz o bem... (A1).

...o paciente tem úlcera de grau elevado, [ ] mas não tem prescrição, não tem orientação como curativo protetor, hidratação da pele e mudança de decúbito [ ] ....não pode achar que só colocar a placa de hidrocolóide resolve tudo. Os pacientes usam fralda, é muito calor, ficam molhados, não se mexe, o lençol amarrotado e na mesma posição durante horas. [ ] ...e sabem que o paciente vai complicar ainda mais o quadro e fecham os olhos para isso. Tinha gente que colocava no calcâneo, aumentando ainda mais a pressão (uso do coxim). ...um descaso com essa patologia. Se fosse aqui tava todo mundo processado. Colocaram um outro colchão que não é o apropriado, foi o colchão caixa de ovo. Mas eles tão errado, tem que mudar. Se ele está fazendo errado, não dá pra trabalhar naquilo ali. O paciente não escolheu ser cuidado por uma pessoa incompetente, mas ele escolheu cuidar de um paciente (A2).

...só fazem prevenção depois que surgiu a úlcera, porque não avaliam o paciente de risco... Tinha um paciente de alto risco e não havia nada prescrito. Eles têm que começar a ver isto antes (A3).

Não dão muita importância no caso de prevenção de UP, dão importância, por exemplo, no caso de fratura de fêmur. A pessoa não está nem conseguindo se mexer, mas dão importância só pra fratura. Melhorou bastante a UP sacral desse paciente depois que colocou a almofada gel. ...é preguiça (A3).

O colchão sumiu, ele foi para a cirurgia e depois que ele voltou não estava mais com a gente. Eu não via isso. (referente à mudança de decúbito) (A3).

...você vê o paciente sempre molhado, o lençol sempre amarrotado [ ] às vezes não era limpo direito [ ] é um descaso. É sempre do mesmo jeito. Até tem um paciente que vocês sempre arrumam ele, a gente chegava e ele estava sempre do mesmo jeito. Às vezes não... (uso do coxim), estava bem debaixo do calcâneo (A4).

...acho que era almofada gel. O nosso paciente estava usando [ ]. ...não tinha hidratação da pele, uso de hidrocoloide, o que mais prescrevia era mudança de decúbito (A5).

...se não fizermos mudança de decúbito, alimentação adequada, só o colchão não vai adiantar. ...acho que é falta de tempo deles e também uma certa preguiça. ...acho que é mais cômodo para o funcionário, talvez, colocar a placa de hidrocoloide e deixar, e não 
tomar outras medidas de prevenção. Acho que eles não gostam da gente avaliando ali, observando as coisas que estão errada (A7).

...nenhum funcionário sabia se ele tinha ou não úlcera. ...nenhum colchão especial (A8).

Sob a panturrilha (referente ao uso correto de travesseiros para manter o calcâneo flutuante) (vários estudantes).

\subsubsection{A importância da família nos cuidados de enfermagem na úlcera por pressão}

Nos relatos dos estudantes observa-se que esses perceberam que a presença da família junto ao paciente fazia diferença na assistência, tanto na vigilância do cuidado quanto na provisão de materiais e recursos necessários.

...quando a família não está, fica como aquele paciente jogado as traças. O seu José que não fica ninguém com ele, coitado. Fica jogado às traças (A1).

...é diferente quando a família está com o paciente, eles ficam em cima até na hora do banho. É um descaso, se não tem a família em cima. O nosso paciente estava melhorando bem, mas é que a família sempre levava tudo (A4).

...a família trouxe a almofada gel (A5).

...se não tem uma família que luta pelo direito do paciente, ele fica só evoluindo o quadro. Chega até a ser inconveniente (a família) na enfermaria, mas se não ficar em cima, não faz (A8).

\subsubsection{Identificando a realidade da prescrição e das anotações de enfermagem em relação à úlcera por pressão}

Surgem nas falas as percepções dos estudantes de como estão sendo realizadas as anotações em prontuário e a prescrição de enfermagem em relação à UP, no que diz respeito ao aspecto, classificação (estágio), "checagem" no prontuário do cuidado realizado e ausência de registros. As falas abaixo demonstram essa realidade.

...às vezes está checado o uso da placa de hidrocoloide, mas o paciente está sem a placa. A classificação da úlcera... pelo menos eu não encontrei (A1). 
Estava prescrito dieta bonitinho, só que o paciente não conseguia engolir a dieta... continuava comendo bolachinha, e não conseguia comer a dieta. único paciente que a gente viu que está anotado que tem úlcera de grau IV [que agora que eles viram] nossa apareceu uma úlcera de grau IV, eles foram lá e anotaram agora, mas já tinha que ter visto isto antes de evoluir para grau IV (A2).

...não há anotações relacionadas com o aspecto da úlcera, [ ] a gente não acha nada. Não tem nada escrito em relação a mudança de decúbito, mas está escrito realizado curativo em úlcera... ...não se fala o grau da úlcera. Ele já tava no grau I. Não tinha nada prescrito. Era difícil, porque a gente não achava nada (A3).

Não era nem feito, não tava prescrito (A4).

Foi meio decepcionante. A gente ia atrás o que estava sendo feito, às vezes estava checado, vai saber se estava fazendo de verdade. Escrever como estava a ferida, nada também. Nunca tinha nada registrado... (A5).

...às vezes está prescrito para relatar o aspecto da úlcera, mas mesmo assim não se escreve nada (A6).

...eu vi registrado: em estágio inicial, mas a úlcera não estava em estágio inicial (A8).

\subsubsection{Percebendo a necessidade de transformar a prática da enfermagem em relação à úlcera por pressão}

A partir da experiência de participar da coleta de dados da pesquisa, os estudantes verbalizaram a necessidade da realização de atividades de capacitação para os funcionários, fazer conscientização sobre a realidade, assistir o paciente de forma holística e ter materiais adequados como colchão especial para a prevenção da UP. As sugestões apresentadas pelos estudantes com o objetivo de transformar a prática da enfermagem em relação à prevenção da úlcera por pressão, ficaram evidentes nas falas a seguir.

Pelo menos ensinar avaliar os pacientes, utilizar a escala. ...achei muito frustrante, eu fiquei descontente com a enfermagem, tem tanta coisa que a gente podia fazer, mas parece que só tem a visão da perna machucada, do antibiótico, do remédio pra dor. [ ] a prescrição de enfermagem é pobríssima,[ ] a úlcera só falta atravessar o paciente de tão grande (A1). 
Ter uma capacitação, umas aulas, um curso igual ao que a gente teve. Eles já são formados..., depois passar para os funcionários o conhecimento... O colchão é uma boa. Devia colocar (o colchão) nos pacientes da enfermaria 11 que são mais críticos, são os que tem mais necessidade (A2).

...só na patologia (A4).

... a gente tem que ver o paciente como um todo, o psicológico e a úlcera (A6).

Mostrar para os enfermeiros que é possível não ter UP, porque tem lugares (instituições) que não têm (A7).

Mostrar as fotos que nós tiramos para eles se sensibilizarem e ficar consciente do que existe na Unidade, porque muitas vezes eles não sabem. Muita coisa é checada e não é feito. Até os próprios funcionários, conscientizá-los melhor. Será que eles não se colocam no lugar do paciente? (A8). 


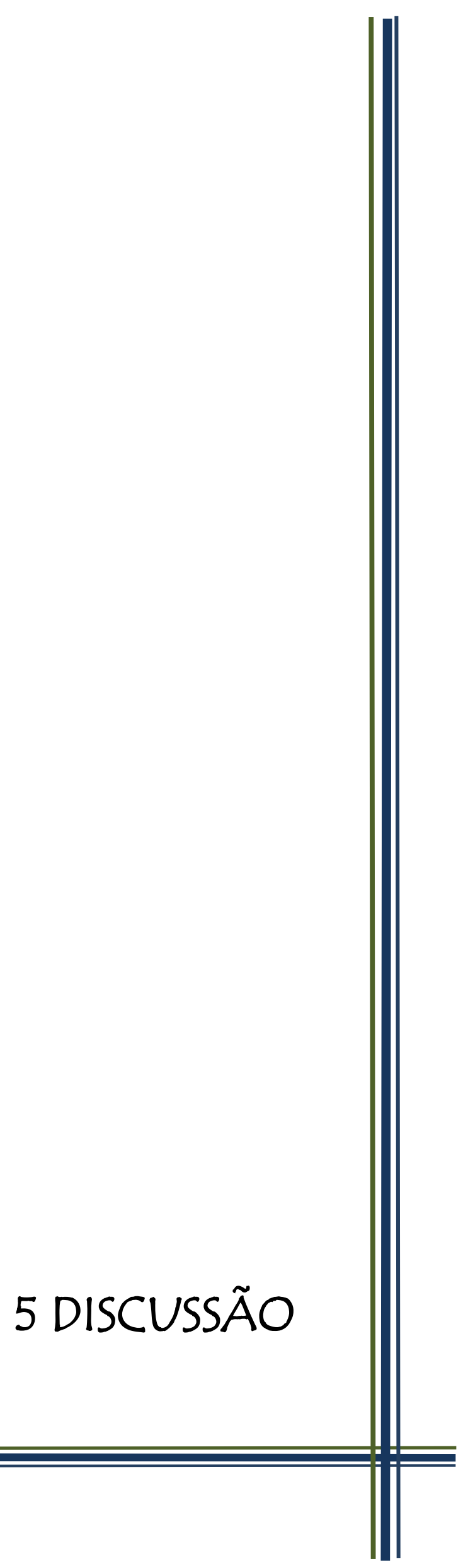


A discussão do estudo é apresentada considerando os objetivos propostos.

\subsection{Identificação do risco para úlcera por pressão e a ocorrência do problema}

Com relação à caracterização sociodemográfica dos pacientes, a faixa etária de maior frequência foi de 40-59 anos (42,86\%). Resultados semelhantes foram encontrados em estudo realizado para analisar os fatores de risco para o desenvolvimento de UP em pacientes internados em UTI com média de idade de 48,75 anos e uma frequência de $32,5 \%$, entre os pacientes com idade de 40 a 59 anos (SOUSA et al., 2013).

A idade é considerada fator intrínseco ao desenvolvimento de UP que, no entanto, não pode ser considerado isoladamente de outros fatores extrínsecos. As pessoas jovens e sadias normalmente apresentam características no tecido muscular e adiposo diferente das pessoas idosas, que apresentam redução de massa muscular e tecido subcutâneo. O processo de envelhecimento da pele predispõe o organismo a maior risco para a perda da integridade da pele, afetando todas as suas camadas. Com o avanço da idade, observa-se um declínio nas funções em relação à função de barreira, substituição de células, clearance químico, hidratação epidérmica, resposta imunológica, proteção mecânica, produção sebácea, percepção sensorial, produção de suor, termorregulação, produção de vitamina D e cicatrização (DOMANSKI; BORGES, 2012; WOLFF et al., 2011).

Com relação à cor da pele dos pacientes, verificou-se que a maioria era de cor branca $(66,7 \%)$, seguida da cor negra (19\%). Sabe-se que a estrutura da pele difere de acordo com a pigmentação, dando à pele vários tipos de coloração branca, parda, amarela e negra. Também é encontrada diferença estrutural no estrato córneo que, nos indivíduos de pele negra, é mais compacto, dando à pele maior resistência às agressões químicas, protegendo-a com maior efetividade dos estímulos externos. Dessa forma, a pele negra é mais resistente contra a friç̧ão e umidade, considerados fatores externos ao risco para o desenvolvimento de UP (MAKLEBUST; SIEGGREEN, 2001). 
Em indivíduos de pele clara as manifestações clínicas da UP são mais fáceis de serem reconhecidas. Na avaliação dos indivíduos de pele de cor escura, é mais difícil a identificação do estágio I da UP e a detecção das características que conduzem à suspeita de lesão tissular profunda pela presença na pele de manchas de coloração avermelhada, púrpura ou castanha (DOMANSKY, BORGES, 2012). De acordo com as recomendações da NPUAP/EPUAP (2009), deve-se usar recursos adicionais para a inspeção da pele de indivíduos com pele mais pigmentada como a avaliação do calor localizado, a presença de edema ou tumefação e da dor.

Considerando que as doenças do sistema osteomuscular e do tecido conjuntivo foram as mais frequentes $(42,86 \%)$ nos pacientes estudados e que os tratamentos mais comuns para as afecções ortopédicas restringem os pacientes ao leito por suas características peculiares, como a colocação de aparelho gessado, tração e fixadores externos, entende-se que o risco desses pacientes para a UP é maior, pois apresentavam limitações para a mobilidade e atividade.

Essa observação foi confirmada pela primeira avaliação dos pacientes quanto ao risco para o desenvolvimento de UP, onde a média da pontuação do escore total da Escala de Braden foi de 11,9, mostrando que, em geral, os pacientes apresentavam risco alto para UP. Dos 21 pacientes participantes da pesquisa, na primeira avaliação, $10(47,64)$ possuíam risco muito alto ou risco alto, isto é, escores menores que 12 e somente um (4,76\%) não tinha risco.

Pesquisa desenvolvida em Ribeirão Preto, SP, em 2007, com pacientes internados com fratura de quadril mostrou que todos apresentavam risco para UP, sendo que $6,7 \%$ possuía risco muito alto, $46,6 \%$ risco alto, $20 \%$ risco moderado e $26,7 \%$ baixo risco. A imobilidade também estava presente devido às condições clínicas dos pacientes, semelhante aos dados encontrados neste estudo (FAUSTINO, 2008).

Em um estudo com objetivo de estimar a incidência de UP em pacientes submetidos a cirurgias de médio e grande porte, em hospital privado, mostrou que as cirurgias ortopédicas foram as mais representativas (25\%) em 
relação às outras especialidades. Os pacientes participantes dos estudos encontravam-se com uma frequência maior na faixa etária de 40-59 anos, considerando o sexo masculino e feminino (SCARLATTI et al., 2011).

Estudo transversal, realizado por Menegon et al. (2012), em um hospital universitário no Sul do Brasil, em unidade médico-cirúrgica, teve o objetivo de identificar a pontuação da Escala de Braden e das subescalas em pacientes adultos hospitalizados com escore menor ou igual a 13 e associar os escores aos principais motivos de internação hospitalar, às comorbidades e às características demográficas. Foi identificado que $34,8 \%$ dos 187 pacientes, 65 (34,8\%) obtiveram 13 pontos na Escala de Braden, 35 (18,7\%) obtiveram 12 pontos e 32 (17,1\%) obtiveram 11 pontos. Não foi encontrada associação entre o escore total da Escala de Braden e sexo e idade dos pacientes e nem com as comorbidades ou com os motivos de internação. A maioria dos pacientes $(83,4 \%)$ estava acamada e com mobilidade física bastante limitada. Mais de 60\% tinha nutrição inadequada e 50\% tinha problema de friç̧ão/cisalhamento e percepção sensorial muito limitada. Quanto à umidade da pele, $44 \%$ apresentava a pele ocasionalmente molhada.

No estudo aqui conduzido, quanto aos subescores da Escala de Braden, na primeira avaliação, as menores médias foram encontradas nos domínios atividade e friç̧ão $(1,19)$, seguida do domínio mobilidade $(1,57)$. A maior média $(3,1)$ foi referente ao domínio percepção sensorial. Esses padrões também foram observados nas avaliações subsequentes, onde fricção e cisalhamento, atividade e mobilidade obtiveram as menores médias e a percepção sensorial a maior.

No estudo de Zambonato, Assis e Beghetto (2013) em adultos hospitalizados em unidades clínicas e cirúrgicas, com o objetivo de identificar quais alterações, na pontuação das subescalas de Braden, estão associadas com o risco do desenvolvimento de UP, foi identificado que apresentar alteração na percepção sensorial triplicou as chances para UP (OR=3,5; IC95\%: 1,5 - 8,2; $p<0,01)$.

Segundo os descritores para essas subescalas, os pacientes estavam geralmente confinados ao leito, não faziam mudanças na posição do corpo ou extremidades sem ajuda e requeriam de assistência moderada a máxima da 
equipe para a movimentação. Quanto à percepção sensorial, a avaliação é feita considerando a capacidade do paciente de reagir significativamente à pressão relacionada com o desconforto, o que permite que o indivíduo/paciente procure mudar de posição ou solicitar que outra pessoa o ajude nas mudanças do seu corpo. O escore 3 significa limitação sensorial leve, quando o indivíduo nem sempre é capaz de comunicar o desconforto ou expressar a necessidade de ser mudado de posição, ou quando apresenta um certo grau de deficiência sensorial que limita a sua capacidade de sentir dor ou desconforto.

Os escores totais e subescores da Escala de Braden auxiliam o enfermeiro no raciocínio clínico e na decisão das medidas que precisam ser prescritas e realizadas pela equipe de enfermagem para controlar esses fatores que interferem no manejo do excesso de pressão e influenciam a ocorrência da úlcera e da sua cicatrização. Assim a escala de avaliação do risco é uma ferramenta que deve ser incorporada na prática assistencial, conforme recomendado nas diretrizes internacionais e também com base nas evidências provenientes de estudos nacionais.

A elevada ocorrência de UP, identificada já na primeira avaliação em $13(61,9 \%)$ pacientes, confirmam que o problema ocorre na unidade de internação onde o estudo foi realizado. A localização das úlceras foi mais frequente na região sacral (44\%) e regiões do calcâneo (16\%), que são as regiões mais vulneráveis com os pacientes mantidos em posição dorsal.

Em outra pesquisa, realizada na mesma instituição do estudo, entre os meses de novembro de 2008 e janeiro de 2009, nas unidades masculina e feminina, os autores avaliaram a presença de úlcera em 36 pacientes com escore de Braden menor do que 13 e que apresentavam maior grau de dependência para os cuidados de enfermagem (graus 3 e 4, considerando uma classificação de 4 graus). Identificaram que 19 (52,7\%) pacientes apresentavam UP na primeira avaliação com maior frequência de lesões nos homens. Quanto à localização, a região sacral também foi a mais frequente (50\%), seguida da região trocantérica (FURMAN et al., 2010). 
Em outros estudos, nacionais e internacionais, a região sacral é apresentada como a região mais predisponente ao desenvolvimento de UP com a frequência variando de 21,6 a 71\% (AMIR, 2013; FAUSTINO, 2008; NOGUEIRA, 2005; ONIGBINDE; OGUNSANYA; ONIYANG, 2012; PINI, 2012; RIBAS, 2011; RICH, 2011; RINALDI, 2011; SIMÃO, 2010; URSI, 2010).

Para Pieper (2012), as regiões coccígea, sacral e calcâneas são as mais vulneráveis ao desenvolvimento da UP por apresentarem menos tecidos moles entre os ossos e a pele.

Quanto ao estadiamento das UPs na primeira avaliação, verificou-se o predomínio de lesões nos estágios I e II (64\%). No estudo já citado, que foi realizado na mesma instituição (FURMAN et al., 2010), a maior frequência também foi de úlceras em estágio III (37\%), seguidas do estágio I (27,7\%). Outros autores que avaliaram a prevalência da UP em hospitais de outras regiões do país também encontraram maior frequência de lesões em estágios I e II (RINALDI, 2012; ROGENSKI; SANTOS, 2006). Esse resultado indica que essas lesões, por estarem em estágios ou graus com menor comprometimento tissular e assim não envolverem camadas mais profundas como tecido subcutâneo, músculos e ossos, podem evoluir para regeneração com utilização das medidas para controle dos fatores de risco extrínsecos e terapia tópica adequada, intervenções essas do domínio do profissional de enfermagem.

\subsection{Exploração da relação entre a presença da úlcera e algumas variáveis demográficas e clínicas}

A UP está associada a diversos fatores que interferem na redução da tolerância da pele à pressão, podendo ser intrínsecos ou extrínsecos. A idade avançada é uma característica demográfica que frequentemente é apresentada nos estudos como associada ao aumento do risco para UP. Embora a UP afete indivíduos de todas as idades, os idosos (com idade acima de 65 anos, em países desenvolvidos, e acima de 60 , em países em desenvolvimento) são considerados de grande risco. Indivíduos com mais de 75 anos e com prejuízo na mobilidade e 
atividade têm o risco mais elevado (NATIONAL PRESSURE ULCER ADVISORY PANEL AND EUROPEAN PRESSURE ULCER ADVISORY PANEL, 2009).

Em alguns estudos nacionais realizados em unidades médicocirúrgica, cirúrgica, UTI, unidade de cuidados semi-intensivos e em Serviço de Atenção Básica de Saúde, foi observado que ser idoso foi considerado um fator de risco para UP (FERREIRA et al., 2012; PASSAMANI; BRANDÃO; PASSAMANI, 2012; ROGENSKI, SANTOS, 2006; SOUSA et al., 2013).

Neste estudo, não foi encontrada associação entre a presença de úlcera por pressão e a faixa etária. Esse resultado provavelmente ocorreu pela limitação do número de pacientes e pelo pequeno número de internados na faixa etária com mais de 60 anos. Também, em relação à cor, embora a presença de UP tenha sido mais frequente nos indivíduos de cor branca e amarela $(66,67 \%)$, não foi encontrada associação entre as duas variáveis. Entretanto, sob o ponto de vista clínico esse resultado merece reflexões, considerando as observações de autores no que tange à maior facilidade existente para detectar as características da UP em estágios I, em indivíduos de pele clara. Em outros estudos de ocorrência e prevalência de UP, em contextos de internação ou assistência domiciliar, a cor branca também foi a mais predominante nos indivíduos participantes (CHAYAMITI, 2008; NOGUEIRA, 2005; RIBAS 2011; RINALDI, 2012).

Em estudo realizado nos Estados Unidos, avaliou-se a validade preditiva da Escala de Braden para determinar os riscos para UP em idosos negros e latino/hispânicos e para identificar as variáveis associadas com a presença da lesão. Em amostra de 74 sujeitos em risco, a incidência de UP foi de $21 \%$ entre os negros e $11 \%$ em latino/hispânicos. Ainda, nesse estudo, a Escala de Braden foi altamente significativa para prever UP em negros com idade $\geq 75$ anos e não preditiva para negros e latino/hispânicos com menos de 74 anos. $O$ autor afirmou que a maior incidência de UP em indivíduos de pele negra se deve à dificuldade que os enfermeiros possuem em identificar as úlceras em estágio I nesses indivíduos, o que leva à detecção da lesão somente nos estágios subsequentes. Ressalta que os enfermeiros devem estar cientes sobre as questões que envolvem a raça e etnia no momento da avaliação da pele e que estudos futuros são necessários para 
compreensão dessas variáveis (LYDER et al.,1999).

Lyder e Ayello (2008) argumentam que, embora pesquisadores tenham encontrado que ser indivíduo da pele branca é um preditor da UP, o pequeno número de pessoas com pele negra na maior parte desses estudos, torna o resultado questionável. Enfatizam que os poucos estudos que incluíram número suficiente de pessoas com pele escura na análise identificou-se que os de raça negra têm UP em estágios mais avançados do que os não negros.

Essas observações dos autores citados evidenciam que, ao prestar os cuidados aos pacientes com cor de pele com mais pigmentação, a equipe de saúde, e de modo especial a equipe de enfermagem, deve estar atenta para esse fator, utilizando estratégias para uma avaliação eficaz desses pacientes.

Também, em relação às variáveis tempo de internação, tipo de saída e diagnóstico médico não foram encontradas associações com a presença de UP.

Quanto à variável diagnóstico médico, resultado semelhante foi também encontrado na pesquisa de Rinaldi (2012) que apresentou como, objetivo verificar a prevalência e os fatores de risco para úlcera por pressão em um hospital no interior do Paraná, caracterizar o perfil sociodemográfico dos pacientes internados na instituição em estudo e descrever as características clínicas das úlceras por pressão. O estudo foi desenvolvido em unidades de internação com atendimento a diversas especialidades médicas e de alta complexidade. Como resultados foram apresentados que os antecedentes clínicos por sistema não apresentaram correlação e somente quando o diagnóstico insuficiência renal crônica foi analisado, de forma isolada, é que foi demonstrada relação com a ocorrência de UP $(p=0,035)$.

Diferente resultado foi encontrado no estudo de Ribas (2011) que teve como objetivo verificar a prevalência e os fatores de risco para a presença de UP em um hospital de ensino de Curitiba, caracterizar o perfil sociodemográfico dos pacientes acometidos por UP; explorar relação entre variáveis sociodemográficas e clínicas e a ocorrência de UPs; avaliar as características clínicas das UP e sua classificação. Trata-se de estudo epidemiológico, observacional, de delineamento 
transversal. A amostra foi constituída por pacientes atendidos em unidades de internação com atendimento clínico e cirúrgico (adulto e pediátrico), materno infantil e transplante de medula óssea e que apresentaram UP. O estudo identificou relação significativa $(p<0,001)$ entre as doenças dos sistemas imunorreumatológico e nervoso e a presença de UP.

Outro achado desse estudo, onde não foi encontrada a associação esperada entre o escore total da Escala de Braden na primeira avaliação dos pacientes e a presença de UP, poderia ser explicado pelo número limitado de pacientes participantes da pesquisa e pela condição do paciente no momento da avaliação que poderia não ser a mesma do momento do início da UP, já que muitos estavam internados por vários dias antes do início da pesquisa. Entretanto, o resultado encontrado tem significância clínica para a prática de enfermagem, pois quando se observa a distribuição dos pacientes por nível de risco, identifica-se que, à medida que diminuem os escores obtidos na Escala de Braden e aumentam os níveis de risco, houve aumento da percentagem de pacientes com presença de UP.

Esse resultado também foi obtido no estudo realizado em 2008, em um hospital universitário de Minas Gerais com coleta de dados feitas em um só dia com os 16 pacientes internados em unidade de médico-cirúrgica para identificar o risco para o desenvolvimento de UP, a prevalência e classificação das úlceras, quanto à localização e estadiamento. Os pacientes foram avaliados pela Escala de Braden e pela inspeção da pele. Identificou-se que 12 (74,9\%) não estavam em risco e 4 tinham risco elevado ou muito elevado. Os principais fatores relacionados ao risco foram a limitação na percepção sensorial, estar acamado e completamente imobilizado e requerer assistência moderada a máxima para mover-se (e evitar a fricção e cisalhamento). Dos quatro pacientes em risco, três apresentavam úlcera por pressão com total de 17 lesões, sendo 10 no estágio IV (58,9\%), 4 do estágio II $(23,5 \%)$ e 3 em estágio I. A localização anatômica de maior frequência foi a região trocantérica (23,5\%), seguida das regiões sacral e calcânea (17,6\%) e escápula e maléolo (11,8\%). Os autores concluíram que a avaliação de risco com a Escala de Braden é uma ferramenta eficaz para a prevenção de UP, sendo esse instrumento importante para nortear as ações de enfermagem, no que diz respeito ao uso adequado e racional das medidas preventivas, à redução do tempo de internação 
hospitalar e dos custos com o tratamento e, sobretudo, do sofrimento dos pacientes (SALES; BORGES; DONOSO, 2010).

Estudo de revisão sistemática, desenvolvido por Coleman et al. (2013) esclarece alguns aspectos da influência dos fatores de risco na gênese da UP. Utilizaram métodos rigorosos, recomendados pela Colaboração Cochrane, para investigar os fatores de risco que são independentemente preditivos para 0 desenvolvimento da UP em pacientes adultos, em diferentes contextos do cuidado.

Os autores enfatizaram que não há um fator único isolado que possa explicar o risco para UP, mas, sim, uma complexa interação de fatores que aumentam a probabilidade do desenvolvimento da lesão. Destacaram que a redução da atividade/mobilidade foram considerados os fatores-chaves. A diminuição da perfusão (incluindo o diagnóstico de diabetes) também foi considerada fator importante. Outro fator onde uma forte associação foi encontrada foi referente às condições de alterações da pele (úlcera de estágio I, presença da UP e história prévia de UP). Os autores concluíram que os resultados da revisão foram consistentes com os conceitos teóricos que explicam a etiologia da UP. Outros fatores como umidade da pele, idade, componentes hematológicos (como albumina, proteína, hemoglobina), nutrição e condição geral de saúde também apareceram como importantes, mas não no mesmo nível que a atividade/mobilidade; diminuição da perfusão e alterações da pele.

\subsection{Registro das evidências para a prevenção da úlcera por pressão pelos enfermeiros nas prescrições de enfermagem}

Uma das principais intervenções para a prevenção da UP e uma questão básica na avaliação dos pacientes para o planejamento do cuidado é a identificação do risco e os fatores que os colocam em risco. A avaliação do risco é considerada componente central da prática clínica, pois permite a identificação de pacientes suscetíveis e o planejamento de intervenções apropriadas para o controle do risco (NATIONAL PRESSURE ULCER ADVISORY PANEL AND EUROPEAN PRESSURE ULCER ADVISORY PANEL 2009). A recomendação da Diretriz da 
NPUAP/EPUAP (2009) enfatiza que cada serviço de saúde deve ter uma política estabelecida que inclua recomendações claras para o uso de abordagem estruturada para a avaliação do risco, o momento em que deve ser feita a avaliação e a reavaliação, a documentação da avaliação e a comunicação dessa informação para toda a equipe de saúde. Os pacientes que já apresentam a úlcera também devem ser avaliados, pois, geralmente, continuam em risco para novas úlceras e necessitam de intervenções para controle dos fatores que também interferem na resolução das lesões presentes.

Nessa pesquisa não foi identificado o registro do uso da Escala de Braden pelos enfermeiros, em nenhum dos prontuários dos pacientes participantes, em qualquer dia da avaliação. Outro estudo realizado na mesma instituição e publicado em 2002 mostrou os resultados do uso de um protocolo para prevenção de UP nos pacientes críticos na UTI e citou o uso da Escala de Braden, destacando que a escala possibilitou fazer com segurança o diagnóstico do paciente com risco para desenvolver úlcera por pressão (BARROS et al., 2002).

Simão, em estudo realizado em 2009, com 346 pacientes internados em quatro UTIs de um hospital universitário do Estado de São Paulo, identificou que os enfermeiros realizavam a avaliação de risco dos pacientes diariamente usando a Escala de Braden, pois essa informação fazia parte dos dados do Programa Compromisso com a Qualidade Hospitalar (CQH). No entanto, a informação era encaminhada para a coordenação do programa $\mathrm{CQH}$ e não era registrada em nenhum dos prontuários, o que significa que não era utilizada para o planejamento da assistência aos pacientes.

Bergstrom (2008) afirma que, embora a meta do uso da Escala de Braden seja identificar os pacientes em risco e auxiliar no planejamento de ações efetivas de prevenção, muitas vezes nas instituições não existe a preocupação com a diminuição da ocorrência da UP, mas, sim, em atender os requerimentos dos programas de qualidade que incluem o uso desse instrumento. Destaca que outros fatores sistêmicos para o não uso incluem falhas na educação do estudante e a capacitação do enfermeiro para o uso e também o número inadequado de enfermeiros para fazer a avaliação do paciente. Aponta, ainda, que o uso de versões 
simplificadas da escala como parte do prontuário do paciente, contendo somente o subtítulo dos domínios da subescala sem incluir os descritores, dificulta a identificação do problema do paciente e o planejamento do cuidado, assim a informação obtida não é considerada fidedigna.

Também no registro das condições de integridade da pele foram identificadas falhas na documentação. $O$ fato de que em nenhum prontuário foi encontrado o registro da informação da classificação (estágio/grau) da UP aponta para a necessidade de investigações que identifiquem os motivos da falta de registro, de modo que medidas educativas possam ser promovidas. A recomendação da Diretriz da NPUAP/EPUAP (2009) enfatiza que os profissionais precisam ser educados sobre o uso apropriado do sistema de classificação e a aparência dos diferentes tipos de tecidos presentes na lesão. Na Diretriz é destacado que a capacitação pode ser feita pelo uso de fotografias, aulas expositivas formais ou usando o computador e que o reconhecimento dos diferentes tipos de tecidos presentes na lesão geralmente requer treinamento além do ensino formal básico da graduação. Ressalta, ainda, que nos programas de formação de todos os profissionais de saúde deveria ser avaliada a necessidade de melhorias na educação dos estudantes para a prevenção, classificação e tratamento das UPs (NATIONAL PRESSURE ULCER ADVISORY PANEL AND EUROPEAN PRESSURE ULCER DIVISORY PANEL, 2009).

Esses resultados encontrados são análogos aos apresentados por Thoroddsen et al. (2013) que investigaram a acurácia, exatidão e abrangência das informações sobre UPs documentadas nos prontuários de pacientes $(n=45)$ em um hospital universitário da Islândia. Dos 45 prontuários de pacientes identificados com UP somente 27 (60\%) tinham registros com informações sobre as UPs e os registros foram feitos na sua maioria por enfermeiros $(60 \%)$ e somente sete $(16 \%)$ por médicos. Os aspectos documentados com maior frequência estavam relacionados aos sinais e sintomas (42\%), diagnóstico de enfermagem (44\%) e prescrição das medidas preventivas (42\%). Os autores concluíram que, pelos resultados do estudo, os objetivos da documentação em registrar, estabelecer uma comunicação e dar suporte para apoiar a continuidade de informações nos registros em prontuário dos pacientes não foram alcançados e que isso compromete a segurança do paciente, a 
continuidade e a qualidade do cuidado.

Bergstrom (2008) assevera que lapsos na acuracidade da documentação relacionada ao cuidado e aos seus resultados, diminui a integridade profissional e obscurece o valor da prática dos profissionais de enfermagem.

A prescrição de enfermagem para pacientes em risco ou com UPs precisa enfatizar os cuidados que controlem os fatores relacionados à ocorrência do problema para que novas úlceras sejam evitadas e as lesões presentes possam cicatrizar. Esses cuidados são apresentados na Diretriz da NPUAP/EPUAP (2009) como recomendações e incluem: cuidado da pele, suporte nutricional, medidas para reposicionamento corporal e uso de superfícies de suporte para redistribuição da pressão (NATIONAL PRESSURE ULCER ADVISORY PANEL AND EUROPEAN PRESSURE ULCER DIVISORY PANEL, 2009).

Neste estudo, na busca pelas prescrições de enfermagem nos prontuários, considerando algumas das intervenções preconizadas nas diretrizes como essenciais no manejo dos pacientes em risco, identificou-se que as ações prescritas com maior frequência foram a mudança de decúbito, proteção da pele, da incontinência e hidratação da pele. O uso de coxins, suplemento nutricional, curativo/cobertura, obtiveram maior frequência de prescrições somente para os pacientes que tiveram mais do que 11 avaliações, ou seja, estavam há mais tempo na unidade.

Outras medidas de prevenção que são recomendadas nas diretrizes, como a manutenção da cabeceira elevada até $30^{\circ}$ e uso de colchão especial, obtiveram poucas prescrições (variação de 0 a $25 \%$ ).

Outros estudos também identificaram que a mudança de decúbito tem sido a ação realizada e documentada com maior frequência para pacientes em risco ou com UP em hospitais (NOGUEIRA, 2005; STEIN et al., 2012).

O reposicionamento do paciente com a mudança de decúbito, em períodos de 2 a 3 horas, alivia a pressão existente em determinada área. Moore, Cowman e Posnett (2013) compararam a incidência de UP e o custo do tempo gasto 
pelo enfermeiro em dois tipos de reposicionamento do paciente no leito, e avaliaram a relação custo-benefício. Os pacientes participantes do estudo foram randomizados e alocados em um grupo experimental, com reposicionamento a cada 3 horas, com rotação lateral a $30^{\circ}$, e em grupo controle com reposicionamento a cada 6 horas, usando rotação lateral de $90^{\circ}$. Os resultados demonstraram que o reposicionamento a cada 3 horas com $30^{\circ}$ mostrou ser mais efetivo na redução da incidência de UP e com menos custo no tempo gasto pela enfermagem. Esses achados vêm ao encontro das recomendações das diretrizes da NPUAP/EPUAP (2009), no que tange à realização dos cuidados de enfermagem no reposicionamento do paciente para a prevenção de UP, implicando, também, menores custos com o paciente hospitalizado.

Em estudo já citado, realizado na UTI, na instituição desta pesquisa, foi aplicado protocolo para prevenção de UP em 29 pacientes considerados de risco, admitidos sem a presença de UP. O protocolo foi elaborado pelos enfermeiros do setor, utilizando as recomendações da Diretriz da Agency for Health Care Policy and Research (AHCPR) (FERNANDES, 2006). Os resultados evidenciaram que 17 (59\%) pacientes não apresentaram alterações na pele e 12 (41\%) apresentaram alteração, apesar de serem avaliados, diariamente, pelo protocolo de prevenção. Os autores concluíram que a aplicação do protocolo proporcionou cuidado individualizado para cada paciente, promoveu resolutividade em relação à UP e a equipe de enfermagem se mostrou mais atenta aos cuidados de prevenção prescritos (BARROS, 2002).

Barker et al. (2013) realizaram estudo visando determinar se, com a implementação de programa de prevenção de UP baseado em evidências, havia redução na ocorrência de UP adquirida no hospital e se as práticas recomendadas pelas diretrizes estavam sendo implementadas nos cuidados diários dos pacientes de um hospital, na Austrália. Os autores constataram que houve redução na prevalência da UP de 12,6 para 2,6\% e grande adesão na avaliação de risco e nas intervenções prescritas pelos enfermeiros, sugerindo que esses resultados são reflexo de uma prática fundamentada nas recomendações das diretrizes.

Espera-se que as prescrições de enfermagem, em relação às 
recomendações para prevenção da UP, sejam elaboradas considerando a avaliação do risco, o que não foi constatado neste estudo. A prescrição de enfermagem permite que todos os membros da equipe de saúde e de enfermagem tenham ciência das decisões relacionadas ao cuidado, realizem as ações e possam observar os resultados obtidos por cada um dos pacientes internados.

A SAE nos cuidados com a úlcera por pressão envolve o comprometimento do enfermeiro em realizar as etapas que compõem o PE. Dessa forma, a primeira etapa compreendida pelo histórico de enfermagem ou investigação é o momento em que são coletadas informações sobre o paciente, seguida do diagnóstico de enfermagem em que é feito o julgamento clínico sobre os dados da investigação. Identificado o diagnóstico de enfermagem, o enfermeiro faz o planejamento decidindo quais são os problemas prioritários, quais são as metas do cuidado e as intervenções. A quarta etapa refere-se à implementação do cuidado planejado e sua documentação. A última etapa consiste em avaliar se as intervenções atingiram os resultados esperados (CARPENITO-MOYET, 2007).

Em um hospital universitário do Sul do Brasil, enfermeiras utilizam o PE como metodologia norteadora da assistência nos cuidados para a prevenção e tratamento da UP. Dessa forma, na coleta de dados do paciente, é usada a Escala de Braden no auxílio para identificação do risco da UP, como subsídios para a realização do diagnóstico de enfermagem, planejamento e prescrição das intervenções, de acordo com o Protocolo Assistencial de Prevenção e Tratamento de Úlcera por Pressão (SANTOS et al., 2013).

O PE também foi o condutor na pesquisa de Bavaresco (2012) quando afirma que a organização da assistência de enfermagem possibilita ao enfermeiro diagnosticar uma situação de risco, prescrever e executar intervenções adequadas. Com o objetivo de validar as intervenções de enfermagem NIC Classificação das Intervenções de Enfermagem - para o diagnóstico Risco de Integridade da Pele Prejudicada em pacientes em risco de UP, essa autora validou nove intervenções e 73 atividades de enfermagem. As intervenções, denominadas prioritárias e validadas foram: prevenção de úlceras de pressão, controle da pressão, supervisão da pele, banho, cuidados da pele: tratamentos tópicos, 
monitorização de sinais vitais, cuidados na incontinência urinária, posicionamento e terapia nutricional. As implicações dessa pesquisa são de grande importância, uma vez que as intervenções validadas são fundamentais no cuidado com o paciente em risco para UP.

Os estudos de Bavaresco (2012) confirmam os pressupostos de Magnan e Maklebust (2009) que argumentam que enfermeiros não podem obter progresso na prevenção da UP se não houver uma junção e uma conexão entre a avaliação de risco, planejamento da prevenção, uso das intervenções e avaliação dos resultados. Essas atividades, ou seja, as fases que compõem o PE não devem ser realizadas de forma isolada e distinta, porque uma fase se sobrepõe a outra.

Esses mesmos autores mostram a importância e a maneira de como gerenciar os cuidados de enfermagem a pacientes com a UP por meio do PE, recomendando e orientando como realizar a ligação entre a avaliação-diagnósticoplanejamento-implementação-avaliação/evolução. Destacam que primeiramente deve-se realizar uma avaliação de risco com acurácia. Na sequência, usar os resultados obtidos pela Escala de Braden para direcionar a identificação dos diagnósticos de enfermagem e planejar as intervenções de prevenção. O terceiro passo seria a implementação das intervenções para atingir objetivos e resultados centrados no paciente e, como etapa final do PE, a avaliação/evolução deverá identificar se esses resultados foram alcançados.

Essa conexão não foi evidenciada no estudo de Fossum et al. (2011) que exploraram qualitativamente o raciocínio clínico e as estratégias aplicadas pelos enfermeiros durante uma simulação para o planejamento dos cuidados a pacientes idosos institucionalizados, referente à nutrição e à UP. Identificaram que, embora os enfermeiros $(n=30)$ tenham usado uma variedade de estratégias, nenhum elaborou de forma estruturada uma avaliação de risco e que a maioria iniciava o raciocínio clínico pelo planejamento das intervenções. O que foi observado é que havia lacuna nas fases do PE.

$\mathrm{Na}$ instituição onde esta pesquisa foi realizada, a Metodologia da Assistência de Enfermagem foi implantada na década de 80 e, desde então, 
esforços têm sido realizados na concretização do PE (SENTONE, 2005). Os trabalhos foram desde a criação de um grupo de estudo com o objetivo de refletir sobre a prática assistencial e a elaboração de normas para o aperfeiçoamento da elaboração da metodologia da assistência até a implantação da prescrição de enfermagem eletrônica. A prescrição de enfermagem é fundamentada em protocolos de assistência, subsidiados nas necessidades humanas básicas (VITURI, 2013).

Entretanto, o que se observa atualmente é que os enfermeiros elaboram a prescrição de enfermagem através das necessidades humanas básicas identificadas por meio do exame físico realizado nos pacientes. Não é feito um julgamento clínico mais acurado sobre quais as medidas preventivas para UP, uma vez que também não é realizada uma avaliação de risco com instrumentos apropriados como, por exemplo, a Escala de Braden. Provavelmente essa lacuna foi um dos fatores responsáveis pelos resultados desta pesquisa que mostraram prescrições de enfermagem com poucas medidas preventivas para UP.

Estudo de Vituri (2013), que teve como objetivo testar a confiabilidade interavaliadores de indicadores de qualidade e utilizá-los na avaliação da assistência de enfermagem mostrou que o desempenho da equipe de enfermagem, em relação aos registros das ações de cuidados, estava comprometida. O estudo foi realizado no HUL, em unidades de internação médicocirúrgicas, sendo que uma dessas unidades também compôs o local de estudo da presente pesquisa.

Os resultados do estudo mostram que a ocorrência de úlceras por pressão é alta, sendo imprescindível a ação da enfermagem nas medidas preventivas através da implantação e implementação de protocolos/programas que visem a adoção de medidas preventivas, por meio de uma avaliação criteriosa na identificação dos fatores de risco. Essas práticas são importantes uma vez que os custos econômicos com o tratamento da UP são onerosos e, consequentemente, refletem também em custos elevados nos aspectos sociais e emocionais dos pacientes e de seus familiares.

Com relação à associação entre a prescrição da medida de prevenção pelos enfermeiros e a condição da pele ou aparência das UPs dos 
pacientes, considerando a classificação em estágio/grau, observou-se que houve uma associação com significância estatística $(p$-valor $<0,05)$ para o uso do curativo em úlceras de maior profundidade, isto é, em estágio III, IV e não classificável. Conclui-se que as coberturas eram utilizadas para tratamento da úlcera. Entretanto dentre as recomendações para a prevenção da UP um aspecto enfatizado é o uso de coberturas de hidrocoloide (fino) ou filme de poliuretano para proteção da pele quanto a fricção.

Com relação à associação entre a prescrição das medidas de prevenção e os fatores de risco avaliados pela Escala de Braden em suas subescalas, não foi encontrada nenhuma associação. Do ponto de vista clínico observa-se que muitos pacientes não tiveram prescrições de enfermagem que seriam necessárias considerando o fator de risco presente, avaliado na subescala. Essas informações poderão ser utilizadas na instituição para avaliação das ações dos enfermeiros e a decisão pela adoção da Escala de Braden como instrumento para auxiliar no raciocínio clínico que norteia a seleção das medidas prescritas para prevenção.

Não foram encontrados na literatura estudos cujas metodologias permitissem comparações de associações entre as medidas preventivas com os subescores da Escala de Braden. Alguns estudos são relatados referentes ao uso de protocolos na prevenção de UP e intervenções registradas pelo enfermeiro (NOGUEIRA, 2005; VANDENKERKHOF, 2011; SWANSON, 2011; PETERSON, 2013; ARMOUR-BURTON, 2013).

Entretanto, foram encontrados estudos que abrangiam parcialmente o uso das medidas preventivas, como evidenciado no estudo de Moore e Cowman (2011) que teve como objetivo estabelecer a prevalência da UP e a prevenção em idosos institucionalizados. Esse estudo mostrou que houve uma associação estatisticamente significante entre os escores da atividade e mobilidade e o uso de dispositivos de redistribuição da pressão em pacientes acamados. Os dados foram coletados em 12 instituições situadas na região urbana e rural da República Irlandesa, em 1.100 pacientes.

Ressalta-se que os resultados apresentados referentes aos objetivos 2.2.1 e 2.2.2 demonstram que a participação dos estudantes na coleta de dados da 
pesquisa permitiu a experiência de identificar o perfil dos pacientes em risco para a UP e conhecer a ocorrência do problema da unidade de internação. Também apontam que os estudantes puderam identificar aspectos da prevenção da UP que estão sendo realizados pelos profissionais da instituição e aspectos que precisam ser implementados para que a prática seja baseada em evidências.

\subsection{Significado da experiência dos estudantes da $2^{\text {a }}$ série do curso de enfermagem da UEL referente à metodologia de ensino proposta}

\section{Primeira categoria - Aprendendo sobre o tema úlcera por pressão}

Esta categoria mostra as visões dos estudantes sobre o processo de aprendizagem acerca do tema UP nos momentos teóricos e práticos, desenvolvidos em sala de aula e nas enfermarias da Unidade Masculina, ou seja, o quão importante foi participar do workshop da PBE proposto nesta pesquisa.

A primeira subcategoria "correlacionando a teoria com a prática" expressou a satisfação apresentada pelos estudantes em realizar a conexão da teoria e da prática. A relação teoria e prática deve ser trabalhada simultaneamente e constitui uma unidade indissolúvel, onde a prática não é simplesmente a aplicação da teoria, mas constitui-se no ponto de partida e no ponto de chegada. A teoria é formulada a partir das necessidades concretas da realidade à qual se pretende responder (DELLAROZA; VANUCHI, 2005). Essa relação constitui-se em um dos princípios do $\mathrm{Cl}$ do Curso de Enfermagem da UEL, porém, percebe-se, pela fala dos estudantes, que conseguiram correlacionar a teoria somente após o workshop da PBE.

A lacuna entre a teoria e a prática é amplamente documentada e relatada na literatura sobre o ensino e a prática profissional da enfermagem. Embora diferentes soluções têm sido propostas para romper essa lacuna, ainda parece não haver uma resposta simples para resolver esse problema (HATLEVIK, 2012). 
teoria e prática. No estudo de Mira et al. (2011), com o objetivo de avaliar, sob a óptica dos estudantes do $8^{\circ}$ semestre de graduação, o ensino prático do curso de graduação de enfermagem da Escola de Enfermagem da Universidade de São Paulo desenvolvido no Hospital Universitário, mostrou que os estudantes conseguiram relacionar a teoria e a prática durante os estágios, contribuindo para a formação de um enfermeiro crítico e reflexivo.

Santos (2012), quando analisou o ensino da temática feridas, no curso de graduação em enfermagem da UFPB (Universidade Federal da Paraíba), mostrou que nos relatos dos docentes há facilidade em estabelecer a relação entre teoria e prática, por meio de metodologias ativas, como a problematização, proporcionando integração entre o ensino e a realidade.

Resultado semelhante foi encontrado no estudo de Salomé e Espósito (2008) que objetivou compreender e apreender os sentimentos vivenciados pelos acadêmicos do curso de enfermagem quando realizava curativos, durante 0 estágio curricular e extracurricular de um hospital. Os resultados apresentados na categoria "dificuldades dos acadêmicos de enfermagem para associar a teoria à prática" identificaram, entre os estudantes participantes do estudo, que houve dificuldades de atuação no campo de estágio para articular a prática à teoria aprendida na sala de aula. De acordo com o autor, a dissociação entre teoria e prática e entre ensinar e cuidar é algo que prejudica, desfavorece e dificulta o processo de ensino-aprendizagem.

Preocupados com a lacuna existente entre a teoria e a prática, Swardt; Toi; Botha (2012) desenvolveram pesquisa qualitativa com o objetivo de estabelecer a influência de um guia de reflexão com os estudantes de enfermagem em cuidados intensivos. O guia de reflexão é uma forma de reflexão estruturada que ocorre entre facilitadores e profissionais ou estudantes, com o objetivo de estimular o raciocínio e reflexão crítica. Participaram desse estudo 7 estudantes de enfermagem em cuidados intensivos, alocados em hospital privado em Gauteng, Província da África do Sul. A coleta de dados foi realizada por meio de entrevista em que o estudante escolhia um incidente que considerava complexo e que tivesse sido vivenciado com paciente crítico. Os principais temas que emergiram dessa coleta 
foram: descrição do incidente vivenciado, análise crítica do conhecimento, análise crítica dos sentimentos e mudanças de pensamento em vários aspectos. Nesse estudo, os autores relataram que, quando aplicado o guia de reflexão, houve integração da teoria com a prática e que resultou em perspectiva transformadora no aprendizado e na prática clínica.

$\mathrm{Na}$ segunda subcategoria "o despertar para as competências da enfermagem na avaliação do paciente com risco para UP", ficou evidente que os estudantes identificaram como sendo competência do enfermeiro a avaliação dos pacientes com desenvolvimento para UP.

Reforça-se que competência é um conjunto de conhecimentos, habilidades e atitudes que resulta em uma aplicação prática - saber, saber fazer e saber ser. $\mathrm{O}$ conjunto de saberes constitui em saberes teóricos necessários para a compreensão do objeto a ser cuidado, baseado em evidências e com o propósito de consolidar as melhores práticas na assistência ao ser humano. $O$ saber fazer referese à implementação por meio de procedimentos e protocolos validados e direcionados para as "boas práticas". O saber ser caracteriza-se pelos comportamentos individuais e de grupos, fundamentados por princípios da bioética (BALSANELLI et al., 2008).

A formação acadêmica do enfermeiro, a qualidade da educação, o conhecimento adquirido e uma prática baseada nas melhores evidências refletem significativamente sobre a assistência de enfermagem com qualidade.

Foi identificado no estudo de Chianca et al. (2010) que os enfermeiros apresentaram déficit de conhecimento acerca da prevenção de UP e os princípios da avaliação (identificação dos estágios), especialmente entre os enfermeiros que possuíam maior tempo de experiência profissional. O estudo foi realizado com 106 enfermeiros de um hospital universitário em Belo Horizonte, que aplicou o teste de conhecimento.

No estudo de Fernandes (2006) onde a autora pesquisou os efeitos de intervenções educativas no conhecimento e práticas de profissionais de enfermagem e na incidência de UP em Centro de Terapia Intensiva, verificou-se que 
quando aplicou um questionário para os enfermeiros sobre o conhecimento no tema úlcera por pressão houve índice de acertos de 12\%, referente ao posicionamento do paciente em cadeira de rodas, considerado um percentual baixíssimo, indicando déficit significativo de conhecimento. Também outras questões apresentaram baixos índices de acertos referentes à inspeção sistemática da pele, à massagem em proeminências ósseas, ao uso de protetores para a pele, ao reposicionamento do paciente, ao uso da luva d'água, ao uso de almofadas do tipo argolas, ao grau de elevação da cabeceira da cama e à definição de cisalhamento.

De acordo com Miyasaki (2009), quando aplicou um teste de conhecimento para mensurar o nível de conhecimento entre profissionais de enfermagem sobre as recomendações para a prevenção de UP, verificou-se que os enfermeiros apresentaram média de acertos de $79,4 \%$, o que foi considerado índice insuficiente.

Faustino et. al. (2010) identificaram o conhecimento de enfermeiros que atuam em hospital público no Distrito Federal, sobre os novos descritores na classificação da UP. Os resultados apontaram que somente $7 \%$, dos 30 participantes do estudo, tinham conhecimento sobre a nova nomenclatura dos estágios de UP - de acordo com a NPUAP/EPUAP (2009) e 52\% ainda usavam a nomenclatura anterior. Ainda mostraram que os enfermeiros conseguiram identificar corretamente o estágio I da UP. Os autores concluíram que os enfermeiros estão desatualizados em relação aos estágios de UP e que os mesmos devem ser encorajados a buscar atualização sobre o tema.

Outros resultados foram encontrados no estudo de Strand e Lindgren (2010) que investigaram entre enfermeiros, atitudes, conhecimento, oportunidade e obstáculos percebidos em relação à prevenção de UP em Unidade de Cuidados Intensivos, em um hospital da Suécia. Os enfermeiros ( $n=144)$ foram convidados a responder um questionário com perguntas abertas e fechadas. Em relação aos fatores de risco, não foi observado déficit de conhecimento, somente alguns enfermeiros não responderam à questão que tratava da força de cisalhamento, níveis baixos e elevados de albumina. O nível de conhecimento foi considerado bom. $\mathrm{Na}$ abordagem das medidas preventivas, o alívio da pressão 
esteve presente em 97,3\% na resposta dos enfermeiros e apenas 2,8\% na avaliação de risco. Quando questionados sobre a identificação dos estágios de UP, 46,8\% ( $n=139)$ dos enfermeiros apresentaram uma resposta correta. Os autores concluíram que, nesse estudo, foram apresentados os aspectos relevantes para facilitar as medidas preventivas e que o aumento do conhecimento entre os enfermeiros contribuirá de forma significativa para atingir tais resultados, ou seja, a realização de medidas preventivas de UP.

Pancorbo-Hidalgo (2007) realizou estudo com enfermeiros da Espanha para avaliar o nível de conhecimento das diretrizes sobre prevenção e tratamento de UPs, as implementações das diretrizes na prática clínica e os fatores profissional e educacional que influenciam o conhecimento e a prática. Identificou que, em relação às medidas preventivas, um grupo de medidas foi considerada apropriada em pelos menos $75 \%$ dos enfermeiros: avaliação nutricional, aplicações tópicas de produtos que protegem a pele, educação com os familiares dos pacientes sobre os cuidados com UP e reposicionamento do paciente, tanto em cadeira como no leito. Entretanto, verificaram que alguns profissionais consideraram correto intervenções não recomendadas pelas diretrizes como a aplicação tópica de produtos à base de álcool, uso de almofadas do tipo argola e massagem em proeminência óssea hiperemiada. Os autores afirmaram que, apesar das recomendações nos cuidados com UP, encontradas nas diretrizes, sejam conhecidas pelos enfermeiros, ainda há um grupo de intervenções que são de conhecimento insuficiente pelos mesmos e também com baixos índices de implementação.

Em estudo, Joseph e Clifton (2013), sobre o conhecimento da avaliação de risco de UP entre enfermeiros, os autores utilizaram a revisão de literatura com pesquisa em base de dados como o CINAHL, OVID, British Nursing Index e outras fontes da internet, de publicações no período de 1995 a 2011 . Os resultados encontrados nos artigos analisados permitiu concluir que a avaliação de risco é importante, tanto na prevenção como no tratamento de UP, mas que são necessárias pesquisas do tipo ensaio clínico randomizado para identificar a conexão entre escalas de avaliação de risco e redução de incidência de UP. A revisão da literatura identificou que os enfermeiros podem utilizar escalas de avaliação de risco 
para o mesmo paciente de diferentes formas e que a interpretação pode ser subjetiva, levando a problemas de consistência dos cuidados. Isso indica a necessidade de educar os profissionais de saúde sobre os fatores de risco envolvidos no desenvolvimento de UP para aprimorar o conhecimento. O autor afirma que as medidas preventivas no desenvolvimento de UP envolvem a combinação de conhecimento do enfermeiro, avaliação clínica do paciente e avaliação de risco através de escalas.

Os resultados dos estudos anteriormente citados mostraram que 0 déficit de conhecimento, entre os enfermeiros, sobre a fundamentação teórica no tema UP, é um problema nacional e internacional. Infere-se que esse déficit também foi uma das observações realizadas pelos estudantes da presente pesquisa, ao constatarem a precariedade das prescrições de enfermagem relacionadas à prevenção e à avaliação de risco para UP.

Em relação às subcategorias "aprimorando o conhecimento nos estágios da UP", "aprimorando o conhecimento sobre os fatores de risco da UP" e "a Escala de Braden como suporte para avaliação de risco da UP”, os estudantes revelaram ser de fundamental importância o workshop recebido sobre a PBE para consolidar o aprendizado sobre UP.

A prática baseada em evidência tem se mostrado como um dos mais importantes princípios norteadores nos cuidados com a saúde e, por consequência, em melhora na assistência ao paciente.

Essa afirmação foi corroborada nos estudos de Holst et al. (2010) com a inserção de estudantes de Enfermagem, de uma pequena universidade localizada no Sul da Suécia, em um projeto com o objetivo de prevenir e reduzir a UP em pacientes atendidos em ambiente hospitalar. As atividades realizadas foram fundamentadas por uma PBE que constou da realização de revisão sistemática da literatura, avaliação sistemática do risco para UP, observação sistemática da pele, documentação referente aos aspectos da UP e sessões educativas e de treinamento com duração de duas a quatro horas. Após essas atividades, eram realizadas discussões sobre os achados e as intervenções propostas. Durante o 
desenvolvimento desse projeto, nenhum paciente desenvolveu UP. Os autores concluíram que ter proporcionado aos estudantes a oportunidade de aplicarem a PBE, no tema UP, permitiu que os mesmos fizessem reflexões e conexões entre a qualidade do cuidado e o resultado final.

Ayello et al. (2010), em outro estudo, descreveram a percepção e a documentação do conteúdo/programa úlcera por pressão, ministradas nas escolas de enfermagem norte-americanas. Foi enviado instrumento para coleta de dados para 267 instituições com cursos de bacharelado, entre os 50 estados americanos, incluindo o distrito de Columbia, porém somente 77 docentes responderam o instrumento. Como resultados foram encontradas várias deficiências no conteúdo da UP, indicando a necessidade de reexaminar os currículos na abordagem do tema. Nem todas as faculdades estavam ensinando a avaliação do risco para UP e apenas 2/3 dos programas estavam ensinando índices de incidência e prevalência e uso de almofadas e superfícies de suporte que fazem a redistribuição de pressão.

O estudo de Ferreira et al. (2013), onde investigaram o conhecimento, prática e fontes de informações de graduandos de enfermagem, de uma instituição de ensino superior pública, sobre o cuidado de pacientes com feridas, mostrou que o nível de conhecimento é baixo, sugerindo que investimentos no ensino são necessários. Quando os estudantes participantes $(n=68)$ do estudo foram questionados se eram capazes de identificar os estágios das UPs, somente $17,6 \%$ responderam que sim. Quanto à avaliação da pele, como sendo uma parte das atividades que executam no campo de estágio, 51,5\% dos estudantes responderam que não realizam essa atividade. Ainda no teste de conhecimento, $64,7 \%$ não sabiam o que a Escala de Braden avaliava, e também $41 \%$ responderam corretamente que o primeiro estágio da UP é dificilmente identificado nas pessoas de pele escura/negra.

Em estudo com o objetivo de analisar o conhecimento sobre UP entre 54 graduandos de enfermagem matriculados na $5^{\underline{a}}$ e $7^{\text {a }}$ etapas de uma universidade privada, no interior paulista, foram questionados sobre o papel do enfermeiro junto à equipe de saúde para a prevenção de UP. Como resultado foram apresentados que somente 24 estudantes atribuíram ao enfermeiro a 
responsabilidade para prescrever cuidados de enfermagem e 12 estudantes em avaliar e orientar o paciente sobre UP. Na avaliação em relação aos fatores de risco, foi observada a maior frequência de resposta, em 47 estudantes, no item “imobilidade, não realizar mudança de decúbito". Em relação ao termo escara, houve percentual significativo de respostas certas, inferindo que os estudantes apresentaram conhecimento do termo, acima de $88 \%$ de acertos. Os estudantes apresentaram conhecimento importante quanto aos aspectos preventivos, com percentual de acertos significativo, acima de 70\%. Apesar desses percentuais positivos no conhecimento sobre UP, os autores afirmam que é um desafio para o ensino, durante a graduação, formar enfermeiros com habilitação para promover prevenção e assistência aos clientes em risco ou com UP (TIAGO et al., 2012).

$\mathrm{Na}$ investigação de Cullen e Moore (2013) realizadas com o fim de determinar o conhecimento de 60 estudantes do $4^{\circ}$ ano do curso de enfermagem e atitudes em relação à prevenção da UP, encontraram que os mesmos apresentaram déficit de conhecimento nos aspectos referentes à prevenção, porém, demonstraram resultado positivo na atitude. Os autores concluíram que ainda há lacuna no conhecimento da prevenção da UP.

Os educadores de enfermagem precisam estar atentos e preparados para proporcionar ensino-aprendizado que contribua significativamente para a formação de um profissional com conhecimentos, habilidades e competência na assistência de enfermagem à prevenção de UP. Ressalta-se que se faz necessária a educação continuada para a equipe de enfermagem sobre UP e a aplicação de protocolos, garantindo, assim assistência de enfermagem de qualidade.

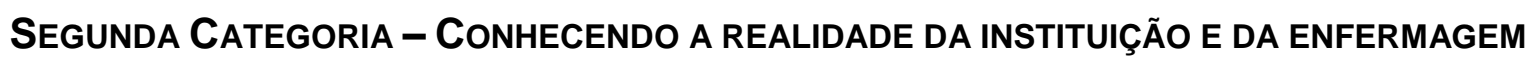

Em relação a subcategoria " a falta de cuidado de prevenção na UP”, as falas dos estudantes evidenciaram falhas na equipe de enfermagem na prevenção ao desenvolvimento de UP. Sabe-se que as ações dos profissionais são componentes da qualidade dos serviços, considerando o desenvolvimento ou não de UP em pacientes em risco e que a UP é considerada um evento adverso, implicando 
em cuidado não seguro ao paciente.

As diretrizes descritas pela NPUAP/EPUAP (2009) na prevenção de UP determinam que sejam aplicadas medidas, tais como: avaliação de risco para UP, avaliação da pele, avaliação dos aspectos nutricionais do paciente, reposicionamento do paciente, uso de superfícies de suporte e, ainda, cuidados com pacientes cirúrgicos.

O estudo qualitativo de Rios e Veloso (2010) teve como objetivo conhecer os cuidados de enfermagem e as dificuldades e/ou facilidades encontradas, entre os profissionais de enfermagem, para prevenir UP em uma unidade de clínica médica de uma instituição hospitalar pública de Feira de Santana, Bahia. Os resultados mostraram que a realização da mudança de decúbito nos pacientes acamados é insuficiente, os cuidados com a higiene e hidratação da pele foram citados pelos profissionais, e um profissional expressou a importância nutricional do paciente. Também foi apontado pelos profissionais de enfermagem que a falta de recursos humanos e materiais e a inexistência de protocolo contribuem para o déficit na prevenção de UP.

No que tange à subcategoria relacionada à importância da família junto ao paciente, verbalizada pelos estudantes no estudo, também Studart et al. (2011) afirmam que a presença da família, de um companheiro ou pelo menos um cuidador/acompanhante, junto ao paciente hospitalizado, foi observada como sendo essencial, pois, muitas vezes, desempenham um papel de realizar até mesmo as atividades de enfermagem, como as mudanças de decúbito, arrumar a cama, auxiliar no banho, alimentar e reposicionar o paciente no leito.

Ainda no estudo, as falas dos estudantes identificaram que havia diferença na maneira como os pacientes eram assistidos quando estavam com acompanhante quando comparados com aqueles que recebiam cuidados somente pela equipe de enfermagem, ou seja, naqueles que tinham acompanhantes as medidas preventivas de UP eram realizadas com maior frequência.

Também nos estudos de Rios e Velosso (2010) foi citada a importância da participação da família na prevenção da UP, identificando que o 
acompanhante está sempre alertando para fazer a mudança de decúbito ou que o familiar auxilia no banho e na alimentação do paciente.

Nos tempos atuais muito tem-se valorizado o papel do acompanhante como facilitador no restabelecimento da saúde de pacientes hospitalizados. Essas afirmações são respaldadas pelas orientações das políticas públicas de saúde que, pelo princípio da "Integralidade", é definido como o "conjunto articulado e contínuo das ações e serviços preventivos e curativos, individuais e coletivos, exigidos para cada caso em todos os níveis de complexidade do sistema" que garantam assistência humanizada (SANCHES et al., 2013). Também observase que o envolvimento da família é uma das estratégias propostas pela OMS em busca de cuidado seguro nos serviços de saúde (WORLD HEALTH ORGANIZATION, 2009).

Em relação à subcategoria "identificando a realidade da prescrição e das anotações de enfermagem", ficou nítido que o registro dos dados referentes à UP foram incompletos ou ausentes. As anotações têm a finalidade de registrar informações sobre a assistência prestada, assegurando a comunicação entre os profissionais de saúde, dando continuidade ao cuidado nas 24 horas. Além disso, fornecem respaldo legal, pois é o único documento que relata todas as ações de enfermagem. A Lei do Exercício Profissional apresenta as fundamentações legais das anotações de Enfermagem (Lei oㅜ 7.498/86).

O estudo de Simão (2010) apresenta dados análogos ao da presente investigação ao mostrar que houve deficiência nas anotações/registros de enfermagem, em relação ao risco de desenvolvimento de UP, às características da pele e das úlceras, estadiamento e medidas preventivas.

A subcategoria "percebendo a necessidade de transformar a prática da enfermagem" remete para a prática de enfermagem segura. Atualmente, a melhoria da segurança do paciente e da qualidade da assistência à saúde têm recebido atenção especial em âmbito global. De acordo com a Organização Mundial da Saúde, a segurança do paciente é definida como a redução, a um mínimo aceitável, do risco de dano desnecessário associado ao cuidado de saúde 
(AGÊNCIA NACIONAL DE VIGILANCIA SANITÁRIA, 2013).

Dentre as medidas de segurança ao paciente, tem-se as ações para prevenir as UPs, visto que são consideradas como um efeito adverso, ou seja, um incidente, um evento que resultou em um dano desnecessário ao paciente. Ressalta-se que a presença da UP é um indicador da qualidade da assistência de enfermagem (AGÊNCIA NACIONAL DE VIGILANCIA SANITÁRIA, 2013).

Alguns estudos apresentaram a presença de UP como efeito adverso nos serviços de saúde.

No estudo de Paranaguá et al. (2013) estimou-se a prevalência de incidentes sem dano e eventos adversos em uma clínica cirúrgica. A amostra foi constituída pela análise de prontuários de 750 internações de pacientes internados na clínica cirúrgica de um hospital pertencente à Rede de Hospitais Sentinela da Agência Nacional de Vigilância Sanitária. Foi evidenciado que em 140 internações houve exposição a evento adverso, sendo que a UP apareceu com frequência de $2,75 \%$. Os autores apontaram que a presença de UP exigia maior tempo para o cuidado e, assim, não havia realização de medidas preventivas para UP.

Em outro estudo (SANTOS; CEOLIM, 2009), com o objetivo de identificar as principais iatrogenias de enfermagem que acometiam idosos internados em duas enfermarias de um hospital universitário, encontrou o registro da UP em $30,8 \%$, em 26 prontuários analisados.

Em estudo sobre as características da produção científica, no período de 2000 a 2009, em relação às iatrogenias na assistência de enfermagem, mostrou que a UP está entre as principais iatrogenias abordadas nas bases de dados pesquisadas, com UP 10,3\% (FARIAS et al., 2010).

Vaismoradi, Salsali e Marck (2011) exploraram a perspectiva dos estudantes de enfermagem iranianos em relação à segurança do paciente e ao papel do educador de enfermagem no desenvolvimento das suas capacidades, para proporcionar um cuidado seguro. $O$ foco da entrevista realizada com 17 estudantes de enfermagem foi em relação a qual significado davam para a segurança do 
paciente, experiências de aprendizado na segurança do paciente e sugestões para preparar os estudantes, no ensino, a prover cuidado seguro. Em relação ao significado de segurança, a maioria dos participantes mencionou dois aspectos para conceituar segurança do paciente: conforto físico e psicológico. Em relação ao aprendizado, os estudantes se mostraram insatisfeitos de como o tema segurança do paciente era abordado em sala de aula, relatando que os educadores gastavam mais tempo ensinando a fisiopatologia das doenças, prognóstico e tratamento. $E$, por fim, sugeriram que o ensino deveria prover a oportunidade de aprender os princípios de segurança do paciente com mais profundidade. Reforça-se assim, que os educadores de enfermagem têm importante papel no desenvolvimento de conhecimentos, habilidades e atitudes entre os estudantes de enfermagem, relacionados à segurança do paciente.

Vaismoradi (2012) sugere que os currículos de enfermagem devem atender os estudantes no ensino da segurança do paciente. As competências necessárias para a segurança do paciente devem ser elaboradas com os gestores dos serviços de saúde e educadores, usar de criatividade no ensino do tema, considerar os diferentes aspectos da segurança do paciente e incorporar fatores culturais no currículo.

O currículo de enfermagem dos estudantes participantes deste estudo não provê nenhuma competência específica para a discussão da segurança do paciente, no entanto, há preocupação com docentes que ministram o módulo Práticas do Cuidar em permitir que sejam feitas discussões acerca do tema, bem como no workshop em PBE, onde foram feitas reflexões sobre as implicações da segurança do paciente quando do aparecimento da UP como um evento adverso.

Em contrapartida, na instituição onde foi realizado este estudo, a Gerência de Risco coordena as atividades do "Projeto Hospital Sentinela" e tem se preocupado com a questão da segurança do paciente. Para tanto, lançou um programa, desde o ano 2011, para prover cuidado seguro. A Comissão de Lesões de Pele também vem demonstrando esforços na questão da segurança e está em fase final de revisão para, posteriormente, ser implantado nessa instituição o Protocolo de Prevenção de UP. 
Diante do exposto acima pode-se afirmar que, tanto no ensino como na assistência, a educação com enfoque nas competências para a segurança contribui para o cuidado seguro do paciente de forma geral e em especial nas UPS, em que os profissionais de saúde, especialmente os de enfermagem, vêm dando maior atenção ao tratamento da UP em detrimento das medidas de prevenção para UP. No ensino, o tema da segurança deve contemplar todo o currículo, com abordagens e discussões nos diferentes cenários de assistência à saúde. Na assistência, o olhar do profissional deve estar atento aos múltiplos fatores que colocam em risco a segurança do paciente no processo de cuidado (URBANETTO; GERHARDT, 2013).

De acordo com a Organização Mundial da Saúde os estudantes da área da saúde precisam incorporar, na sua formação acadêmica, as questões que envolvem a segurança do paciente, visto que são os futuros provedores de cuidados e devem ser preparados para propiciar uma prática segura. É imprescindível que os currículos, entre os cursos da área da saúde, abordem as competências e habilidades sobre os princípios e conceitos acerca da segurança do paciente. Preocupados com este tema a Organização Mundial da Saúde elaborou um guia curricular voltado para professores e estudantes da área da saúde. Na primeira seção desse guia são feitas abordagens para auxiliar os professores, nas suas instituições de ensino, a implementar o tema segurança do paciente nos currículos. Em um segundo momento o guia curricular oferece, tanto para professores como para estudantes, estratégias de ensino-aprendizagem sobre a segurança do paciente (WORLD HEALTH ORGANIZATION, 2011).

Nesse estudo também foram elaboradas competências e habilidades, a partir do modelo de Pieper (2013), com objetivos, estratégias de ensino-aprendizagem e sugestão de bibliografia para o ensino das medidas de prevenção para a UP. São propostas que tem por finalidade, além do ensino da UP, contribuir para que esse evento adverso seja minimizado e oferecer uma prática segura na assistência de enfermagem aos pacientes com risco para desenvolver UP (ANEXO G). 


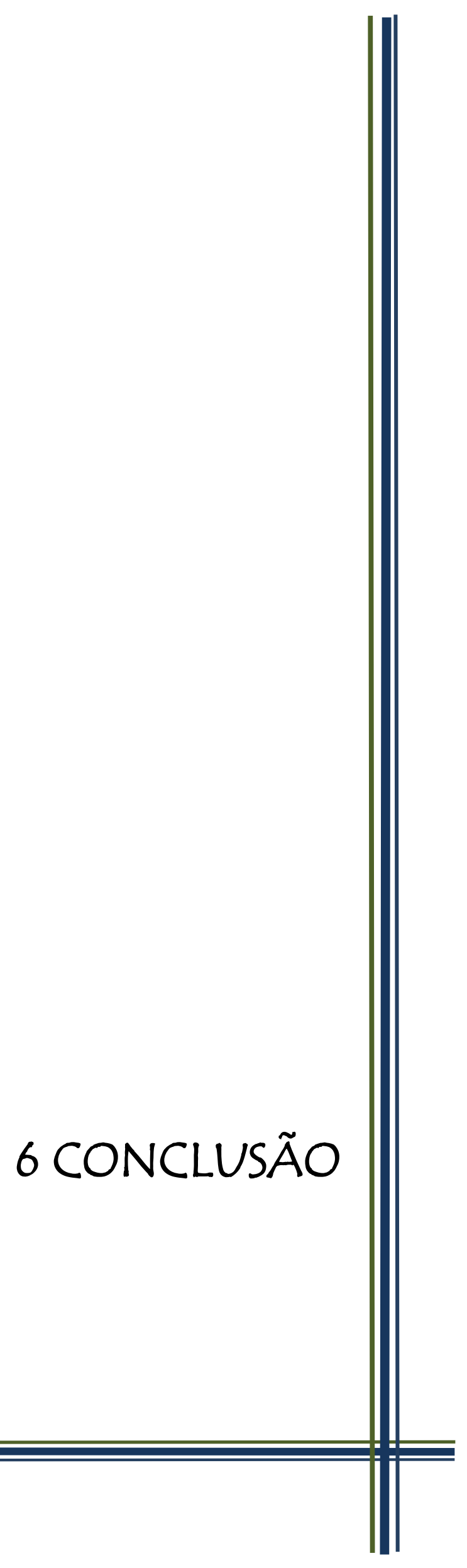


A realização do workshop da prática baseada em evidência, proposto nessa pesquisa, permitiu aos estudantes uma aprendizagem significativa acerca do tema úlcera por pressão.

As conclusões foram apresentadas de acordo com a sequência dos objetivos propostos neste estudo.

\section{Quanto à identificação do risco para úlcera por pressão e à ocorrência do problema:}

* a idade mínima dos pacientes foi de 19 anos e a máxima de 86, com predomínio da cor da pele branca $(66,67 \%)$;

* houve predomínio das doenças do sistema osteomuscular e do tecido conjuntivo $(42,86 \%)$, seguidos das doenças do sistema nervoso $(28,57 \%)$;

* o tipo de saída do paciente, ao término da coleta, predominou a permanência da internação do paciente no hospital (61,91\%);

* o tempo médio de internação hospitalar, antes do início da coleta de dados, foi de 14,10 dias;

* os pacientes tiveram entre 2 e 15 avaliações quanto ao risco para UP;

* o escore total da Escala de Braden, no primeiro dia de avaliação, obteve média de 11,9 .

* a maioria dos pacientes foi classificada na categoria de risco muito alto $(33,33 \%)$ e risco moderado $(33,33 \%)$;

* as subescalas com menores médias $(1,19)$, na primeira avaliação, foram nos domínios atividade e fricção e cisalhamento;

* a condição da pele dos pacientes, no primeiro dia da coleta de dados, predominou a presença de UP (61,90\%);

* das 25 UPs identificadas na primeira avaliação, a localização mais frequente foi a sacral (44,0\%) e 16 UPs eram de estágio I ou II;

* as variáveis faixa etária, cor, tipo de saída, diagnóstico médico principal, nível de risco para UP não apresentaram associação com a presença ou ausência de UP. 


\section{Quanto à identificação das ações para prevenção da úlcera por pressão prescritas ou não pelos enfermeiros:}

* na análise dos registros em prontuários realizados pelos enfermeiros não foi encontrado, em nenhuma das avaliações, anotações referentes ao uso da Escala de Braden e os escores de risco para desenvolvimento de UP;

* em dois pacientes que tinham pele íntegra foram encontrados somente dois registros, durante todas as avaliações sobre as condições da pele;

- o registro da presença de UP foi identificada em $21,4 \%$ dos prontuários;

* o registro da classificação do estágio da UP não foi observada em nenhum prontuário;

* houve frequência muito baixa do registro da localização da UP;

* a medida de prevenção mudança de decúbito apresentou registro com maior frequência a partir da $12^{\mathrm{a}}$ avaliação (83,33\%);

* a medida de prevenção referente, ao uso de colchão especial, foi prescrita somente para um paciente;

* na medida de prevenção uso de coxins houve predomínio da prescrição da $12^{\mathrm{a}}$ à $14^{a}$ avaliação $(66,67 \%) ;$

* o suplemento nutricional foi uma medida de prevenção pouco prescrita, com predomínio de $33,33 \%$ da $12^{a}$ à $14^{a}$ avaliação;

* a medida de prevenção proteção da incontinência apresentou frequência alta, variando de 57,14 a $83,33 \%$ no registro da prescrição de enfermagem;

* na medida de prevenção hidratação da pele, na primeira avaliação, 42,86\% apresentaram na prescrição e paulatinamente a frequência foi aumentando, culminando com $75 \%$ na $15^{\text {a }}$ avaliação;

* a medida de prevenção uso de curativo/cobertura foi utilizada como forma de tratamento, não sendo encontrada em nenhuma prescrição de enfermagem para prevenção;

* a medida de prevenção manutenção da cabeceira elevada $30^{\circ}$ foi evidenciada da $1^{1}$ à $10^{a}$ avaliação, com frequência variando de 9,09 a 23,81\%;

* quanto à associação das medidas de prevenção prescritas, considerando as categorias de UP (Avançada ou Leve), somente para a prescrição do uso de curativo/cobertura o teste exato de Fischer apresentou significância estatística 
(p-valor <0,05);

* quanto à associação entre a prescrição das medidas de prevenção e os fatores de risco, avaliados pela Escala de Braden, foi observado que não houve associação.

\section{Quanto ao significado da experiência dos estudantes da $2^{\mathbf{a}}$ série do Curso de Enfermagem da UEL referente à metodologia de ensino proposta:}

* oito estudantes participaram da pesquisa, sendo que sete $(87,5 \%)$ eram do sexo feminino e um (12,5\%) do sexo masculino. A média de idade dos estudantes foi de 21,25 anos;

* foram identificadas duas categorias: aprendendo sobre o tema úlcera por pressão e conhecendo a realidade da instituição e da enfermagem sobre a UP;

* da categoria "aprendendo sobre o tema úlcera por pressão" pode-se afirmar que os estudantes consideraram essencial participar do workshop de PBE, visto que puderam correlacionar a teoria à prática, identificaram as competências do enfermeiro na avaliação do paciente com risco para UP, aprimoraram o conhecimento nos estágios da UP e identificaram a Escala de Braden como suporte para avaliação de risco da UP, consolidando o aprendizado sobre UP;

* da categoria conhecendo a realidade da instituição e da enfermagem sobre a UP, conclui-se que os alunos identificaram a falta de cuidado de prevenção na UP pela equipe de enfermagem, a importância da família nos cuidados de enfermagem na UP, identificaram que os dados referentes à UP estavam incompletos ou ausentes nas prescrições e anotações de enfermagem e perceberam a necessidade de prática da enfermagem segura em relação à UP.

Em síntese, a metodologia de ensino utilizada com os estudantes com a realização do workshop sobre a prática baseada em evidência e posteriormente com a coleta de dados de pesquisa permitiu a experiência de identificar o perfil dos pacientes em risco para a UP e conhecer a ocorrência do problema da unidade de internação. Também permitiu que identificassem aspectos da prevenção da UP que estão sendo realizados pelos profissionais da instituição e 
7 Conclusão

aspectos que precisam ser implementados para que a prática seja baseada em evidências. A metodologia permitiu também aos estudantes uma aprendizagem significativa acerca do tema úlcera por pressão. 
7 CONSIDERAÇÕES FINAIS 
Embora os alunos que participaram desta investigação vivenciem um modelo de currículo inovador, integrado e com metodologia ativa no processo de ensino-aprendizagem os resultados demonstram que os mesmos não se sentiram suficientemente preparados em relação aos conhecimentos essenciais para a avaliação de risco e prevenção das UPs nos pacientes internados, quando terminavam o módulo Práticas do Cuidar.

Assim sendo, fica evidenciado que é de suma importância propiciar aos alunos sucessivas aproximações de ensino-aprendizagem sobre o tema UP, no decorrer dos diversos módulos da graduação do Curso de Enfermagem da UEL, onde se contempla a avaliação dos pacientes em risco, os aspectos de prevenção e de tratamento. Destaca-se, ainda, a necessidade de aplicar resultados de pesquisas que impactam nas práticas de cuidados de forma efetiva e eficaz e, por consequência, melhorem a qualidade da assistência ao paciente com UP.

Os estudantes ainda destacaram que somente após a participação no workshop sobre as PBEs, proposto como uma metodologia de ensino pela autora desta investigação é que foram despertados para a magnitude do problema das UPs, identificando na prática, quando foram participar da coleta de dados da referida pesquisa, que a equipe de enfermagem coloca em segundo plano a prevenção e que as prescrições de enfermagem para os pacientes de risco pouco ou nada continham sobre as recomendações das guidelines referentes à prevenção da UP.

Sabe-se que é fundamental para a equipe de enfermagem ter conhecimento científico acerca do tema úlcera de pressão, para que possam desenvolver na prática ações que visem concretamente a avaliação e a prevenção, bem como o tratamento adequado nas distintas fases dessa enfermidade. Assim sendo, é imprescindível que, na formação da equipe de enfermagem, os currículos contemplem e valorizem o tema úlcera por pressão, principalmente o modo de preveni-las, visto que ainda há predomínio de práticas de cuidar na qual o curar se sobrepõe à prevenção. Esse fato está diretamente correlacionado à formação tradicional de saúde, onde o biologicismo é preponderante, além disso, adotam-se métodos de ensino na maioria das vezes sem efetiva correlação da teoria com a prática. 
Dessa forma, torna-se imperioso que os currículos tenham ementas que abordem todos os aspectos que envolvem as UPs, para isso é necessário tempo suficiente para estudar com profundidade e metodologias de ensino e aprendizagem que sejam eficazes e significativas para os alunos. Uma das metodologias tida como capaz de propiciar uma relação teoria e prática é a fundamentada no paradigma da PBE. Entretanto, essa é ainda pouco utilizada no meio acadêmico brasileiro, bem como pelos profissionais de enfermagem que atuam nos diferentes serviços.

Denota-se, ainda, que, na formação dos profissionais de enfermagem, os currículos devem primar pelo ensino da sistematização da assistência, pois se constitui em uma das principais ferramentas que pode ser utilizada para a prevenção das UPs.

Destaca-se que outros fatores que dificultam as ações para a prevenção e o tratamento das UPs estão relacionados à deficiência de recursos humanos, em número inadequado, na falta de capacitação ou educação permanente e falta de adesão da equipe, nos recursos materiais inadequados ou deficientes para garantir a promoção, o conforto e a segurança do paciente, associado a isso têm-se a falta de padronização das ações da equipe de enfermagem, ou mesmo a falta de sistematização da assistência de enfermagem (ROLIM et al.,2013).

Assim sendo, sugere-se que sejam aplicadas as competências do enfermeiro na prevenção de UP, fundamentadas nas diretrizes da NPUAP/EPUAP (2009), para o ensino nos cursos de graduação e implementadas nos serviços de saúde (APÊNDICE G).

Sugere-se, ainda, que os currículos de enfermagem adotem as discussões de caso como estratégia de metodologia ativa de ensino-aprendizagem sobre UP, e também que na prática clínica sejam utilizados como forma de educação permanente entre a equipe de enfermagem.

Por fim, destaca-se que apresente pesquisa teve limitações que incluem: 
o estudo ter sido realizado com apenas alunos de um curso de graduação em enfermagem, limitando as generalizações dos resultados encontrados;

$>$ o tamanho amostral, tanto dos alunos participantes como dos pacientes avaliados pelos alunos, também se configurou como fator limitante à generalização dos achados;

$>$ o estudo ter sido realizado somente com alunos da segunda série do curso de enfermagem, impedindo a correlação com alunos que já cursaram outras séries;

$>$ a escassez de estudos sobre o tema UP com alunos que vivenciam currículos com metodologias ativas de ensino-aprendizagem.

Diante das limitações apontadas, faz-se necessário 0 desenvolvimento de novas pesquisas sobre a temática ensino-aprendizagem sobre UP nos currículos, com metodologias ativas para que assim seja possível relacionar os resultados encontrados com outros cursos de graduação de enfermagem.

Entretanto, independentemente de novas investigações, é imprescindível que o Curso de Enfermagem da UEL se aproprie de outras metodologias ativas como a utilizada na presente investigação, visto ter demonstrado que os alunos tiveram conhecimento significativo sobre a UP, principalmente na correlação efetiva com a prática.

Destaca-se, ainda, que não se configurou como objetivo do estudo avaliar a prática da equipe de enfermagem do HUL relacionada à UP, porém devido à metodologia utilizada, desvelou-se que são incipientes os cuidados de enfermagem prestados aos pacientes em risco para UP e até mesmo aos pacientes com a UP. Assim sendo, é fundamental que a instituição e a equipe de enfermagem busquem alternativas concretas para mudar esse cenário e, por consequência propicie uma assistência aos pacientes com qualidade. 


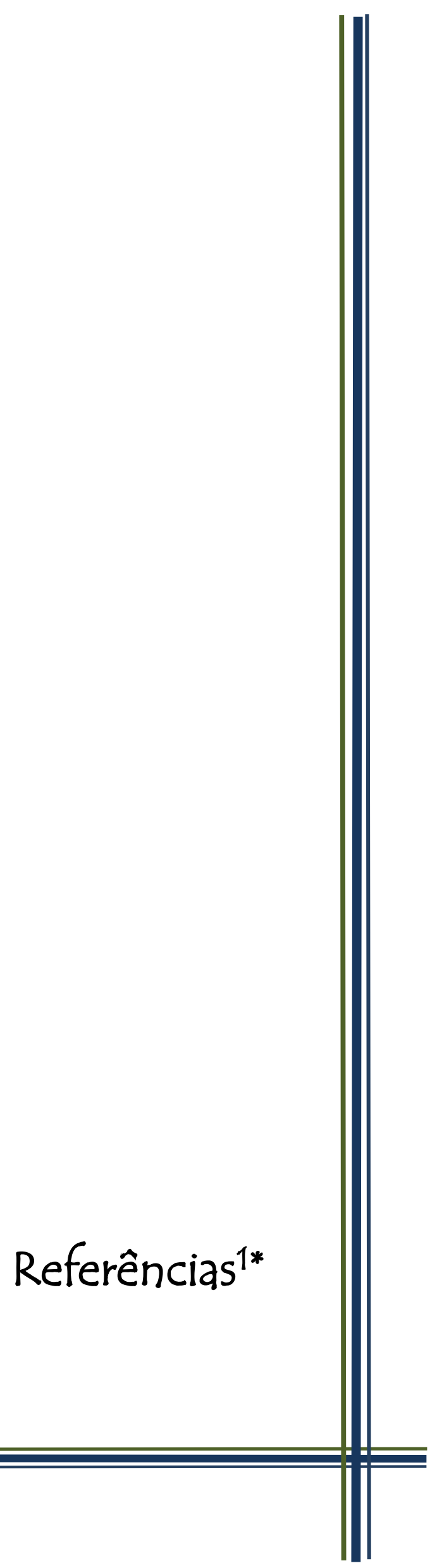

*De acordo com a Associação Brasileira der Normas Técnicas (NBR 6023) 


\section{REFERÊNCIAS}

AGÊNCIA NACIONAL DE VIGILÂNCIA SANITÁRIA (ANVISA). Assistência segura: uma reflexão teórica aplicada à prática. Brasília, DF, 2013. (Série segurança do paciente e qualidade em serviços de saúde).

ALFARO-LEFEVRE, R. Aplicação do processo de enfermagem: promoção do cuidado colaborativo. 5. ed. Porto Alegre: Artmed, 2005.

ALMEIDA, N. M. S. Formação do enfermeiro e reorientação do modelo de assistência à saúde: um estudo cartográfico. 2012. 107 f. Dissertação (Mestrado) Departamento de Saúde. Universidade Estadual do Sudoeste da Bahia, Jequié, 2012.

AMANTE, L. N.; ROSSETO, A. P.; SCHINEIDER, D. G. Sistematização da assistência de enfermagem em unidade de terapia intensiva sustentada pela Teoria de Wanda Horta. Revista da Escola de Enfermagem da USP, São Paulo, v. 43, n. 1, p. 54-64, 2009.

AMIR, Y. et al. Pressure ulcer prevalence and quality of care in stroke patients in an Indonesian hospital. Journal of Wound Care, London, v. 22, n. 5, p. 254-260, 2013.

AYELLO, E.A. et al. Pressure ulcer content in undergraduate programs. Nursing Outlook, v.58, n.2, march, p.e4, 2010.

BALSANELLI, A. P. et al. Competências gerenciais: desafio para o enfermeiro. São Paulo: Martinari, 2008.

BARDIN, L. Análise de conteúdo. Lisboa: Edições 70, 2010.

BARKER, A.L. et al. Implementation of pressure ulcer prevention best practice recommendations in acute care: na observational study. International Wound Journal, v.10, n.3,June, p.313-320, 2013.

BARROS, S.K.S.A. et al. Aplicação de protocolo para prevenção de úlcera de pressão em Unidade de Terapia Intensiva. Semina:Ciências Biológicas e da Saúde, Londrina, v.23, n.1, p.25-32, 2002.

BAVARESCO, T. Validação de intervenções de enfermagem para o diagnóstico risco de integridade da pele prejudicada para pacientes em risco de úlcera por pressão. 2012. 127f. Dissertação (Mestrado em Enfermagem) - Programa de PósGraduação em Enfermagem, Escola de Enfermagem, Universidade Federal do Rio Grande do Sul, Porto Alegre, 2012.

BERBEL, N. A. N. Metodologia da problematização: fundamentos e aplicações. Londrina: UEL, 1999.

BERGSTROM, N. On accuracy. Journal of Wound Ostomy and Continence Nursing, St. Louis, v. 35, n. 2, p. 211-212, Mar./Apr. 2008. 
BORDENAVE, J. D.; PEREIRA, A. M. Estratégias de ensino-aprendizagem. 24. ed. Rio de Janeiro: Vozes, 2002.

BRADEN, B J; MAKLEBUST, J. Preventing pressure ulcers with the Braden Scale. The American Journal of Nursing, New York, v. 105, n. 6, June, p. 70-72, 2005.

BRADLEY, D.; DIXON, J. F. Staff nurses creating safe passage with Evidence-Based Practice. The Nursing Clinics of North America, Philadelphia, v. 44, n. 1, p. 71-81, 2009.

BRASIL. Conselho Nacional de Educação. Câmara de Educação Superior.

CNE/CES 3/2001. Institui diretrizes curriculares nacionais do curso de graduação em enfermagem. Diário Oficial da União, Brasília, DF, 9 nov. 2001. Seção 1, p. 37.

BRASIL. Conselho Nacional de Saúde. Resolução 196/96, de 10 de outubro de 1996. Cadernos de Ética em Pesquisa, Brasília, v. 1, n. 1, p. 34-42, 1998.

BRASIL. Ministério da Saúde. Ministérios da Educação. Programa Nacional de Reorientação da Formação Profissional em Saúde. Série C. Projetos, Programas e Relatórios, Brasília: Ministério da Saúde, Ministérios da Educação, p.19, 2007.

BRYANT, R. A. Acute \& chronic wounds: nursing management. 2nd ed. St. Louis: Mosby, 2000.

CALIRI, M. H. L. A utilização da pesquisa na prática clínica de enfermagem. Limites e possibilidades. 2002. 152 f. Tese (Livre Docência) - Escola de Enfermagem de Ribeirão Preto, Universidade de São Paulo, Ribeirão Preto, 2002.

CALIRI, M. H. L.; MIYAZAKI, M. Y.; PIEPER, B. Knowledge of pressure ulcers by undergraduate nursing students in Brazil. Ostomy Wound Manage, King of Prussia Pa, v. 49, n. 3, p. 54-63, 2003.

CARPENITO-MOYET, L. J. Compreensão do processo de enfermagem: mapeamento de conceitos e planejamento do cuidado para estudantes. Porto Alegre: Artmed, 2007.

CHAYAMITI, E. M. P. C. Prevalência de úlcera por pressão em pacientes em assistência domiciliária em um distrito de saúde de Ribeirão Preto. 2008. 135 f. Dissertação (Mestrado) - Escola de Enfermagem de Ribeirão Preto, Universidade de São Paulo, Ribeirão Preto, 2008.

CHIANCA, T. C. M. et al. Pressure ulcer knowledge among nurses in a Brazilian University Hospital. Ostomy Wound Management, King of Prussia Pa, v. 56, n. 10, p. 58-64, 2010.

CHICÓRIA, M. I. G. Cuidados de enfermagem: uma prática baseada em evidência. 2013. 140 f. Dissertação (Mestrado) - Escola Superior de Enfermagem de Coimbra, Portugal, 2013. 
COLEMAN, S. et al. Patient risk factors for pressure ulcer development: Systematic review. International Journal of Nursing Studies, Oxford, v. 50, n. 7, p. 974-1003, 2013.

CONSELHO FEDERAL DE ENFERMAGEM (COFEN). Resolução COFEN no 358, de 15 de outubro de 2009. Dispõe sobre a sistematização da assistência de enfermagem e a implantação do processo de enfermagem em ambientes, públicos e privados, em que ocorre o cuidado profissional de enfermagem, e da outras providencias. Brasília, DF, 2009.

COSTA, I. G. Incidência de úlcera de pressão e fatores de risco relacionados em pacientes de um centro de terapia intensiva. 2003. 134 f. Dissertação (Mestrado) - Escola de Enfermagem de Ribeirão Preto, Universidade de São Paulo, Ribeirão Preto, 2003.

CULLEN, G. E.; MOORE, Z. An exploration of fourth-year undergraduate nurses' knowledge of and attitude towards pressure ulcer prevention. Journal of Wound Care, London, v. 22, n. 1, p. 618-622, 2013.

CULLUM, N. et al. Enfermagem baseada em evidências: uma introdução. Porto Alegre: Artmed, 2010.

DELLAROZA, M. S. G.; VANUCHI, M. T. O. (Org.) O currículo integrado do curso de Enfermagem da Universidade Estadual de Londrina: do sonho à realidade. São Paulo: Hucitec, 2005.

DENZIN, N. K.; LINCOLN, Y. S. 'Introduction: the discipline and practice of qualitative research'. In: DENZIN, N. K.; LINCOLN, Y. S. (Ed.). Handbook of qualitative research. 2nd ed. Thousand Oaks: Sage Publications, 2000. p. 1-29.

DESSUNTI, E. M. et al. O curso de enfermagem na Universidade Estadual de Londrina: uma história de lutas e realização. In: DELLAROZA, M. S. G.; VANNUCHI, M. T. O. (Org.). O currículo integrado do Curso de Enfermagem da Universidade Estadual de Londrina: do sonho à realidade. São Paulo: Hucitec, 2005.

DOMANSKY, R. C.; BORGES, E. L. Manual para prevenção de lesões de pele. Rio de Janeiro: Rubio, 2012.

DRUMOND,J.P.; SILVA,E. Medicina baseada em evidências: novo paradigma assistencial e pedagógico. São Paulo:Atheneu, 2002.

FARIAS, G. M. et al. latrogenias na assistência de enfermagem: características da produção científica no período de 2000 a 2009. InterScience Place: Revista Científica Internacional, v. 1, n. 11, p. 19-39, jan./fev. 2010. Disponível em: http://www.interscienceplace.org/interscienceplace/article/view/112/107. Acesso em: 24 fev. 2014. 
FAUSTINO, A. M. et al. The knowledge of nurses about new descriptors for classification of pressure ulcers: descriptive study. Online Brazilian Journal of Nursing, Niteroí, v. 9, n. 1, May 2010. Disponível em: http://www.objnursing.uff.br/index.php/nursing/article/view/j.16764285.2010.2800 Acesso em: 23 jan. 2014.

FAUSTINO, A. M. Úlcera por pressão e fatores de risco em pacientes hospitalizados com fratura de quadril e fêmur. 2008. $131 \mathrm{f}$. Dissertação (Mestrado) - Escola de Enfermagem de Ribeirão Preto, Universidade de São Paulo, Ribeirão Preto, 2008.

FERNANDES, L. M. Efeitos de intervenções educativas no conhecimento e práticas de profissionais de enfermagem e na incidência de úlcera de pressão em centro de terapia intensiva. 2006. $215 \mathrm{f}$. Tese (Doutorado) - Escola de Enfermagem de Ribeirão Preto, Universidade de São Paulo, Ribeirão Preto, 2006.

FERNANDES, L. M.; CALIRI, M. H. L. Uso da escala de Braden e de Glasgow para identificação de risco para úlceras de pressão em pacientes internados em centro de terapia intensiva. Revista Latino-americana de Enfermagem, Ribeirão Preto, v. 16, n. 6, p. 973-978, nov. 2008.

FERNANDES, L. M.; CALIRI, M. H. L.; HAAS, V. J. Efeito de intervenções educativas no conhecimento dos profissionais de enfermagem sobre prevenção de úlceras de pressão. Acta Paulista de Enfermagem, São Paulo, v. 21, n. 2, p. 305311, 2008.

FERNANDES, N. C. S.; TORRES, G. V. Incidência e fatores de risco de úlceras de pressão em pacientes de unidade de terapia intensiva. Ciência Cuidado e Saúde, Maringá, v. 7, n. 3, p. 304-310, jul./set. 2008.

FERREIRA, A M. et al. Conhecimento e prática de acadêmicos de enfermagem sobre cuidados com portadores de feridas. Escola Anna Nery Revista de Enfermagem, Rio de Janeiro, v. 17, n. 2, jun. 2013. Disponível em: <http://www.scielo.br/pdf/ean/v17n2/v17n2a02.pdf>. Acesso em: 24 jan. 2014.

FERREIRA, J. D. L. et al. Risco e prevalência de úlcera por pressão em usuários da rede básica de saúde. Revista enfermagem UFPE Online, Recife, v. 6, n. 9, p. 2045-2051, 2012. Disponível em:

http://www.revista.ufpe.br/revistaenfermagem/index.php/revista/article/view/2751/pdf 1497>. Acesso em 24 jan. 2014.

FISHER, R. A. The logic of inductive inference. Journal of the Royal Statistical Society, London, v. 98, n. 1, p. 39-82, 1935.

FLICK, U. Uma introdução à pesquisa qualitativa. Porto Alegre: Bookman, 2009.

FOSSUM, M. et al. Registered nurses' thinking strategies on malnutrition and pressure ulcers in nursing homes: a scenario-based think-aloud study. Journal of Clinical Nursing, Oxford, v. 20, p. 2425-2435, Sept. 2011. 
FURMAN, G. F. et al. Úlceras por pressão: incidência e associação de fatores de risco em pacientes de um hospital universitário. Revista de Enfermagem UFPE Online. Recife, v. 4, n. 3, p. 1506-514, jul./set. 2010. Disponível em: http://www.revista.ufpe.br/revistaenfermagem/index.php/revista/article/view/1148>. Acesso em: 10 jan. 2014.

GALVÃO, M. C.; SAWADA, N. O.; ROSSI, L. A. A prática baseada em evidências: considerações teóricas para sua implementação na enfermagem perioperatória. Revista Latino-americana de Enfermagem, Ribeirão Preto, v. 10, n. 5, p. 690-695, set./out. 2002.

GLASZIOU, P. Prática clínica baseada em evidências: livro de exercícios. 2. ed. Porto Alegre: Artmed, 2010.

GODOY, C. B.; SOUZA, N. A. Construindo uma nova proposta pedagógica no curso de enfermagem da Universidade Estadual de Londrina. Semina: Ciências Biológicas e da Saúde, Londrina, v. 22, n. 1 p. 25-31, jan./dez. 2001.

HATLEVIK, I.K.R. The theory-practice relationship: reflective skills and theoretical knowledge as key factors in bridging, the gap between theory and practice in initial nursing education. Journal of Advanced Nursing, Oxford, v.68, n.4, p. 868-877, April, 2012.

HIDALGO-PACORBO,P L. et al. Risk assessment scales for pressure ulcer prevention: a systematic review. Journal of Advanced Nursing, Oxford, v. 54, n. 1, p. 94-110, April, 2006.

HOLST, G. et al. Quality of care: prevention of pressure ulcers: nursing students facilitating evidence-based practice. Vard I Norden, Kobenhavn, v. 30, n. 1, p. 40-42, 2010.

HOSMER, D. W.; LEMESHOW, S. Assessing the fit of the model. In:

Applied logistic regression. New York: John Wiley and Sons, 1989. p. 135-173.

HUGHES, R. G. (Ed.). Patient safety and quality: an evidence-based handbook for nurses. AHRQ Publication n. 08-0043. Rockville, MD: Agency for Healthcare Research and Quality, 2008

INGERSOLL, G. L. Evidence-based nursing. Nursing Outlook, St. Louis, v. 48, n. 4, p. 151-152, July/Aug. 2000.

JOSEPH, J.; CLIFTON, D. Nurses' knowledge of pressure ulcer risk assessment. Nursing Standard, London, v. 27, n. 33, p. 54-60, 2013.

JUNG, G. O estado da arte: enfermagem baseada em evidências e os protocolos clínicos. In: Mancia JR, Vargas MAO. Livro-Tema da 66ª Semana Brasileira de Enfermagem. A bioética e os modos de ser da enfermagem. Brasília: Associação Brasileira de Enfermagem, p. 58-74, 2005. 
KIKUCHI, E. M.; GUARIENTE, M. H. D. M. (Org.). Currículo integrado: a experiência do curso de enfermagem da Universidade Estadual de Londrina. Londrina: UEL, 2012.

LEMOS, I. D. Incidência de úlcera por pressão no pós-operatório. 2011. 34 f. Trabalho de Conclusão de Curso (Graduação em Enfermagem) - Departamento de Enfermagem, Universidade Estadual de Londrina, 2011.

LYDER, et al. The Braden Scale for Pressure Ulcer Risk: Evaluating the Predictive Validity in Black and Latino/Hispanic Elders. Applied Nursing Research, Philadelphia, vol. 12, n. 2, p.60-68, May, 1999.

LYDER,C.H.; AYELLO,E.A. Pressure Ulcers: A Patient Safety Issue. In: HUGHES,R.G.,editor. Patient Safety and Quality: An Evidence-Based Handbook for Nurses. Rockville (MD): Agency for Healthcare Research and Quality (US); 2008 Apr. Chapter 12. Available from: http://www.ncbi.nlm.nih.gov/books/NBK2650/

MAGNAN, M. A.; MAKLEBUST, J. The nursing process and pressure ulcer prevention: making the connection. Advances in Skin e Wound Care, Springhouse, v. 22, n. 2, p. 83-92, Feb. 2009.

\section{MAKLEBUST, J.; SIEGGREN, M. Pressure ulcers guidelines for prevention and} nurse management. Springhouse: Pennsylvania House, 2001.

MARTINS, J. T. Prazer e sofrimento no trabalho do enfermeiro em unidades de terapia intensiva: estratégias defensivas. 2008. $199 \mathrm{f}$. Tese (Doutorado) - Escola de Enfermagem de Ribeirão Preto, Universidade de São Paulo, Ribeirão Preto, 2008.

MARTINS, J. T.; VOLPATO, M. P.; KRELING, M. C. G. D. Inserção da área fundamental em um currículo integrado. Enfermagem Atual, Rio de Janeiro, p. 2022, jan./fev. 2005.

MCSHERRY, R.; PROCTOR-CHILDS, T. Promoting evidence-based practice through an integrate model of care: a patient case studies as a teaching method. Nurse Education in Practice, Edinburgh, v. 1, n. 1, p. 19-26, Mar. 2001.

MELNYK, B. M. et al. Nurse practitioner educators' perceived knowledge, beliefs and teaching strategies regarding evidence based practice: implications for accelerating the integration of evidence-based practice into graduate programs. Journal of Professional Nursing, Philadelphia, v. 24, n. 1, p. 7-13, 2008.

MELNYK, B. M.; FINEOUT-OVERHOLT, E. Evidence-based practice in nursing \& healthcare: a guide to best practice. Philadelphia: Lippincott Williams \& Wilkins, 2005.

MENEGON, D. B. et al. Análise das subescalas de Braden como indicativos de risco para úlcera por presão. Texto e Contexto Enfermagem, Florianópolis, v. 21, n. 4, out./dez. 2012. 
MILTRE, S. M. et al. Metodologias ativas de ensino-aprendizagem na formação profissional em saúde: debates atuais. Ciências e Saúde Coletiva, Rio de Janeiro, v. 13, p. 2133-2144, 2008. Suplemento 2.

MIRA, V. L. et al. Avaliação do ensino prático desenvolvido em um hospital universitário na perspectiva da graduandos em Enfermagem. Revista Eletrônica de Enfermagem, Goiânia, v. 13, n. 3, p. 483-92, jul./set. 2011. Disponível em: http://www.fen.ufg.br/revista/v13/n3/v13n3a14.htm. Acesso em: 10 jan. 2014.

MIYAZAKI, M. Y. Conhecimento das recomendações para prevenção da úlcera por pressão pela equipe de enfermagem de um hospital universitário. 2009. 116 f. Dissertação (Mestrado em Enfermagem Fundamental) - Escola de Enfermagem de Ribeirão Preto, Universidade de São Paulo, Ribeirão Preto, 2009.

MONTGOMERY, D. C. Design and analysis of experiments. 5th ed. New York: John Wiley \& Sons, 2000.

MOORE, A.; COWMAN,W. Pressure ulcer prevalence and prevention practices in care of the older person in the Republic of Ireland. Journal of Clinical Nursing, Oxford, v.21,p.362-371, 2011.

MOORE, A.; COWMAN, S.; POSNETT, J. An economic analysis of repositioning for the prevention of pressure ulcers. Journal of Clinical Nursing, Oxford, v. 22, n. 1516, p. 2354-2360, 2013.

NASCIMENTO, C. C. P. et al. Indicadores de resultados da assistência: análise dos eventos adversos durante a internação hospitalar. Revista Latino-Americana de Enfermagem, Ribeirão Preto, v. 16, n. 4, p. 746-751, 2008.

NATIONAL PRESSURE ULCER ADVISORY PANEL AND EUROPEAN PRESSURE ULCER ADVISORY PANEL (NPUAP/EPUAP). Prevention and treatment of pressure ulcers: quick reference guide. Washington: National Pressure Ulcer Advisory Panel, 2009. Disponível em: http://www.epuap.org > Acesso em: 29 set. 2013.

NOGUEIRA, P. C. N. Ocorrência de úlcera de pressão e pacientes hospitalizados com lesão traumática de medula espinhal. 2005. $77 \mathrm{f}$. Dissertação (Mestrado) - Escola de Enfermagem de Ribeirão Preto, Universidade de São Paulo, Ribeirão Preto, 2005.

NONINO, E. A. P. M. Avaliação da qualidade dos procedimentos de enfermagem - banho e curativo - segundo o grau de dependência assistencial dos pacientes internados em um Hospital Universitário. 2006. $242 \mathrm{f}$. Tese (Doutorado em Enfermagem Fundamental) - Escola de Enfermagem de Ribeirão Preto, Universidade de São Paulo, Ribeirão Preto, 2006.

OLIVEIRA, F. E. L. et al. A gerência do enfermeiro na estratégia saúde da família. Revista Rene: Revista da Rede de Enfermagem do Nordeste. Fortaleza, v. 13, n. 4, p. 834-844, 2012. 
ONIGBIND, A. T.; OGUNSANYA, G. I.; ONIYANGI, S. O. Pressure ulcer incidence among high-risk inpatients in Nigeria. British Journal of Nursing, London, v. 21, n. 12, p. S4-10, 2012. Suplemento.

ORGANIZACIÓN PANAMERICANA DE LA SALUD. División de desarrollo de sistemas y servicios de salud (HSP). Programa de desarrollo de recursos humanos (HSR). El desafio educativo de las reformas sectoriales: cambios en la capacitación y la evaluación para el trabajo en salud. Buenos Aires, 1997.

PACHEMSHY, L. R. Úlcera por pressão: estudo da incidência em pacientes com grau de dependência da assistência de enfermagem III e IV. 2009. 39 f. Dissertação (Mestrado em Medicina e Ciências da Saúde) - Centro de Ciências da Saúde, Universidade Estadual de Londrina, Londrina, 2009.

PANCORBO-HIDALGO, P. L. et al. Pressure ulcer care in Spain: nurses' knowledge and clinical practice. Journal of Advanced Nursing, Oxford, v. 58, n. 4, p. 327-338, 2007.

PARANAGUÁ, T. T. B. et al. Prevalência de incidentes sem dano e eventos adversos em uma clínica cirúrgica. Acta Paulista de Enfermagem, São Paulo, 26, n. 3, p. 256-62, 2013.

PARANHOS, W. Y. Avaliação de risco para úlceras de pressão por meio da Escala de Braden na língua portuguesa. 1999. 79 f. Dissertação (Mestrado) Escola de Enfermagem, Universidade de São Paulo, São Paulo, 1999.

PASSAMANI, R. F.; BRANDÃO,E. S.; PASSAMANI,R. F. Úlcera por pressão: avaliação do risco em pacientes cirúrgicos. Revista Estima, São Paulo, v. 10, n. 2, 12-18, 2012.

PERRENOUD, P. Construir as competências desde a escola. Porto Alegre: Artmed, 1999.

PIEPER, B. Registered nurse competency-based curriculum: pressure ulcer prevention. 2013 Disponível em: http://www.npuap.org/wpcontent/uploads/2012/03/Updated-NPUAP-RN-5-29-13.pdf. Acesso em: 01 maio 2014.

PINI, L. R. Q. Prevalência, risco e prevenção de úlcera de pressão em unidades de cuidados de longa duração. 2012. 126 f. Dissertação (Mestrado) - Instituto Ciências da Saúde, Universidade Católica Portuguesa, Lisboa, 2012.

POLETTI, N. A. A. O ensino da prevenção e tratamento de úlceras de pressão em escolas públicas do estado de São Paulo. 2005. 178 f. Tese (Doutorado) Escola de Enfermagem de Ribeirão Preto, Universidade de São Paulo, Ribeirão Preto, 2005.

RAMOS, L. A. R.; CARVALHO, E. C.; CANINI, S. R. M. S. Opinião de auxiliares e técnicos de enfermagem sobre a sistematização da assistência de enfermagem. Revista Eletrônica de Enfermagem, Goiânia, v. 11, n. 1, p. 39-44, 2009. Disponível 
em: < http://www.fen.ufg.br/fen_revista/v11/n1/pdf/v11n1a05.pdf>. Acesso em: 28 dez. 2013.

RANGEL, E. M. L. Conhecimento, práticas e fonte de informação de enfermeiros de um hospital escola sobre a prevenção e tratamento da úlcera de pressão. 2004. 74 f. Dissertação (Mestrado) - Escola de Enfermagem de Ribeirão Preto, Universidade de São Paulo, Ribeirão Preto, 2004.

REASON, J. Human error. Cambridge: Cambridge University Press, 2003.

RIBAS, J. D. Prevalência de úlcera por pressão: um estudo epidemiológico da enfermagem. 2011. 134 f. Dissertação (Mestrado) - Setor Ciências da Saúde, Universidade Federal do Paraná, Curitiba, 2011.

$\mathrm{RICH}, \mathrm{S}$. E. et al. Pressure-redistributing support surface use and pressure ulcer incidence in elderly hip fracture patients. Journal of the American Geriatrics Society, New York, v. 59, n. 6, p. 1052-1059, June 2011.

RINALDI, E. C. A. Prevalência de úlcera por pressão: estudo epidemiológico em um hospital no interior do Paraná. 2011. 97 f. Dissertação (Mestrado emEnfermagem) - Setor de Ciências da Saúde, Universidade Federal do Paraná, Curitiba, 2011.

RIOS, L. C.; VELÔSO, I. B. P. Cuidados de enfermagem na prevenção de úlcera por pressão em um hospital público de Feira de Santana, Bahia. Revista Estima, São Paulo, v. 8,. n, 2, p. 20-27, 2010.

ROCHA, S. M. M.; ALMEIDA, M. C. P. O processo de trabalho da enfermagem em saúde coletiva e a interdisciplinaridade. Revista Latino-americana de Enfermagem, Ribeirão Preto, v. 8, n. 6, p. 96-101, dez. 2000.

ROGENSKI, N. M. B. Avaliação da implementação de um protocolo de prevenção de úlceras por pressão. 2011. 132 f. Tese (Doutorado) - Escola de Enfermagem, Universidade de São Paulo, São Paulo, 2011.

ROGENSKI, N. M. B.; SANTOS, V. L. C. G. Estudo sobre a incidência de úlceras por pressão em um hospital universitário. Revista Latino-Americana de Enfermagem, Ribeirão Preto, v. 13, n. 4, p. 474-480, jul./ago. 2005.

ROGENSKI, N. M.; SANTOS, V .L. C. G. Estudo sobre a prevalência de úlceras por pressão em um Hospital Universitário. Revista Estima, São Paulo, v. 4 , n. 2, p. 16 22, 2006.

SACKETTI, D. L. et al. Evidence based medicine: what it is and what it isn't. British Medical Journal, London, v. 312, n. 7023, p. 71-72, Jan. 1996.

SALES, M. C. M; BORGES ,E .L.; DONOSO, M. T. V. Risco e prevalência de úlceras por pressão em uma unidade de internação de um hospital universitário de Belo Horizonte. REME: Revista Mineira de Enfermagem, Belo Horizonte, v. 14, n. 4. P. 566-575, out./dez., 2010. 
SALOMÉ, G. M.; ESPÓSITO, V. H C. Vivências de acadêmicos de enfermagem durante o cuidado prestado às pessoas com feridas. Revista Brasileira de Enfermagem, Brasília, v. 61, n. 6, p. 822-827, 2008.

SAMMER, C. E. et al. What is patient safety culture? A review of the literature. Journal of Nursing Scholarship, Indianápolis, v. 42, n. 2, p. 156-165, 2010.

SANCHES, I. C. P. et al. Acompanhamento hospitalar: direito ou concessão ao usuário hospitalizado? Ciência e Saúde Coletiva, Rio de Janeiro, v.18, n. 1, p. 6776, 2013.

SANTOS, A. A. R. O ensino da temática feridas no curso de graduação em enfermagem da Universidade Federal da Paraíba. 2012. 130 f. Dissertação (Mestrado) - Centro de Ciências da Saúde, Universidade Federal da Paraíba, João Pessoa, 2012.

SANTOS, C. T. et al. Indicador de qualidade assistencial úlcera por pressão: análise de prontuário e de notificação de incidente. Revista Gaúcha de Enfermagem, Porto Alegre, v. 34, n. 1, p. 111-118, 2013.

SANTOS, J. C dos; CEOLIM, M. F. latrogenias de enfermagem em pacientes idosos hospitalizados. Revista da Escola de Enfermagem da USP, São Paulo, v. 43, n. 4. p. 810-817, 2009.

SANTOS, V. C. G.; CALIRI, M. L. Conceito e classificação de úlcera por pressão: atualização do NPUAP. Revista Estima, São Paulo, v. 5, n. 3, p. 43-44, jul./set. 2007.

SAS INTITUTE. SAS/SAT® User's Guide. Version 9.0. Cary: SAS Institute Inc., 1999.

SCARLATTI, K. C. et al. Úlcera por pressão em pacientes submetidos a cirurgia: incidência e fatores associados. Revista da Escola de Enfermagem da USP, São Paulo, v. 45. n. 6, p. 1372-1379, 2011.

SCHMIDT, N. A.; BROWN, J. M. Use of the innovation-decision process teaching strategy to promote evidence-based practice. Journal of Professional Nursing, Philadelphia, v. 23, n. 3, p. 150-156, May/June 2007.

SCHNEID, S. et al Protocolos clínicos baseados em evidências: a experiência do Grupo Hospitalar Conceição. Revista ARMIGS, Porto Alegre, v. 47, n. 2 , p. 104114, 2003.

SENTONE, A. D. D. Análise dos indicadores da qualidade na elaboração da prescrição de enfermagem em uma unidade de internação de um hospital universitário público. 2005. 110 f. Dissertação (Mestrado em Enfermagem) Universidade de São Paulo, Escola de Enfermagem de Ribeirão Preto, Ribeirão Preto, 2005.

SIMÃO, C. M. F. Úlcera por pressão em unidades de terapia intensiva e conformidade das ações de enfermagem. 2010. 135 f. Dissertação (Mestrado) - 
Escola de Enfermagem de Ribeirão Preto, Universidade de São Paulo, Ribeirão Preto, 2010.

SIMON, J. M. Evidence-based practice in nursing. Nursing Diagnosis, Philadelphia, v. 10, n. 1, p. 3, Jan./Mar. 1999. Editorial.

SIMPSON, B. Evidence-based nursing practice: the state of the art. Canadian Nurse, v.92, n. 10, p.22-5, Nov. 1996.

SOUZA, P. R. A. et al. Avaliação de risco para desenvolvimento de úlceras por pressão em pacientes críticos. Revista de Enfermagem da UFPI, Teresina, v. 2, n. 1, p. 9-15, jan./mar. 2013.

STEIN, E. A. et al. Ações dos enfermeiros na gerência do cuidado para prevenção de úlceras por pressão em unidade de terapia intensiva. Revista de Pesquisa: Cuidado é Fundamental Online, Rio de Janeiro, v. 4, n. 3, p. 2605-2612, jul./set. 2012 http://www.seer.unirio.br/index.php/cuidadofundamental/article/view/1606/pdf 599>. Acesso em: 10 jan. 2014.

STETLER, C. B. et al. Evidence-based practice and the role of nursing leadership. Journal of Nursing Administration, Wakefield, v. 28, n. 7-8, p. 45-53, July/Aug. 1998.

STRAND, T. S.; LINDGREN, M. Knowledge, attitudes and barriers towards prevention of pressure ulcers in intensive care units: a descriptive cross-sectional study. Intensive and Critical Care Nursing, Edinburgh, v. 26, n. 6, p. 335-342, Dec. 2010.

STUDART, R.M.B. et al. Tecnologia de enfermagem na prevenção da úlcera por pressão em pessoas com lesão medular. Revista Brasileira de Enfermagem, Brasília, v.64, n.3, p. 494-500, mai-jun. 2011.

SWARDT, H.C.; du TOIT, H.S.; BOTHA, A. Guided reflection as a tool to deal with the theory-practice gap in critical care nursing students. Health SA Gesondheid. v.17, n.1, p. 1-9, 2012.

TACLA, M. T. G. M. Desenvolvendo o pensamento crítico em alunos de Enfermagem: uma experiência através da metodologia da problematização. Goiânia: AB, 2002.

TAKAHASHI, A. A. et al. Dificuldades e facilidades apontadas por enfermeiras de um hospital de ensino na execução do processo de enfermagem. Acta Paulista de Enfermagem, São Paulo, v. 21, n. 1, p. 32-38, 2008.

THORODDSEN, A. et al. Accuracy, completeness and comprehensiveness of information on pressure ulcers recorded in the patient record. Scandinavian Journal of Caring Sciences, Stockholm, v. 27, n. 1, p. 84-91, 2013. 
TIAGO, F. et al. Conhecimento dos graduandos de enfermagem relative à úlcera por pressão: um estudo no cenário privado. Revista Nursing, v. 14, n. 164, p. 21-28, 2012.

URBANETTO, J. S.; GERHARDT, L. M. Segurança do paciente na tríade assistência ensino pesquisa. Revista Gaúcha de Enfermagem, Porto Alegre, v. 34, n. 3, p. 8-9, 2013. Editorial.

URSI, E. S. Avaliação do desenvolvimento de úlceras por pressão em pacientes cirúrgicos. 2010. $128 \mathrm{f}$. Tese (Doutorado) - Escola de Enfermagem de Ribeirão Preto, Universidade de São Paulo, Ribeirão Preto, 2010.

VAISMORADI, M. Nursing education curriculum for improving patient safety. Journal of Nursing Education and Practice, v. 2, n. 1, p.101-104, Feb. 2012.

VAISMORADI, M.; SALSALI, M.; MARCK, P. Patiente safety: nursing students' perspectives and the role of nursing education to provide safe care. International Nursing Review, Oxford, v. 58, n.4, 434-443, 2011.

VARGAS, M. A. O.; LUZ, A. M. H. Práticas seguras do/no cuidado de enfermagem no contexto hospitalar: é preciso pensar sobre isso e aquilo. Enfermagem em Foco, Brasília, v. 1, n. 1, p. 23-27, 2010.

VITURI, D.W. Avaliação como princípio da Gestão da Qualidade: testando a confiabilidade interavaliadores de indicadores para avaliação da qualidade da assistência de enfermagem. 2013, 208p. Tese (Doutorado em Enfermagem Fundamental) - Universidade de São Paulo, Escola de Enfermagem de Ribeirão Preto, 2013.

VITURI, D. W.; MATSUDA, L. M. Validação de conteúdo de indicadores de qualidade para avaliação do cuidado de enfermagem. Revista da Escola de Enfermagem da USP, São Paulo, v. 43, n. 2, p. 429-437, jun. 2009.

WOLFF, K. et al. Fitzpatrick: tratado de dermatologia. 7. ed. Rio de Janeiro: Revinter, 2011. v.1.

WORLD HEALTH ORGANIZATION. WHO director-general names Sir Liam Donaldson envoy for patient safety. Geneva, 2011. Disponível em: http://www.who.int/mediacentre/news/releases/2011/patient safety 20110721/en/?ut $\mathrm{m}$ source=rss\&utm medium=rss\&utm campaign=who-director-general-names-sirliam-donaldson-envoy-for-patient-safety>. Acesso em: 24 fev. 2014.

WOUND OSTOMY AND CONTINENCE NURSES SOCIETY (WOCN). Guideline for prevention and management of pressure ulcers. 2nd ed. Washington: $A H R Q$ Publication, 2010.

ZAMBONATO, B. P.; ASSIS, M. C .S.; BEGHETTO, M. G. Associação das subescalas de Braden com o risco do desenvolvimento de úlcera por pressão. Revista Gaúcha Enfermagem, Porto Alegre, v. 34, n. 1, p. 21-28, jun. 2013. 


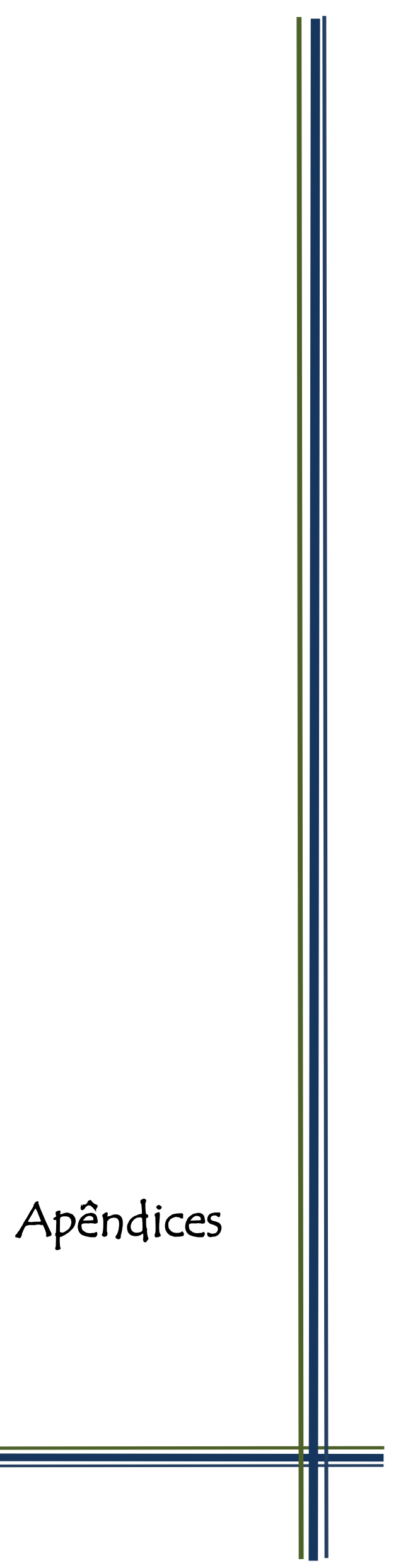




\section{APÊNDICE A - TERMO DE CONSENTIMENTO LIVRE E ESCLARECIDO}

Termo de Consentimento Livre e Esclarecido - Aluno

\section{Titulo da pesquisa}

"Ensino clínico sob o paradigma na prática embasada em evidências: integração da teoria e prática para prevenção da úlcera por pressão"

Prezado(a) Senhor(a):

Gostaríamos de convidá-lo (a) a participar da pesquisa Ensino clínico sob o paradigma na prática embasada em evidências: integração da teoria e prática para prevenção da úlcera por pressão, realizada no Hospital Universitário de Londrina, da Universidade Estadual de Londrina. O objetivo da pesquisa é "Propor e avaliar uma metodologia de ensino para alunos da $2^{\mathrm{a}}$ série do curso de enfermagem da UEL, por meio de desenvolvimento de pesquisas em campo, utilizando o referencial da Prática Baseada em Evidência". A sua participação é muito importante e ela se daria da seguinte forma: participar de workshop sobre o tema úlcera por pressão, realizar acompanhamento dos pacientes hospitalizados no Hospital Universitário da UEL, admitidos na Unidade Masculina, para identificação da incidência e prevalência da úlcera por pressão, fazer a coleta e análise dos registros de enfermagem realizados em prontuários dos pacientes admitidos na unidade masculina, participar das discussões de grupo realizadas entre os estudantes do módulo Práticas do Cuidar e o professor/pesquisador em relação ao desenvolvimento de suas competências para avaliação do risco de pacientes para desenvolvimento da Úlcera por Pressão. Salienta-se que a sua participação, nas discussões de grupo serão gravadas, com a finalidade de avaliar o processo ensinoaprendizagem sobre o risco de pacientes desenvolverem úlcera por pressão. As gravações serão utilizadas somente para o desenvolvimento da pesquisa e descartadas ao término da mesma. Gostaríamos de esclarecer que sua participação é totalmente voluntária, podendo você: recusar-se a participar, ou mesmo desistir a qualquer momento sem que isto acarrete qualquer ônus ou prejuízo à sua pessoa. Informamos, ainda, que as informações serão utilizadas somente para os fins desta 
pesquisa e serão tratadas com o mais absoluto sigilo e confidencialidade, de modo a preservar a sua identidade.

Os benefícios esperados são desenvolver uma proposta de ensino para o curso de graduação em enfermagem em relação à assistência de enfermagem ao paciente em risco para úlcera por pressão.

Informamos que o senhor não pagará nem será remunerado por sua participação. Garantimos, no entanto, que todas as despesas decorrentes da pesquisa serão ressarcidas, quando devidas e decorrentes especificamente de sua participação na pesquisa.

Caso você tenha dúvidas ou necessite de maiores esclarecimentos pode nos contactar Marcia Paschoalina Volpato, residente à rua Rebouças, 323, telefone (43)33275879/99445879, e-mail: volpato@uel.br, ou procurar o Comitê de Ética em Pesquisa Envolvendo Seres Humanos da Universidade Estadual de Londrina, na avenida Robert Kock, no 60, ou pelo telefone 3371-2490. Este termo deverá ser preenchido em duas vias de igual teor, sendo uma delas, devidamente preenchida e assinada entregue a você.

Londrina, de de 2011

Nome do sujeito :

Assinatura:

\section{Marcia Paschoalina Volpato: Pesquisador Responsável}

$R G$ : 


\title{
APÊNDICE B - TERMO DE CONSENTIMENTO LIVRE E ESCLARECIDO
}

\author{
Termo de Consentimento Livre e Esclarecido-Paciente
}

\section{Titulo da pesquisa:}

"Ensino clínico sob o paradigma na prática embasada em evidências: integração da teoria e prática para prevenção da úlcera por pressão"

Prezado(a) Senhor(a):

Gostaríamos de convidá-lo (a) a participar da pesquisa Ensino clínico sob o paradigma na prática embasada em evidências: integração da teoria e prática para prevenção da úlcera por pressão, realizada no Hospital Universitário de Londrina da Universidade Estadual de Londrina. O objetivo da pesquisa é "Propor e avaliar uma metodologia de ensino para alunos da $2^{\mathrm{a}}$ série do curso de enfermagem da UEL por meio de desenvolvimento de pesquisas em campo, utilizando o referencial da Prática Baseada em Evidência". A sua participação é muito importante e ela se daria da seguinte forma: ser sujeito da pesquisa na identificação da incidência e prevalência do desenvolvimento da úlcera por pressão, através de uma avaliação física e registro fotográfico da(s) sua(s) lesão(s). Esta avaliação física e registro fotográfico será realizada pela autora da pesquisa e pelos alunos colaboradores da pesquisa, que consiste em examinar a sua pele, identificando áreas que podem desenvolver a úlcera por pressão. Gostaríamos de esclarecer que sua participação é totalmente voluntária, podendo você: recusar-se a participar, ou mesmo desistir a qualquer momento sem que isto acarrete qualquer ônus ou prejuízo à sua pessoa. Informamos, ainda, que as informações serão utilizadas somente para os fins desta pesquisa e serão tratadas com o mais absoluto sigilo e confidencialidade, de modo a preservar a sua identidade.

Os benefícios esperados são desenvolver uma proposta de ensino para o curso de graduação em enfermagem em relação à assistência de enfermagem ao paciente em risco para úlcera por pressão.

Informamos que o senhor não pagará nem será remunerado por sua participação. Garantimos, no entanto, que todas as despesas decorrentes da pesquisa serão 
ressarcidas, quando devidas e decorrentes especificamente de sua participação na pesquisa.

Caso você tenha dúvidas ou necessite de maiores esclarecimentos pode nos contactar Marcia Paschoalina Volpato, residente à Rua Rebouças, 323, telefone (43)3327-5879/9944-5879, e-mail: volpato@uel.br, ou procurar o Comitê de Ética em Pesquisa Envolvendo Seres Humanos da Universidade Estadual de Londrina, na avenida Robert Kock, no 60, ou pelo telefone 3371-2490. Este termo deverá ser preenchido em duas vias de igual teor, sendo uma delas, devidamente preenchida e assinada, entregue a você.

Londrina, de de 2011

Nome do paciente :

Assinatura do paciente ou familiar:

Marcia Paschoalina Volpato: Pesquisador Responsável

$R G$ : 


\title{
APÊNDICE C - TERMO DE CONFIDENCIALIDADE E SIGILO DA PESQUISADORA
}

\begin{abstract}
Eu, Marcia Paschoalina Volpato, nacionalidade brasileira, estado civil divorciada, profissão enfermeira, inscrita no COREN/PR sob no 44927, abaixo firmado, assumo o compromisso de manter confidencialidade e sigilo sobre todas as informações técnicas e outras relacionadas ao projeto de pesquisa intitulado "Ensaio clínico sob paradigma na prática embasada em evidências: integração da teoria e prática para prevenção da úlcera por pressão", a que tiver acesso nas dependências da unidade de internação unidade masculina do Hospital Universitário de Londrina da Universidade Estadual de Londrina.
\end{abstract}

Por este termo de confidencialidade e sigilo comprometo-me:

1. a não utilizar as informações confidenciais a que tiver acesso, para gerar benefício próprio exclusivo e/ou unilateral, presente ou futuro, ou para o uso de terceiros;

2. a não efetuar nenhuma gravação ou cópia da documentação confidencial a que tiver acesso;

3. a não apropriar para mim ou para outrem de material confidencial e/ou sigiloso da tecnologia que venha a ser disponível;

4. a não repassar o conhecimento das informações confidenciais, responsabilizandome por todas as pessoas que vierem a ter acesso às informações, por meu intermédio, e obrigando-me, assim, a ressarcir a ocorrência de qualquer dano e/ou prejuízo oriundo de uma eventual quebra de sigilo das informações fornecidas.

Neste Termo, as seguintes expressões serão definidas, como indicadas a seguir:

Informação Confidencial significará toda informação revelada através da apresentação da tecnologia, a respeito de, ou, associada com à avaliação, sob a forma escrita, verbal ou por quaisquer outros meios.

Informação Confidencial inclui, mas não se limita, à informação relativa às operações, processos, planos ou intenções, informações sobre produção, instalações, equipamentos, segredos de negócio, segredo de fábrica, dados, habilidades especializadas, projetos, métodos e metodologia, fluxogramas, especializações, componentes, fórmulas, produtos, amostras, diagramas, desenhos de esquema industrial, patentes, oportunidades de mercado e questões relativas a negócios revelados da tecnologia supramencionada. 
Avaliação significará todas e quaisquer discussões, conversações ou negociações entre, ou com as partes, de alguma forma relacionada ou associada com a apresentação da tecnologia "xxx", acima mencionada.

A vigência da obrigação de confidencialidade e sigilo, assumida pela minha pessoa, por meio deste termo, terá a validade enquanto a informação não for tornada de conhecimento público por qualquer outra pessoa, ou mediante autorização escrita, concedida à minha pessoa pelas partes interessadas neste termo.

Pelo não cumprimento do presente Termo de Confidencialidade e Sigilo, fica o abaixo assinado ciente de todas as sanções judiciais que poderão advir.

Londrina, 26/09/2011

Marcia Paschoalina Volpato

Contato: volpato@uel.br/9944-5879

CEP: $3371-2490$

Pesquisador(a) Responsável 


\title{
APÊNDICE C1 - TERMO DE CONFIDENCIALIDADE E SIGILO DOS ESTUDANTES
}

\begin{abstract}
Eu , nacionalidade brasileira, estado civil solteiro(a), estudante do curso de Enfermagem da UEL, sob 0 no de matrícula_ abaixo firmado, assumo o compromisso de manter confidencialidade e sigilo sobre todas as informações técnicas e outras relacionadas ao projeto de pesquisa intitulado "Ensaio clínico sob paradigma na prática embasada em evidências: integração da teoria e prática para prevenção da úlcera por pressão", a que tiver acesso nas dependências da unidade de internação unidade masculina do Hospital Universitário de Londrina da Universidade Estadual de Londrina.
\end{abstract}

Por este termo de confidencialidade e sigilo comprometo-me:

1. a não utilizar as informações confidenciais a que tiver acesso, para gerar benefício próprio exclusivo e/ou unilateral, presente ou futuro, ou para o uso de terceiros;

2. a não efetuar nenhuma gravação ou cópia da documentação confidencial a que tiver acesso;

3. a não me apropriar para mim ou para outrem de material confidencial e/ou sigiloso da tecnologia que venha a ser disponível;

4. a não repassar o conhecimento das informações confidenciais, responsabilizandome por todas as pessoas que vierem a ter acesso às informações, por meu intermédio, e obrigando-se, assim, a ressarcir a ocorrência de qualquer dano e/ou prejuízo oriundo de uma eventual quebra de sigilo das informações fornecidas.

Neste Termo, as seguintes expressões serão definidas da forma mostrada a seguir:

Informação Confidencial significará toda informação revelada através da apresentação da tecnologia, a respeito de, ou associada à avaliação, sob a forma escrita, verbal ou por quaisquer outros meios.

Informação Confidencial inclui, mas não se limita, à informação relativa às operações, processos, planos ou intenções, informações sobre produção, instalações, equipamentos, segredos de negócio, segredo de fábrica, dados, habilidades especializadas, projetos, métodos e metodologia, fluxogramas, especializações, componentes, fórmulas, produtos, amostras, diagramas, desenhos de esquema industrial, patentes, oportunidades de mercado e questões relativas a negócios revelados da tecnologia supramencionada. 
Avaliação significará todas e quaisquer discussões, conversações ou negociações entre, ou com as partes, de alguma forma relacionada ou associada com a apresentação da tecnologia "xxx", acima mencionada.

A vigência da obrigação de confidencialidade e sigilo, assumida pela minha pessoa por meio deste termo, terá a validade enquanto a informação não for tornada de conhecimento público por qualquer outra pessoa, ou mediante autorização escrita, concedida à minha pessoa pelas partes interessadas neste termo.

Pelo não cumprimento do presente Termo de Confidencialidade e Sigilo, fica o abaixo assinado ciente de todas as sanções judiciais que poderão advir.

Londrina, 26/09/2011

\section{Assinatura do estudante}

Contato: volpato@uel.br/9944-5879

CEP: $3371-2490$

Pesquisador(a) Responsável: Marcia Paschoalina Volpato 


\section{APÊNDICE D - INSTRUMENTO DE COLETA DE DADOS - AVALIAÇÃO DA} PELE

\section{DADOS DE IDENTIFICAÇÃO}

Iniciais do paciente $R G$ :

Idade:

Sexo: ( )F ( )M

Datas: Admissão hospitalar:

Admissão na Unidade Masculina:

Diagnóstico médico:

2. AVALIAÇÃO DA PELE:

\begin{tabular}{|c|c|c|c|c|c|c|c|c|c|c|c|c|c|c|c|}
\hline \multirow{2}{*}{$\begin{array}{c}\text { Avaliação da } \\
\text { Pele }\end{array}$} & \multicolumn{15}{|c|}{ DATAS } \\
\hline & 1 & 2 & 3 & 4 & 5 & 6 & 7 & 8 & 9 & 10 & 11 & 12 & 13 & 14 & 15 \\
\hline \multicolumn{16}{|l|}{ Íntegra $(\mathrm{S} / \mathrm{N})$} \\
\hline \multicolumn{16}{|l|}{ Estágio da UP } \\
\hline \multicolumn{16}{|l|}{ Local } \\
\hline \multicolumn{16}{|l|}{ Estágio da UP } \\
\hline \multicolumn{16}{|l|}{ Local } \\
\hline \multicolumn{16}{|l|}{ Estágio da UP } \\
\hline \multicolumn{16}{|l|}{ Local } \\
\hline \multicolumn{16}{|l|}{ Estágio da UP } \\
\hline \multicolumn{16}{|l|}{ Local } \\
\hline \multicolumn{16}{|l|}{ Estágio da UP } \\
\hline \multicolumn{16}{|l|}{ Local } \\
\hline $\begin{array}{l}\text { Outras } \\
\text { observações }\end{array}$ & & & & & & & & & & & & & & & \\
\hline
\end{tabular}




\section{APÊNDICE E - PLANO DE ENSINO DO WORKSHOP DA PRÁTICA BASEADA EM EVIDÊNCIA}

\section{PLANO DE ENSINO}

TíTULO: Prevenção da úlcera por pressão

COORDENAÇÃO: Marcia Paschoalina Volpato (pesquisadora)

PERÍODO DE REALIZAÇÃO: outubro de 2012

HORÁRIO: das 16 às $20 \mathrm{~h}$

DIAS DA SEMANA: de quarta a sexta-feira para os encontros teóricos; de segunda-feira a sábado para a realização da prática.

CARGA HORÁRIA: 60 horas, divididas em 12 horas teóricas e 48 horas práticas.

LOCAL DE REALIZAÇÃo: Centro de Ciências da Saúde

№ DE VAGAS: 12 alunos

PÚBLICO-ALVO: estudantes de graduação do curso de Enfermagem

OBJETIVO GERAL: promover o aprendizado das medidas de prevenção sobre úlcera por pressão aos alunos do $2^{\circ}$ ano do curso de Enfermagem.

PROGRAMA: Encontros com atividades teóricas e práticas.

1. Anatomia e fisiologia da pele

2. Avaliação da pele/sistema tegumentar

3. Fisiopatologia da úlcera por pressão (UP)

4. Regiões predisponentes à formação de UP

5. Estágios da UP

6. Diferenciação da UP com dermatite de contato e hiperemia reativa

7. Fatores de risco para o desenvolvimento da UP

8. Avaliação de risco através da Escala de Braden

9. Diretrizes para prevenção da UP — NPUAP/EPUAP: avaliação de risco, avaliação da pele, nutrição para prevenção da UP, reposicionamento para prevenção de UP, superfícies de suporte 
10. Intervenções de enfermagem para prevenção da UP de acordo com a NPUAP

11. Práticas de avaliação de risco nos pacientes internados no Hospital Universitário e levantamento da ocorrência de UP

12. Discussões em grupo sobre as atividades de avaliação de risco nos pacientes e da ocorrência.

\section{CRONOGRAMA DAS ATIVIDADES}

\begin{tabular}{|c|c|c|c|c|c|c|c|c|c|c|c|c|c|c|c|c|}
\hline ENCONTRO & $1^{\circ}$ & 20 & 3은 & $4^{\circ}$ & $5^{\circ}$ & 60 & $7^{0}$ & $8^{\circ}$ & 9웅 & $10^{\circ}$ & $11^{\circ}$ & $12^{\circ}$ & $13^{\circ}$ & $14^{\circ}$ & $15^{\circ}$ & \\
\hline Anatomia e fisiologia da pele & $\mathrm{X}$ & & & & & & & & & & & & & & & \\
\hline $\begin{array}{l}\text { Avaliação da pele/sistema } \\
\text { tegumentar }\end{array}$ & $\mathrm{X}$ & & & & & & & & & & & & & & & \\
\hline Fisiopatologia da UP & $\mathrm{X}$ & & & & & & & & & & & & & & & \\
\hline $\begin{array}{l}\text { Regiões predisponentes à } \\
\text { formação de UP }\end{array}$ & $\mathrm{X}$ & & & & & & & & & & & & & & & \\
\hline Estágios da UP & & $\bar{X}$ & & & & & & & & & & & & & & \\
\hline $\begin{array}{l}\text { Diferenciação da UP com } \\
\text { dermatite de contato e } \\
\text { hiperemia reativa }\end{array}$ & & $\mathrm{X}$ & & & & & & & & & & & & & & \\
\hline $\begin{array}{l}\text { Fatores de risco para o } \\
\text { desenvolvimento da UP }\end{array}$ & & $\mathrm{X}$ & & & & & & & & & & & & & & \\
\hline $\begin{array}{l}\text { Avaliação de risco através } \\
\text { da Escala de Braden }\end{array}$ & & & $\bar{X}$ & & & & & & & & & & & & & \\
\hline $\begin{array}{l}\text { Diretrizes para prevenção da } \\
\text { UP — NPUAP }\end{array}$ & & & $\bar{X}$ & & & & & & & & & & & & & \\
\hline $\begin{array}{l}\text { Intervenções de enfermagem } \\
\text { para prevenção da UP de } \\
\text { acordo com } \\
\text { NPUAP/EPUAP }\end{array}$ & & & $\bar{X}$ & & & & & & & & & & & & & \\
\hline Superfícies de suporte & & & $X$ & & & & & & & & & & & & & \\
\hline $\begin{array}{l}\text { Práticas de avaliação de } \\
\text { risco nos pacientes } \\
\text { internados no Hospital } \\
\text { Universitário e levantamento } \\
\text { da ocorrência de UP }\end{array}$ & & & & $\bar{X}$ & $\mathrm{X}$ & $\bar{X}$ & $\bar{X}$ & $\bar{X}$ & $\bar{X}$ & $\bar{X}$ & $\bar{X}$ & $\bar{X}$ & $\bar{X}$ & $\bar{X}$ & $\bar{X}$ & $\mathrm{X}$ \\
\hline $\begin{array}{l}\text { Discussões em grupo sobre } \\
\text { as atividades de avaliação } \\
\text { de risco nos pacientes e } \\
\text { levantamento da ocorrência } \\
\text { de UP }\end{array}$ & & & & $\mathrm{X}$ & $\mathrm{X}$ & $\mathrm{X}$ & $\mathrm{X}$ & $\mathrm{X}$ & $\mathrm{X}$ & $X$ & $\mathrm{X}$ & $\mathrm{X}$ & $\mathrm{X}$ & $\mathrm{X}$ & $\mathrm{X}$ & $\mathrm{X}$ \\
\hline
\end{tabular}




\section{REFERÊNCIAS BIBLIOGRÁFICAS}

- National Pressure Ulcer Advisory Panel and European Pressure Ulcer Advisory Panel. Prevention and treatment of pressure ulcers: clinical practice guideline. Washington: National Pressure Ulcer Advisory Panel; 2009.

- Domansky,R. de C.; Borges,E. L. Manual para prevenção de lesões de pele: recomendações baseadas em evidências. Rio de Janeiro: Editora Rubio, 2012.

- Barros, A.L.B.L.de \& cols. Anamnese e Exame Físico: avaliação diagnóstica de enfermagem no adulto. Porto Alegre: Artmed, 2002.

-Castilho, L.D.; Caliri, M.H.L. Úlcera de decúbito e estado nutricional: revisão da literatura. Rev Bras Enferm 2005 set/out; 58(5): 597-601. 


\section{APÊNDICE F - INSTRUMENTO PARA IDENTIFICAR O CONHECIMENTO E EXPERIÊNCIAS SOBRE ÚLCERA POR PRESSÃO PELO ALUNO}

1. Cite os estágios da úlcera por pressão

2. Enumere as suas facilidades e dificuldades para identificar os estágios da UP

3. Relacione os fatores de risco para o desenvolvimento da UP

4. Identifique as medidas preventivas para a UP

5. Identifique como é realizada a avaliação do paciente para detectar o risco de desenvolvimento da UP

6. Descreva a Escala de Braden

7. Liste as medidas preventivas que são prescritas pelo enfermeiro da Unidade Masculina.

8. Comente sobre as medidas preventivas que são executadas pela equipe de enfermagem na Unidade Masculina

9. Fale sobre como foi o processo de busca de informações nos prontuários dos pacientes em relação à prescrição das medidas preventivas de UP

10. Descreva como foi realizada a avaliação do paciente e qual(is) a(s) sua(s) dificuldade(s). 


\section{APÊNDICE G - COMPETÊNCIAS DO ENFERMEIRO NA PREVENÇÃO DE ÚLCERA POR PRESSÃO - objetivos, conteúdo, estratégias de ensino-aprendizagem}

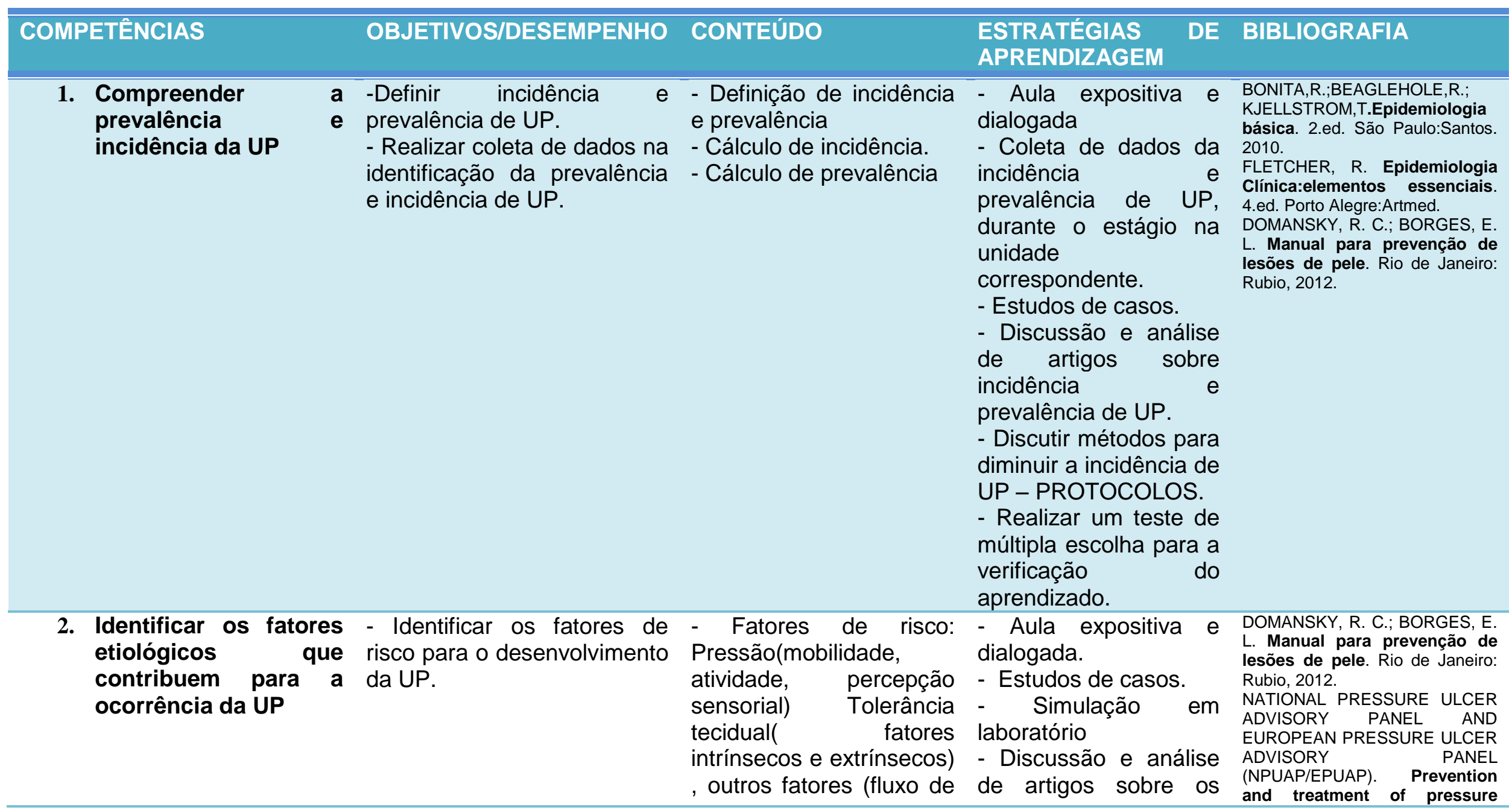




$\begin{array}{lll}\text { líquido } & \text { intersticial, } & \text { fatores de risco. } \\ \text { estresse } & \text { emocional, } & - \text { Uso da plataforma } \\ \text { tabagismo....) } & & \text { moodle. }\end{array}$

a - Realização da avaliação da

Compreender avaliação estruturada pele.

de risco para UP e sua - Identificar as escalas de aplicação

avaliação de risco.

- Aplicar a avaliação de risco para identificar os pacientes com risco para UP.

- Calcular a avaliação de risco através dos escores das escalas.

- Interpretar o significado do escore das escalas no risco para UP.

- Refletir as mudanças que ocorrem na condição clínica/estado de saúde no paciente com risco para UP. definição, aplicação. - Escala definição, aplicação.

de Braden: - Aula expositiva
pontuação, dialogada.

de Norton: laboratório pontuação, avaliação de risco.

- Aplicação da Escala de Braden em paciente hospitalizado, durante o período de estágio.

- Discussão da avaliação de risco realizada nos pacientes: fatores que contribuem dificultam.

ou - Uso da plataforma moodle.

4. Compreender avaliação da como parte avaliação de para UP pele pele. a - Realizar a avaliação da

da - Avaliar a pele na admissão risco do paciente e rotineiramente em pacientes de risco.

- Inspecionar a pele e proeminências ósseas $e$ outras de exposição aos fatores de risco.

- Identificar hiperemia reativa.

- Identificar áreas com
- Aula expositiva

- Exame físico da pele.

- Áreas predisponentes dialogada.

ao desenvolvimento de

UP.

-Registro da avaliação da estudo individual $e$ pele e UP

- Estágios da UP. professor. ulcers: quick reference guide. Washington: National Pressure Ulcer Advisory Panel, 2009 . Disponível em:

<http://www.epuap.org>

DOMANSKY, R. C.; BORGES, E. . Manual para prevenção de lesões de pele. Rio de Janeiro:

NATIONAL PRESSURE ULCER ADVISORY PANEL AND EUROPEAN PRESSURE ULCER ADVISORY PANEL (NPUAP/EPUAP). Prevention and treatment of pressure ulcers: internacional guideline. Washington: National Pressure Ulcer Advisory Panel, 2009. Disponível em: <http://www.npuap.org>

PARANHOS, W. Y. Avaliação de risco para úlceras de pressão por meio da Escala de Braden na língua portuguesa. 1999. 79 f. Dissertação (Mestrado) Escola de Enfermagem, Universidade de São Paulo, São Paulo, 1999.

DOMANSKY, R. C.; BORGES, E. $L$. Manual para prevenção de esões de pele. Rio de Janeiro: Rubio, 2012.

PORTO,C.C.Exame clínico: (linice bases para a pratica medica. o grupo de alunos e Koogan. 2008

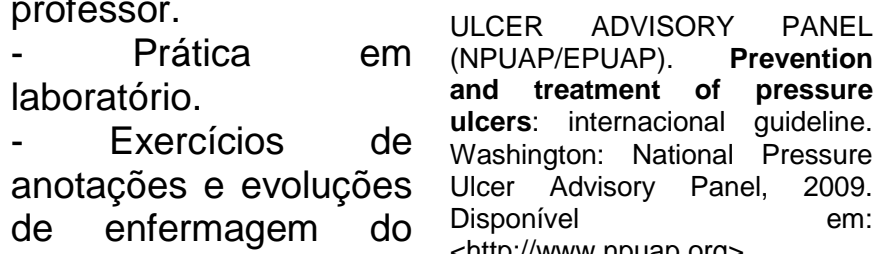


flictemas, calor local, edema,

endurecimento e dor.

- Identificar áreas de risco em indivíduos com coloração da pele negra.

- Avaliar a pele em áreas que estão em contato com dispositivos terapêuticos: sondas, drenos, tubos endotraqueais, cateteres de oxigenoterapia e outros.

- Identificar os estágios da UP.

- Realizar o registro da avaliação da pele.

5. Desenvolver implementar programa individualizado cuidados com a pele e - Discutir o alívio da pressão - Higienização da pele.

um em áreas hiperemiadas em - Hidratação da pele. risco para UP.

de - Discutir a massagem proeminências ósseas.

- Discutir a massagem em áreas hiperemiadas e em risco para UP.

- Discutir os cuidados com a pele: hidratação, higienização, barreiras de proteção. registro e avaliação da pele.

- Uso da plataforma moodle.
- Produtos como barreira - Discussão em grupo. - Demonstração de produtos de proteção para a pele - convidar laboratórios.

- Uso da plataforma moodle.

- Leitura direcionada de artigos.

- Observação da prática, durante 0 período de estágio, com discussão após.

- Realizar

levantamento de

pesquisas sobre

programas de

prevenção da UP.
DOMANSKY, R C : BORGES, E. L. Manual para prevencão de esões de pele. Rio de Janeiro: Rubio, 2012.

ULCER ADVISORY PANEL (NPUAP/EPUAP). Prevention and treatment of pressure ulcers: internacional guideline. Washington: National Pressure Ulcer Advisory Panel, 2009. Disponível em: <http://www.npuap.org> 


\section{Compreender posicionamento reposicionamento tratamento da UP \\ do reposicionamentdo paciente no leito. \\ - Identificar a necessidade do \\ reposicionamento paciente, de acordo com os fatores de risco predisponentes. \\ - Conhecer e demonstrar o posicionamento com elevação da cabeceira a $30^{\circ}$. \\ - Conhecer as técnicas que ajudam a mobilizar o paciente evitando a fricção e cisalhamento.} - - Discutir a realização da - Mudança de decúbito: e mudança de decúbito e técnicas. paciente no leito. mobilização do paciente: técnica.
- Reposicionamento

\section{Simulação \\ laboratório:}

demonstração

técnicas

posicionamento

reposicionamento.

- Aula expositiva dialogada.

- Observação com posterior discussão da prática clínica, durante o estágio.

- Uso da plataforma moodle.
6. Compreender o uso - Identificar as superfícies de de superfícies de suporte. suporte paciente para o - Conhecer para UP suporte.

- Demonstrar proteção dos calcâneos com elevação dos mesmos em dispositivos flutuantes.
- Superfícies de suporte para cama e cadeiras.

- Produtos/materiais pa elevação do calcâneo.

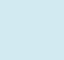


aspectos nutricionais instrumento de avaliação avaliação nutricional

nutricional para os pacientes na prevenção da UP em risco para UP.

- Identificar indivíduos com condição nutricional.

déficit nutricional, realizando - Valor nutricional encaminhamentos para 0 vitaminas e minerais. nutricionista.

- Descrever a importância da nutrição, hidratação,

vitaminas e minerais.

- Identificar os fatores que contribuem para 0 déficit nutricional em pacientes hospitalizados.

- Discutir com nutricionista a dieta para pacientes com risco para UP.
- Hidratação.

Avaliação

considerando laboratoriais. exames nutricional

instrumentos

avaliação nutricional.

boa nutricionista.

de - Estudos de casos.

- Discutir instrumento

qual o avaliação nutricional é utilizado na instituição de realização do estágio.

- Montar um pôster ilustrativo com os sinais e sintomas de deficiência nutricional.

- Avaliação de exames laboratoriais pacientes em risco para UP e com UP.

- Uso da plataforma moddle.

8. Compreender a - Conhecer a documentação -

importância dos necessária para a avaliação

registros sobre

avaliação a de risco, avaliação da pele

avaliação da

estratégias

prevenção para UP

posterior discussão, da e - Elaborar prescrição

de enfermagem intervenções de UP. na prevenção

ão risco desenvolvimento de UP ou com UP.

- Aula

expositiva

Impressos/documentação dialogada.

necessária para realizar os registros da UP.

Observacão,

prática clínica nos registros referentes à UP.

- Uso da plataforma moodle.

- Convidar enfermeiro responsável pelo

Gerenciamento de

Risco e Auditoria da instituição de Ensino. lesões de pele. Rio de Janeiro: Rubio, 2012.

Rubio, 2012. . ULCER ADVISO (NPUAP/EPUAP). Prevention and treatment of pressure ulcers: internacional guideline. Washington: National Pressure Ulcer Advisory Panel, 2009 Disponível

<http://www.npuap.org>

GLORIMAR,R. Avaliação Nutricional do paciente hospitalizado: uma abordagem teórico-prática. Rio de Janeiro:

Guanabara Koogan

DOMANSKY, R. C.; BORGES, E. L. Manual para prevenção de lesões de pele. Rio de Janeiro: Rubio, 2012.

ULCER ADVISORY PANEL (NPUAP/EPUAP). Prevention and treatment of pressure ulcers: internacional guideline. Washington: National Pressure Washington: National Pressure Ulcer Advisory Panel, 2009.

<http://www.npuap.org> 
9. Aplicar o raciocínio - Identificar os diagnósticos - Raciocínio clínico. clínico na tomada de de enfermagem no indivíduo - NANDA, NIC e NOC. decisão em relação a em risco para UP (NANDA).

ao indivíduo em risco - Identificar as intervenções para UP de enfermagem no

indivíduos em risco para UP

(NIC).

- Identificar os resultados de enfermagem esperados no indivíduo com UP (NOC).
- Aula expositiva dialogada.

- Estudos de casos.

- Uso da plataforma modlle.

DOMANSKY, R. C.; BORGES, E. . Manual para prevenção de lesões de pele. Rio de Janeiro: Rubio, 2012.

ULCER ADVISORY PANEL (NPUAP/EPUAP). Prevention and treatment of pressure ulcers: internacional guideline. Washington: National Pressure Ulcer Advisory Panel, 2009. Disponível em:

http://www npuap.org>

GARCEZR.M Ligações entre NANDA, NOC e NIC: diagnósticos, resultados e
intervenções de enfermagem. Porto Alegre: Artmed. 2010

10. Compreender a - Identificar o papel/função - Função do enfermeiro, - Mesa-redonda com a importância da equipe dos membros da equipe nutricionista, médico, presença da equipe multiprofissional na multiprofissional assistência paciente ao prevenção da UP.

na fisioterapeuta, psicólogo e outros na prevenção da UP.

multiprofissional

abordando os aspectos preventivos da UP. para UP em risco

DOMANSKY, R. C.; BORGES, E. lesões de pele. Rio de Janeiro: Rubio, 2012.

ULCER ADVISORY PANEL (NPUAP/EPUAP) Prevention (NPUAP/EPUAP). P Prention and in ulcers: internacional guideline. Washington: National Pressure Ulcer Advisory Panel, 2009 Disponive 


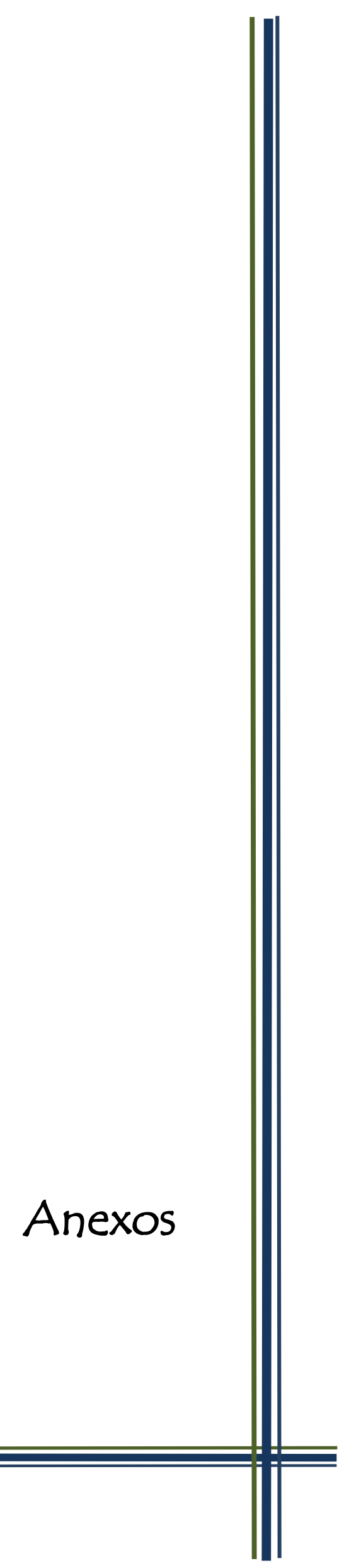




\section{ANEXO A - APROVAÇÃO DO COMITE DE ÉTICA EM PESQUISA}

\section{Esiadualdelondrina}

COMITÊ DE ÉTICA EM PESQUISA ENVOLVENDO SERES HUMANOS

Universidade Estadual de Londrina

Registro CONEP 268

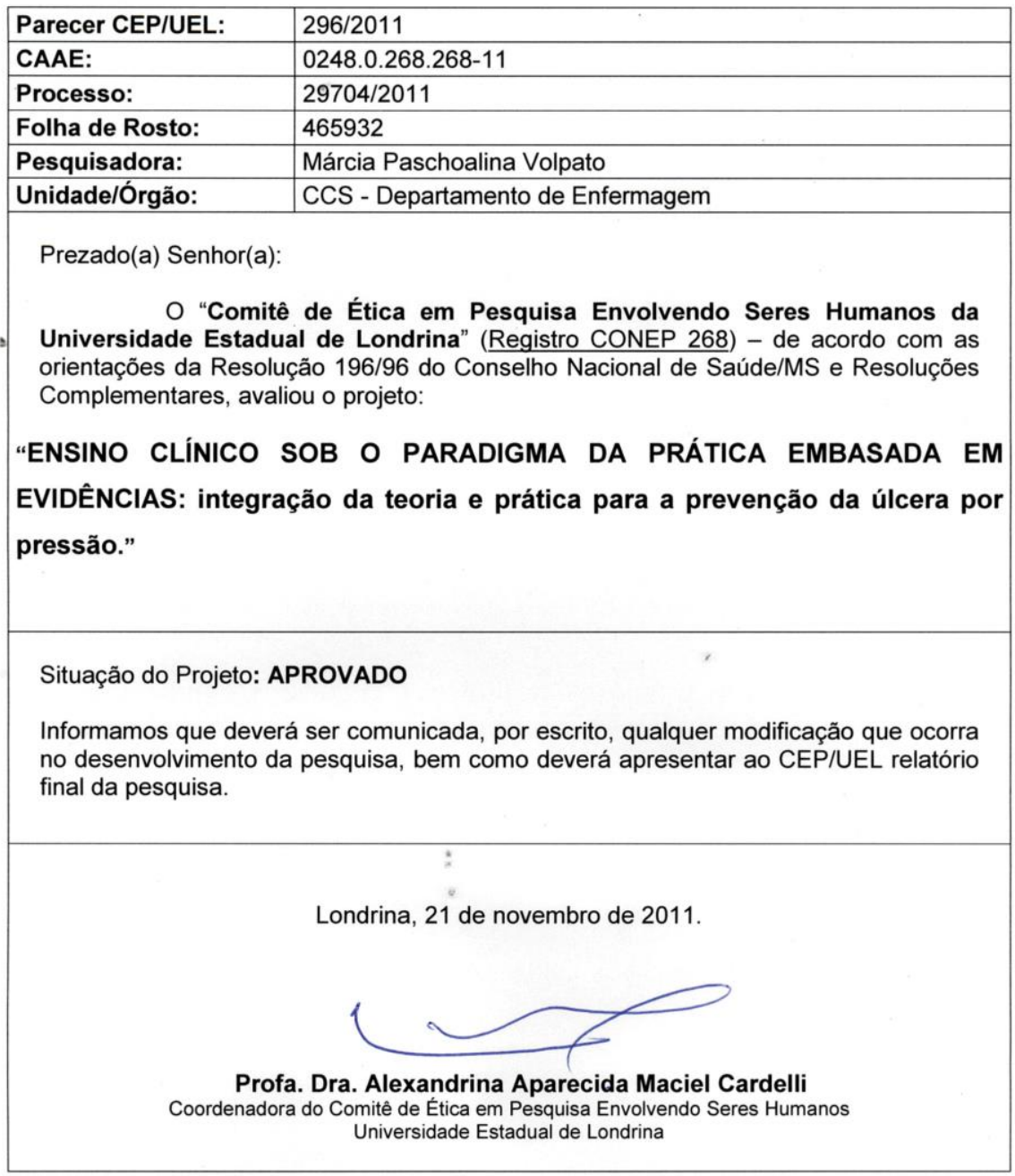




\section{COMITÊ DE ÉTICA EM PESQUISA ENVOLVENDO SERES HUMANOS Universidade Estadual de Londrina Registro CONEP 5231}

\begin{tabular}{|l|l|}
\hline Parecer CEP/UEL: & $296 / 2011$ (emenda) \\
\hline CAAE: & $0248.0 .268 .268 .-11$ \\
\hline Processo: & 25095.2012 \\
\hline Folha de Rosto: & 465932 \\
\hline Pesquisador(a): & MARCIA PASCHOALINA VOLPATO \\
\hline Unidade/Órgão: & CCS - Departamento de Enfermagem \\
\hline
\end{tabular}

Prezado (a) Senhor (a):

O "Comitê de Ética em Pesquisa Envolvendo Seres Humanos da Universidade Estadual de Londrina" (Registro CONEP 5231) - de acordo com as orientações da Resolução 196/96 do Conselho Nacional de Saúde/MS e Resoluções Complementares, avaliou o projeto:

\section{"ENSINO CLÍNICO SOB O PARADIGMA DA PRÁTICA EMBASADA EM} EVIDÊNCIAS: INTEGRAÇÃO DA TEORIA E PRÁTICA PARA A PREVENCÃO DA ÚLCERA PO PRESSÃO"

Emenda: A proposta do projeto original era propor e avaliar uma metodologia de ensino pra alunos da $2^{a}$ série do curso de enfermagem da UEL por meio do desenvolvimento de pesquisas em campo utilizando o referencial da prática baseada em evidência. A solicitação para esse emenda é incluir como sujeitos de pesquisa além dos estudantes e pacientes, os enfermeiros da unidade masculina do $\mathrm{HU}$, será acrescentado um curso de extensão para os alunos particípantes e também serão obtidas informações dos prontuários. Todos os documentos de apresentação obrigatórios foram apresentados e estão de acordo com a Resolução 196/96.

Situação do Projeto: Aprovado

Informamos que deverá ser comunicada, por escrito, qualquer modificação que ocorra no desenvolvimento da pesquisa, bem como deverá apresentar ao CEP/UEL relatório final da pesquisa.

Londrina, 11 de outubro de 2012.

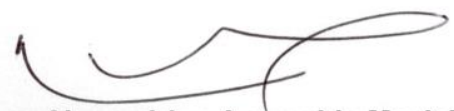

Profa. Dra. Alexandrina Aparecida Maciel Cardelli Coordenadora do Comitê de Ética em Pesquisa Envolvendo Seres Humanos Universidade Estadual de Londrina 


\section{ANEXO B - INSTRUMENTO PARA AVALIAÇÃO DO RISCO DA UP - ESCALA DE BRADEN}

Iniciais do paciente:

Data

da 1aavaliação:

Registro:

\begin{tabular}{|c|c|c|c|c|c|c|c|c|c|c|}
\hline \multicolumn{2}{|r|}{ Escala de Braden } & Avaliação/Data & 1 & 2 & 3 & 4 & 5 & 6 & 7 & 8 \\
\hline \multirow{4}{*}{$\begin{array}{l}\text { Percepção } \\
\text { Sensorial }\end{array}$} & Completamente limitada & & & & & & & & & \\
\hline & Muito limitada & & & & & & & & & \\
\hline & Levemente limitada & & & & & & & & & \\
\hline & $\begin{array}{l}\text { Ausência de deficiência } \\
\text { sensorial }\end{array}$ & & & & & & & & & \\
\hline \multirow{4}{*}{ Umidade } & Constantemente molhada & & & & & & & & & \\
\hline & Frequentemente molhada & & & & & & & & & \\
\hline & Ocasionalmente molhada & & & & & & & & & \\
\hline & Raramente molhada & & & & & & & & & \\
\hline \multirow{4}{*}{ Atividade } & Confinado ao leito (acamado) & & & & & & & & & \\
\hline & Confinado à cadeira & & & & & & & & & \\
\hline & Anda ocasionalmente & & & & & & & & & \\
\hline & Anda frequentemente & & & & & & & & & \\
\hline \multirow{4}{*}{ Mobilidade } & Completamente imóvel & & & & & & & & & \\
\hline & Muito limitada & & & & & & & & & \\
\hline & Levemente limitada & & & & & & & & & \\
\hline & Nenhuma limitação & & & & & & & & & \\
\hline \multirow{4}{*}{ Nutrição } & Muito pobre & & & & & & & & & \\
\hline & Provavelmente inadequada & & & & & & & & & \\
\hline & Adequada & & & & & & & & & \\
\hline & Excelente & & & & & & & & & \\
\hline \multirow{3}{*}{$\begin{array}{l}\text { Fricção e } \\
\text { Cisalhame } \\
\text { nto }\end{array}$} & Problema & & & & & & & & & \\
\hline & Problema potencial & & & & & & & & & \\
\hline & Nenhum problema aparente & & & & & & & & & \\
\hline \multicolumn{2}{|c|}{ Ulcera por Pressão: SIM (S) OU NÃO (N) } & & & & & & & & & \\
\hline
\end{tabular}


ANEXO C - INSTRUMENTO PARA COLETA DE DADOS SOBRE O REGISTRO DA IDENTIFICAÇÃO DO RISCO PARA ÚLCERA POR PRESSÃO, DAS CARACTERÍSTICA DA PELE, DA UP E DAS MEDIDAS DE PREVENÇÃO

Iniciais do paciente: Data:

\begin{tabular}{|l|l|l|l|l|l|l|l|l|l|l|l|l|l|l|l|}
\hline \multirow{2}{*}{ Risco para UP } & \multicolumn{10}{|c|}{ DATAS } \\
\hline & $\mathbf{1}$ & $\mathbf{2}$ & $\mathbf{3}$ & $\mathbf{4}$ & $\mathbf{5}$ & $\mathbf{6}$ & $\mathbf{7}$ & $\mathbf{8}$ & $\mathbf{9}$ & $\mathbf{1 0}$ & $\mathbf{1 1}$ & $\mathbf{1 2}$ & $\mathbf{1 3}$ & $\mathbf{1 4}$ & $\mathbf{1 5}$ \\
\hline İntegra (S/N) & & & & & & & & & & & & & & & \\
\hline $\begin{array}{l}\text { Escore Total da Escala } \\
\text { de Braden }\end{array}$ & & & & & & & & & & & & & & & \\
\hline $\begin{array}{l}\text { Classificação como } \\
\text { paciente de risco (S/N) }\end{array}$ & & & & & & & & & & & & & & & \\
\hline Não registrado & & & & & & & & & & & & & & & \\
\hline
\end{tabular}

\begin{tabular}{|l|l|l|l|l|l|l|l|l|l|l|l|l|l|l|l|}
\hline $\begin{array}{l}\text { Condições da } \\
\text { Pele }\end{array}$ & $\mathbf{1}$ & $\mathbf{2}$ & $\mathbf{3}$ & $\mathbf{4}$ & $\mathbf{5}$ & $\mathbf{6}$ & $\mathbf{7}$ & $\mathbf{8}$ & $\mathbf{9}$ & $\mathbf{1 0}$ & $\mathbf{1 1}$ & $\mathbf{1 2}$ & $\mathbf{1 3}$ & $\mathbf{1 4}$ & $\mathbf{1 5}$ \\
\hline İntegra (S/N) & & & & & & & & & & & & & & & \\
\hline $\begin{array}{l}\text { Úlcera por pressão } \\
\text { (S/N) }\end{array}$ & & & & & & & & & & & & & & & \\
\hline Não registrado & & & & & & & & & & & & & & & \\
\hline
\end{tabular}

\begin{tabular}{|l|l|l|l|l|l|l|l|l|l|l|l|l|l|l|l|}
\hline $\begin{array}{c}\text { Característica } \\
\text { da UP }\end{array}$ & $\mathbf{1}$ & $\mathbf{2}$ & $\mathbf{3}$ & $\mathbf{4}$ & $\mathbf{5}$ & $\mathbf{6}$ & $\mathbf{7}$ & $\mathbf{8}$ & $\mathbf{9}$ & $\mathbf{1 0}$ & $\mathbf{1 1}$ & $\mathbf{1 2}$ & $\mathbf{1 3}$ & $\mathbf{1 4}$ & $\mathbf{1 5}$ \\
\hline Local & & & & & & & & & & & & & & & \\
\hline Estágio & & & & & & & & & & & & & & & \\
\hline & & & & & & & & & & & & & & & \\
\hline Local & & & & & & & & & & & & & & & \\
\hline Estágio & & & & & & & & & & & & & & & \\
\hline & & & & & & & & & & & & & & & \\
\hline Local & & & & & & & & & & & & & & & \\
\hline Estágio & & & & & & & & & & & & & & & \\
\hline & & & & & & & & & & & & & & & \\
\hline Local & & & & & & & & & & & & & & & \\
\hline Estágio & & & & & & & & & & & & & & & \\
\hline & & & & & & & & & & & & & & & \\
\hline Outro Registro &
\end{tabular}




\begin{tabular}{|c|c|c|c|c|c|c|c|c|c|c|c|c|c|c|c|}
\hline \multirow{2}{*}{$\begin{array}{c}\text { Registro das } \\
\text { Ações de } \\
\text { Enfermagem } \\
\text { (S/N) }\end{array}$} & \multicolumn{15}{|c|}{ DATAS } \\
\hline & 1 & 2 & 3 & 4 & 5 & 6 & 7 & 8 & 9 & 10 & 11 & 12 & 13 & 14 & 15 \\
\hline $\begin{array}{l}\text { Mudança de } \\
\text { decúbito 2/2 horas }\end{array}$ & & & & & & & & & & & & & & & \\
\hline Colchão especial & & & & & & & & & & & & & & & \\
\hline Uso de coxins & & & & & & & & & & & & & & & \\
\hline $\begin{array}{l}\text { Suplemento } \\
\text { nutricional/tipo }\end{array}$ & & & & & & & & & & & & & & & \\
\hline $\begin{array}{l}\text { Controle } \\
\text { incontinência }\end{array}$ & & & & & & & & & & & & & & & \\
\hline Hidratação da pele & & & & & & & & & & & & & & & \\
\hline $\begin{array}{l}\text { Curativo } \\
\text { proteção/tipo }\end{array}$ & & & & & & & & & & & & & & & \\
\hline $\begin{array}{l}\text { Cabeceira elevada } \\
\text { até } 30^{\circ}\end{array}$ & & & & & & & & & & & & & & & \\
\hline
\end{tabular}




\section{ANEXO D - ESCALA DE BRADEN (PARANHOS, 1999)}

\begin{tabular}{|c|c|c|c|c|}
\hline $\begin{array}{l}\text { Percepção } \\
\text { sensorial: } \\
\text { Capacidade } \\
\text { de reagir } \\
\text { significativam } \\
\text { ente à } \\
\text { pressão } \\
\text { relacionada } \\
\text { ao } \\
\text { desconforto }\end{array}$ & $\begin{array}{l}\text { 1. Totalmente limitado: } \\
\text { Não reage (não geme, não } \\
\text { se segura a nada, não se } \\
\text { esquiva) a estímulo } \\
\text { doloroso, devido ao nível de } \\
\text { consciência diminuindo ou } \\
\text { devido a sedação, ou } \\
\text { capacidade limitada de } \\
\text { sentir dor na maior parte do } \\
\text { corpo. }\end{array}$ & $\begin{array}{l}\text { 2. Muito limitado: } \\
\text { Somente reage a estímulo } \\
\text { doloroso. Não é capaz de } \\
\text { comunicar o desconforto } \\
\text { exceto através de gemido } \\
\text { ou agitação. Ou possui } \\
\text { alguma deficiência } \\
\text { sensorial que limita a } \\
\text { capacidade de sentir dor } \\
\text { ou desconforto em mais } \\
\text { da metade do corpo. }\end{array}$ & $\begin{array}{l}\text { 3. Levemente Limitado: } \\
\text { Responde ao comando } \\
\text { verbal, mas nem sempre é } \\
\text { capaz de comunicar o } \\
\text { desconforto ou expressar } \\
\text { necessidade de ser } \\
\text { mudado de posição ou } \\
\text { tem um certo grau de } \\
\text { deficiência sensorial que } \\
\text { limita a capacidade de } \\
\text { sentir dor ou desconforto } \\
\text { em } 1 \text { ou } 2 \text { extremidades. }\end{array}$ & $\begin{array}{l}\text { 4. Nenhuma } \\
\text { limitação: Responde ao } \\
\text { comandos verbais. Não } \\
\text { tem déficit sensorial que } \\
\text { limitaria a capacidade } \\
\text { de sentir ou verbalizar } \\
\text { dor ou desconforto. }\end{array}$ \\
\hline $\begin{array}{l}\text { Umidade: } \\
\text { Nível ao qual } \\
\text { a pele é } \\
\text { exposta à } \\
\text { umidade }\end{array}$ & $\begin{array}{l}\text { 1. Completamente } \\
\text { molhada: A pele é mantida } \\
\text { molhada quase } \\
\text { constantemente por } \\
\text { transpiração, urina, etc... A } \\
\text { umidade é detectada às } \\
\text { movimentações do paciente }\end{array}$ & $\begin{array}{l}\text { 2. Muito Molhada: A } \\
\text { pele esta frequentemente, } \\
\text { mas nem sempre } \\
\text { molhada. A roupa de } \\
\text { cama deve ser trocada } \\
\text { pelo menos uma vez ao } \\
\text { dia. }\end{array}$ & $\begin{array}{l}\text { 3. Ocasionalmente } \\
\text { Molhada: A pele fica } \\
\text { ocasionalmente molhada } \\
\text { requerendo uma troca } \\
\text { extra de roupa de cama } \\
\text { por dia. }\end{array}$ & $\begin{array}{l}\text { 4. Raramente molhada: } \\
\text { A pele geralmente está } \\
\text { seca, a troca de roupa } \\
\text { de cama é necessária } \\
\text { somente nos intervalos } \\
\text { de rotina. }\end{array}$ \\
\hline $\begin{array}{l}\text { Atividade: } \\
\text { Grau de } \\
\text { atividade } \\
\text { física }\end{array}$ & $\begin{array}{l}\text { 1. Acamado: confinado a } \\
\text { cama }\end{array}$ & $\begin{array}{l}\text { 2. Confinado à cadeira: } \\
\text { A capacidade de andar } \\
\text { está severamente limitada } \\
\text { ou nula. Não é capaz de } \\
\text { sustentar o próprio peso } \\
\text { e/ou preciosa ser ajudado } \\
\text { a se sentar. }\end{array}$ & $\begin{array}{l}\text { 3. Anda } \\
\text { ocasionalmente: Anda } \\
\text { ocasionalmente durante o } \\
\text { dia, embora distâncias } \\
\text { muito curtas, com ou sem } \\
\text { ajuda. Passa a maior } \\
\text { parte de cada turno na } \\
\text { cama ou cadeira. }\end{array}$ & $\begin{array}{l}\text { 4. Anda } \\
\text { frequentemente: Anda } \\
\text { fora do quarto pelo } \\
\text { menos } 2 \text { vezes por dia e } \\
\text { dentro do quarto pelo } \\
\text { menos uma vez a cada } \\
2 \text { horas durante as } \\
\text { horas em que está } \\
\text { acordado. }\end{array}$ \\
\hline $\begin{array}{l}\text { Mobilidade: } \\
\text { Capacidade } \\
\text { de mudar e } \\
\text { controlar a } \\
\text { posição do } \\
\text { corpo }\end{array}$ & $\begin{array}{l}\text { 1. Totalmente imóvel: Não } \\
\text { faz nem mesmo pequenas } \\
\text { mudanças na posição do } \\
\text { corpo ou extremidade sem } \\
\text { ajuda. }\end{array}$ & $\begin{array}{l}\text { 2. Bastante Limitado: } \\
\text { Faz pequenas mudanças } \\
\text { ocasionais na posição do } \\
\text { corpo ou extremidades, } \\
\text { mas incapaz de fazer } \\
\text { mudanças frequentes ou } \\
\text { significantes sozinho. }\end{array}$ & $\begin{array}{l}\text { 3. Levemente Limitado: } \\
\text { Faz frequentes, embora } \\
\text { pequenas mudanças na } \\
\text { posição do corpo ou } \\
\text { extremidades sem ajuda. }\end{array}$ & $\begin{array}{l}\text { 4. Não apresenta } \\
\text { limitações: Faz } \\
\text { importantes e } \\
\text { frequentes mudanças de } \\
\text { posição sem auxílio. }\end{array}$ \\
\hline $\begin{array}{l}\text { Nutrição: } \\
\text { Padrão usual } \\
\text { de consumo } \\
\text { alimentar }\end{array}$ & $\begin{array}{l}\text { 1. Muito Pobre: Nunca } \\
\text { come uma refeição } \\
\text { completa. Raramente come } \\
\text { mais } 1 / 3 \text { do alimento } \\
\text { oferecido. Come } 2 \text { porções } \\
\text { ou menos de proteína } \\
\text { (carne ou laticínios) por dia. } \\
\text { Ingere pouco líquido. Não } \\
\text { aceita suplemento alimentar } \\
\text { líquido. Ou é mantido em } \\
\text { jejum e/ou mantido em dieta } \\
\text { líquida ou IV por maios de } 5 \\
\text { dias }\end{array}$ & $\begin{array}{l}\text { 2. Provavelmente } \\
\text { Inadequado: Raramente } \\
\text { come uma refeição } \\
\text { completa e geralmente } \\
\text { come cerca da metade do } \\
\text { alimento oferecido. A } \\
\text { ingestão de proteína inclui } \\
\text { somente } 3 \text { porções de } \\
\text { carne ou laticínios por dia. } \\
\text { Ocasionalmente aceitará } \\
\text { um suplemento alimentar. } \\
\text { Ou recebe abaixo da } \\
\text { quantidade satisfatória de } \\
\text { dieta líquida ou } \\
\text { alimentação por sonda. }\end{array}$ & $\begin{array}{l}\text { 3. Adequado: Come } \\
\text { mais da metade da } \\
\text { maioria das refeições. } \\
\text { Como um total de } 4 \\
\text { porções de alimento rico } \\
\text { em proteína (carne ou } \\
\text { laticínio) todo dia. } \\
\text { Ocasionalmente recusará } \\
\text { uma refeição, mas } \\
\text { geralmente aceitará um } \\
\text { complemento oferecido. } \\
\text { Ou é alimentado por } \\
\text { sonda ou regime de } \\
\text { Nutrição Parenteral Total, } \\
\text { o qual provavelmente } \\
\text { satisfaz a maior parte das } \\
\text { necessidades nutricionais. }\end{array}$ & $\begin{array}{l}\text { 4. Excelente: Come a } \\
\text { maior parte de cada } \\
\text { refeição. Nunca recusa } \\
\text { uma refeição. } \\
\text { Geralmente ingere um } \\
\text { total de } 4 \text { ou mais } \\
\text { porções de carne ou } \\
\text { laticínios. } \\
\text { Ocasionalmente come } \\
\text { entre as refeições. Não } \\
\text { requer suplemento } \\
\text { alimentar. }\end{array}$ \\
\hline $\begin{array}{l}\text { Fricção e } \\
\text { cisalhamento }\end{array}$ & $\begin{array}{l}\text { 1. Problema: Requer } \\
\text { assistência moderada a } \\
\text { máxima para se mover. É } \\
\text { impossível levantá-lo ou } \\
\text { erguê-lo completamente } \\
\text { sem que haja atrito com o } \\
\text { lençol. Frequentemente } \\
\text { escorrega na cama ou } \\
\text { cadeira, necessitando } \\
\text { frequentes ajustes de } \\
\text { posição com máximo de } \\
\text { assistência. Espasticidade, } \\
\text { contratura ou agitação leva } \\
\text { a quase constante fricção. }\end{array}$ & $\begin{array}{l}\text { 2. Problema em } \\
\text { Potencial: Move-se, mas, } \\
\text { sem vigor ou requer } \\
\text { mínima assistência. } \\
\text { Durante o movimento } \\
\text { provavelmente ocorre um } \\
\text { certo atrito da pele com o } \\
\text { lençol, cadeira ou outros. } \\
\text { Na maior parte do tempo } \\
\text { mantém posição } \\
\text { relativamente boa na } \\
\text { cama ou cadeira, mas } \\
\text { ocasionalmente } \\
\text { escorrega. }\end{array}$ & $\begin{array}{l}\text { 3. Nenhum Problema: } \\
\text { Move-se sozinho na cama } \\
\text { ou cadeira e tem } \\
\text { suficiente força muscular } \\
\text { para erguer-se } \\
\text { completamente durante o } \\
\text { movimento. Sempre } \\
\text { mantém boa posição na } \\
\text { cama ou na cadeira. }\end{array}$ & \\
\hline
\end{tabular}

\footnotetext{
* Copyright: Barbara Braden \& Nancy Bergstrom, 1988
} 